Campus de São José dos Campos

HUMBERTO LAGO DE CASTRO

AVALIAÇÃO DE TRÊS CIMENTOS RESINOSOS NA RESISTÊNCIA DE UNIÃO ENTRE DENTINA E UMA CERÂMICA DE ZIRCÔNIA ESTABILIZADA POR ÍTRIA

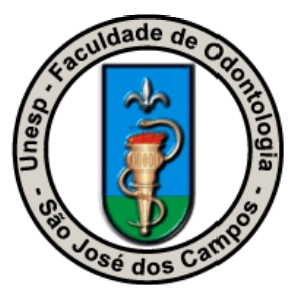

2010 


\section{AVALIAÇÃO DE TRÊS CIMENTOS RESINOSOS NA RESISTÊNCIA DE UNIÃO ENTRE DENTINA E UMA CERÂMICA DE ZIRCÔNIA ESTABILIZADA POR ÍTRIA}

Dissertação apresentada à Faculdade de Odontologia, Campus de São José dos Campos, Universidade Estadual Paulista "Júlio de Mesquita Filho", como parte dos requisitos para a obtenção do título de MESTRE, pelo Programa de Pós-Graduação em ODONTOLOGIA RESTAURADORA, Especialidade em Prótese Dentária.

Orientador: Prof. Dr. Alvaro Della Bona Co-Orientador: Prof. Dr. Tarcísio José de Arruda Paes Junior

São José dos Campos

2010 
Apresentação gráfica e normalização de acordo com:

Alvarez S, Coelho DCAG, Couto RAO, Durante APM. Guia prático para Normalização de Trabalhos Acadêmicos da FOSJC. São José dos

Campos: FOSJC/UNESP; 2008.

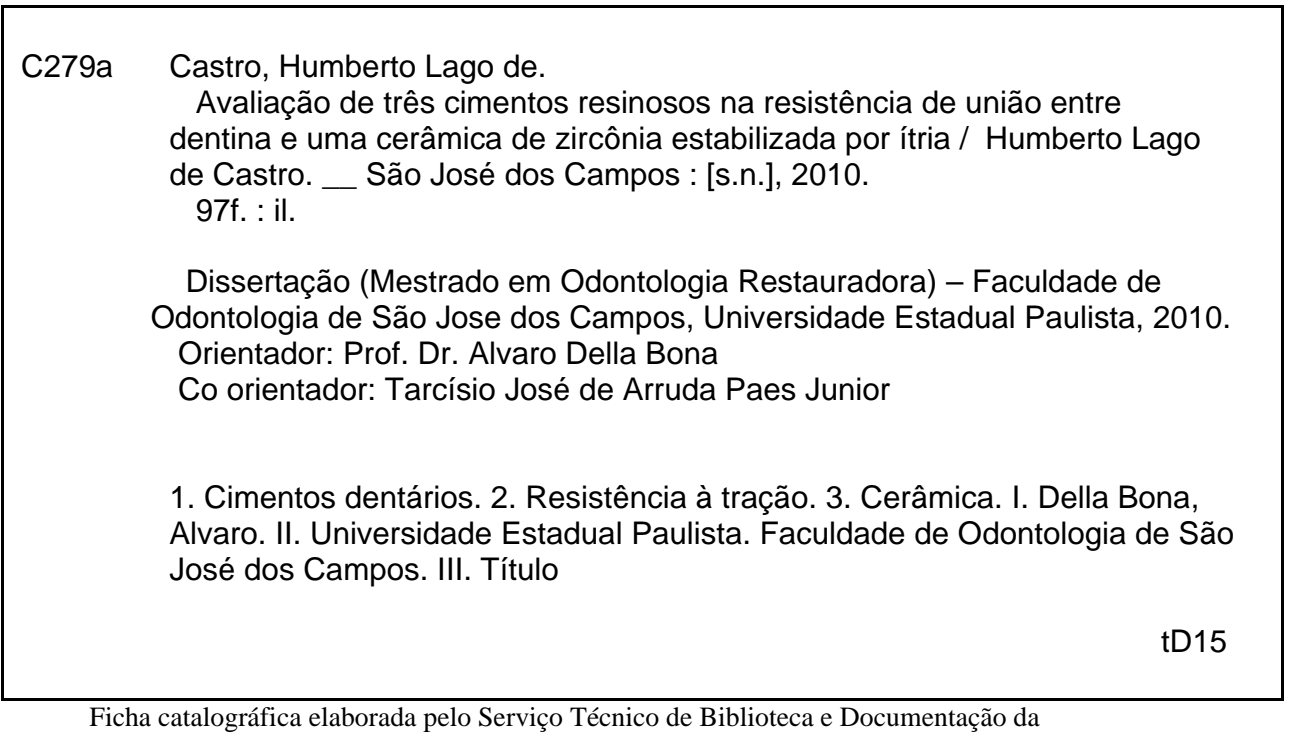
Faculdade de Odontologia de São José dos Campos - UNESP

\section{AUTORIZAÇÃO}

Autorizo a reprodução e divulgação total ou parcial deste trabalho, por qualquer meio convencional ou eletrônico, desde que citada a fonte.

São José dos Campos, 22 de Abril de 2010 .

Assinatura :

E-mail: lagodecastro@yahoo.com.br 


\section{BANCA EXAMINADORA}

Prof. Titular Alvaro Della Bona (Orientador)

Faculdade de Odontologia Universidade de Passo Fundo - UPF

Prof. Adjunto Estevão Tomomitsu Kimpara Faculdade de Odontologia de São José dos Campos Universidade Estadual Paulista - UNESP

Prof. Titular Mário Alexandre Coelho Sinhoreti Faculdade de Odontologia de Piracicaba Universidade Estadual de Campinas - UNICAMP

São José dos Campos, $1^{\circ}$ de junho de 2010. 


\section{DEDICATÓRIA}

À $\mathcal{D E U S}$, por tudo que me Ele me proporciona, pela família que tenho, pelos amigos verdadeiros, pelas oportunidades de vida e por poder dizer: "sou muito feliz".

Aos meus pais, Vmberto Segundo de Castro Jr. e Maira Maria Lago de Castro, que sempre me apoiaram nos momentos decisivos da minha formação, acompanhando cada conquista de perto com entusiasmo e orgulho. Vocês são a minha base e a minha referência, meu maior exemplo de vida.

À minha irmã Bibiane, pelo amor, carinho e amizade, por sempre ter acreditado no meu trabalho e me incentivar na busca dos meus objetivos.

Às minhas avós SNilde e Maria, que com seu "jeitinho de vó" e com um sorriso no rosto conseguem acabar com qualquer preocupação. 


\section{AGRADECIMENTOS ESPECIAIS}

Aos meus pais, Umberto e Maira, por sempre terem me apoiado em todos os momentos, por abrirem meus olhos para as coisas da vida e por terem abdicado de suas próprias vontades para prover estudo à mim. À minha irmã, Bibiane, por fazer parte da minha vida! Vocês são o meu porto seguro, amo vocês!

Ao meu orientador, Prof. Tit. Alvaro Della Bona, pela confiança depositada ao acolher-me como seu orientado desde a iniciação científica, na Universidade de Passo Fundo, até o mestrado, na UNESP. Pelo prazer em compartilhar de seus conhecimentos, sendo um exemplo de competência e dedicação na pesquisa. Seu apoio e atenção foram imprescindíveis para a conclusão de mais esta etapa de vida. Espero tê-lo sempre ao meu lado, como amigo e professor.

Ao meu co-orientador, Prof. Dr. Tarcísio José de Arruda Paes-Jr., pelo apoio e compreensão nas horas difíceis. Disposto e solícito, colaborou com a execução deste trabalho.

Ao Prof. Titular Marco Antonio Bottino pela oportunidade de conhecimento e crescimento profissional, pela sua maneira especial de conduzir a Especialidade de Prótese Dentária do Programa de Pós-Graduação em Odontologia Restauradora e pelo exemplo de profissional.

Ao Prof. Adj. Estevão Tomomitsu Kimpara, pelos ensinamentos e pela pessoa humilde e especial que demonstrou ser nesses anos de convivência.

À equipe de Materiais Odontológicos e Prótese Total: Profs. Estevão, Sigmar, Tango, Alexandre, Guilherme e Paula, pela 
amizade construída nesses anos e por permitirem o contato com a graduação no meu estágio docência.

Ao Prof. Dr. Fernando Eidi Takahashi na Disciplina de Prótese Parcial Fixa, pela confiança depositada e pela oportunidade de manter contato com a clínica bem como com a graduação.

Ao Prof. Ivan Balducci pela amizade, pelos conselhos, pela preciosa contribuição para a realização da análise estatística e atenção dispensada.

Logo que cheguei em São José dos Campos, passei por muitas dificuldades. Recém formado, muito jovem, sempre morando junto dos pais, a vinda a uma cidade distante, a angústia pela busca a carreira profissional e a distância dos amigos e da família foram obstáculos difíceis de serem superados. Graças a Deus, consegui encontrar pessoas muito receptivas e amigas que me acolheram e me fizeram sentir melhor. Vocês podem ter certeza que se eu não tivesse encontrado vocês, não sei se estaria aqui hoje, muito obrigado: Lucas, Liliane, Suzana, Fernanda, Priscila, Sheila, Aleska e Celina.

Às minhas amigas, Diana e Priscila, queridas colegas de turma do mestrado, pela amizade, comprometimento e companhia. Tive muita sorte em ter vocês como minhas companheiras.

Aos meus colegas de apartamento, Lucas Zogheib, Thales Wilson Cardoso, Pedro Corazza e André Couto, pelo convívio, amizade e companheirismo, principalmente nas horas mais difíceis.

Ao meu amigo, Eurípedes Kaizo Ariki, mais conhecido como Kaizão, companheiro de Coronel, excelente protesista, que passou muito conhecimento na área de Prótese Fixa, cedendo material e auxiliando na confecção da minha primeira aula teórica. Tenho certeza que nossa amizade irá perdurar por toda a vida.

Ao meu amigo, Anderson Almeida Castilho, habilidoso cirurgião que abriu as portas e me incentivou veementemente a seguir, também, no caminho da Implantodontia e Cirurgia. Tenho certeza que 
nossas conversas extrapolaram os limites acadêmicos e tem aplicação para a vida.

Ao meu amigo, Mauro Tavares Rozendo e a suas irmãs Dora e Luíza, pelo apoio e confiança depositados em mim.

Aos meus amigos, Luis Felipe e Vinícius Carvalho, parceiros de todas as horas, obrigado pela amizade. Espero que nossa amizade perdure por muitos anos. E a toda sua família, Luiz, Elenira e Ludmila, a qual considero minha família paulista.

Aos meus "amigos irmãos", Vinícius Fabris, Cristian

Nunes, Guilherme Mendonça, Gustavo, Rodrigo Portela, Carlo Ferronato, Fernando Frandalozo, Luis Fernando, Vinícius Doro, Vinícius GORGES, por terem me entendido e me apoiado nesse importante passo da minha caminhada na busca do conhecimento. 


\section{AGRADECIMENTOS}

À Faculdade de Odontologia de São José dos Campos Universidade Estadual Paulista "Júlio de Mesquita Filho" - UNESP, através do seu Diretor Prof. Adjunto José Roberto Rodrigues.

Ao Programa de Pós-Graduação em Odontologia Restauradora, coordenado pelo Prof. Adjunto Clóvis Pagani, pela oportunidade concedida.

À CAPES (Coordenação de Aperfeiçoamento Pessoal de Nível Superior), pela concessão da bolsa de Mestrado para realização deste trabalho.

Ao chefe do Departamento de Materiais Odontológicos e Prótese da faculdade de Odontologia de São José dos Campos UNESP, Prof. Adj. Lafayette Nogueira Júnior e demais docentes do Programa de Pós Graduação em Odontologia Restauradora, pela contribuição na minha formação acadêmica e científica.

Aos Funcionários do Departamento de Materiais Odontológicos e Prótese, Fernando, Inês e Jú, bem como do Laboratório de Pesquisa, Clélia, Anamaria, Júlio e Gabi, o auxílio, a companhia e os momentos de descontração foram fundamentais para a correta execução dos experimentos laboratoriais.

Às secretárias Suzana Cristina de Oliveira e Eliane Wenzel, do departamento de Materiais Odontológicos e Prótese, pelo carinho, amizade e companheirismo durante esses anos de convivência.

Aos meus grandes amigos da Pós-Graduação: Lucas Hian, Luis Gustavo Oliveira de Vasconcellos, Jarbas Francisco Fernandes dos Santos e Luis Guilherme Macedo, pelo 
companheirismo, amizade e os bons momentos compartilhados nesse período, continuaremos sempre amigos.

Aos meus colegas de curso, Fernanda, Regina, Marianna, Liliana, Renata, Susana, Paula, Rodrigo, Celina, Silvinha, Sheila, Priscilla, Aleska, Sandra, Graziella, José Renato, Sabrina, Flávia, Lilian e Marina, pelo convívio e amizade que se estabeleceram durante nosso curso.

Aos meus colegas de especialização, que buscam o conhecimento e crescimento profissional sem deixar de lado a amizade e o companheirismo.

Às secretárias da seção de Pós-Graduação, Erena Michie Hasegawa, Rosemary de Freitas Salgado Pereira e Maria Aparecida Consiglio de Souza, pelas informações e atenção dispensada.

A todos os colegas de Pós-Graduação do Departamento de Odontologia Restauradora (Dentística e Endodontia) pelos conhecimentos compartilhados e pelos momentos de descontração que passamos juntos.

À todas as pessoas que de forma direta e indiretamente me apoiaram para a conclusão desta etapa. 
"Educar o homem não é encher um pote... é acender um fogo!" Aristófanes 


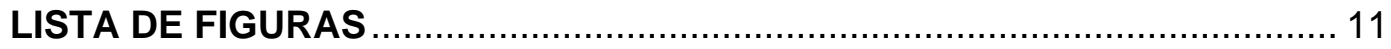

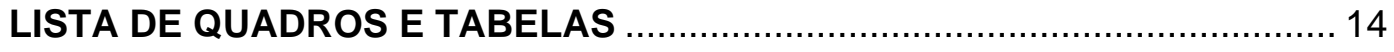

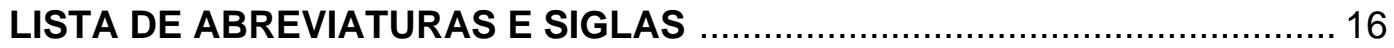

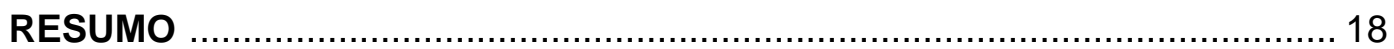

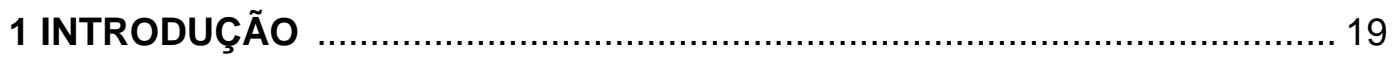

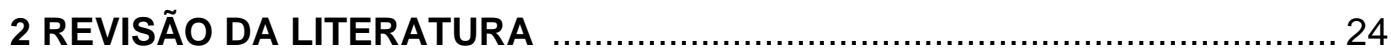

2.1 Evolução dos sistemas adesivos e dos cimentos resinosos ................ 24

2.2 Adesão entre zircônia densamente sinterizada parcialmente estabilizada

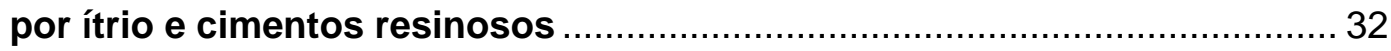

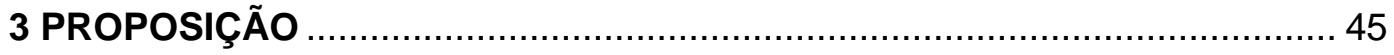

4 MATERIAIS E MÉTODO................................................................. 46

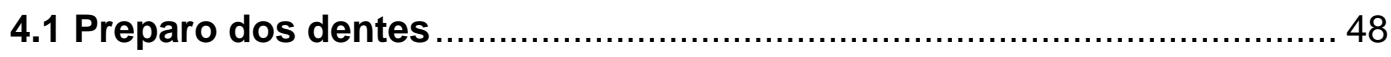

4.2 Preparo dos blocos cerâmicos ......................................................... 50

4.3 Tratamento da superfície cerâmica ................................................. 51

4.4 Processos de cimentação ................................................................... 52

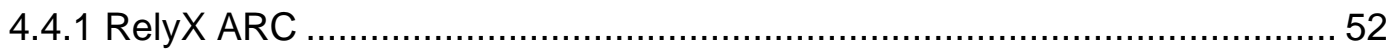

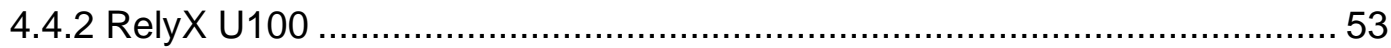

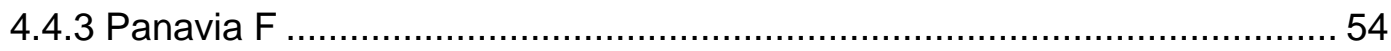

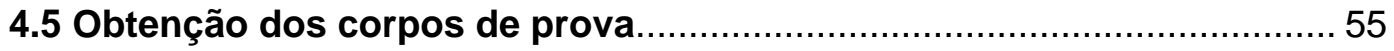

4.6 Ciclagem térmica e armazenagem .............................................. 58

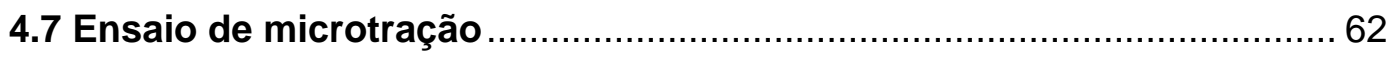

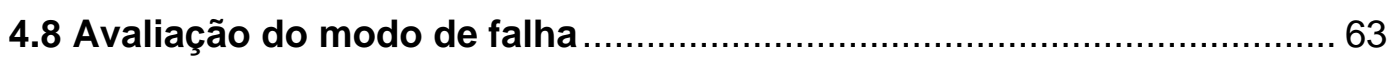

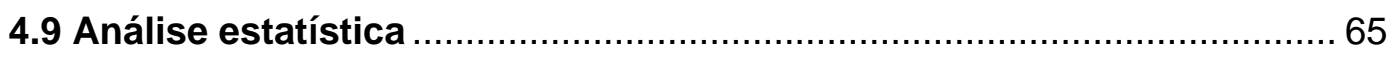

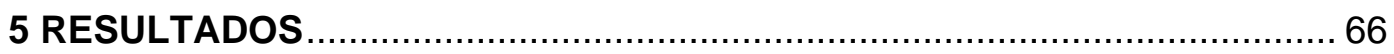

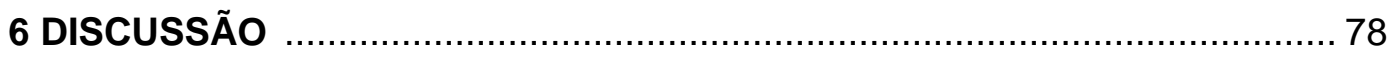

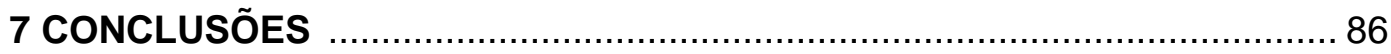

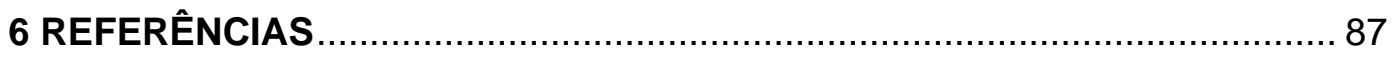

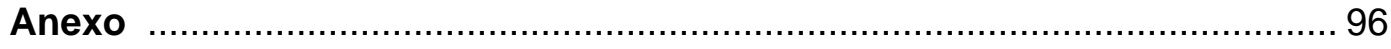

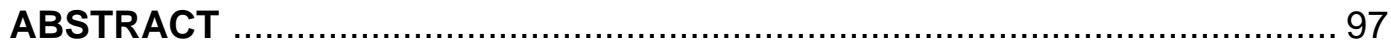




\section{LISTA DE FIGURAS}

Figura 1 - Inclusão dos dentes em resina acrílica e vista oclusal do conjunto após a exposição da dentina.

Figura 2 - Representação gráfica das dimensões do bloco cerâmico após sinterização

Figura 3 - Microjateador e amostra cerâmica posicionada no dispositivo metálico para padronização dos procedimentos de jateamento.

Figura 4 - Cimentação do bloco cerâmico à dentina com aplicação de carga perpendicular $(750 \mathrm{~g})$ e remoção dos excessos......................................

Figura 5 - Imagens representativas do corte dos conjuntos cerâmica-cimento-dente para obtenção dos corpos-de-prova em forma de barra. A e B-corte somente da zircônia nos eixos $X$ e $Y$. CFinalização dos cortes. D- corte final da base dos corpos-de-prova soltando os mesmos da dentina.

Figura 6 - Estufa bacteriológica onde os corpos-de-prova ficaram armazenados em água à uma

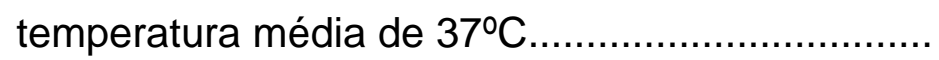


Figura 7 - A- Equipamento para termociclagem. B e Ccontroladores de temperatura, número de ciclos e tempo de banho. Liga-se, primeiramente, os botões 1 a 5 e aguarda-se que a máquina alcance as temperaturas desejadas para ligar o botão 6 .

60

Figura 8 - Dispositivo para ensaio de microtração (OD03d Odeme Equipamentos Médico e Odontológicos Ltda, Joaçaba/SC, Brasil). Corpo de prova fixado nas garras do dispositivo após a realização do teste (cp fraturado)

Figura 9 - Vista frontal do microscópio eletrônico de varredura (Jeol-JSM-5310, Jeol, Japão).

Figura 10 - Gráfico de colunas (média \pm desvio padrão) dos dados de resistência adesiva ( $\mathrm{MPa}$ ) para as 18 condições experimentais

Figura 11 - Efeito Cimento Resinoso. Gráfico de médias segundo as condições experimentais.

Figura 12 - Efeito Cimento Resinoso. Gráfico de médias segundo as condições experimentais.

Figura 13 - Falha ADES-cc: falha adesiva na interface cimento-cerâmica. A: dentina (magnificação: 75x). B: cerâmica (magnificação: 1000x), a fotomicrografia ampliada revela a zircônia jateada, sem cimento resinoso residual. Corpo 
de prova fraturado proveniente do grupo RelyX ARC + Jateamento + Termociclagem.

Figura 14 - Falha ADES-cd: falha adesiva na interface cimento-dentina. A: dentina. B: cerâmica. Magnificação: $75 \mathrm{x}$. Corpo de prova fraturado proveniente do grupo Panavia F + Silicatização + Termociclagem.....................................................

Figura 15 - Falha COES-cim: falha coesiva do cimento resinoso. A: dentina. B: zircônia. Magnificação: 75x. É clara a camada de cimento resinoso sobre as superfícies de cimentação (dentina e cerâmica). Corpo de prova fraturado proveniente do grupo Panavia F + Silicatização + Imediato (24h). 


\section{LISTA DE QUADROS E TABELAS}

Quadro 1 - Tipo de material, nome comercial, número do lote e fabricante dos produtos usados na confecção dos corpos-de-prova.......................................

Quadro 2 - Grupos experimentais conforme os fatores de estudo.

Tabela 1 - Média \pm desvio padrão dos dados de resistência à tração (MPa) segundo os fatores "cimento resinoso", "tratamento de superfície cerâmica" e "condição de envelhecimento"

Tabela 2 - ANOVA 3-fatores dos daos de resistência adesiva

Tabela 3 - Média dos dados de resistência adesiva (MPa) das condições experimentais estabelecidas pelas variáveis "cimento resinoso" e "tratamento de superfície", no fator de envelhecimento "24 horas"

Tabela 4 - Média dos dados de resistência adesiva (MPa) das condições experimentais estabelecidas pelas variáveis "cimento resinoso" e "tratamento de superfície", no fator de envelhecimento "termociclagem". 
Tabela 5 - Média dos dados de resistência adesiva (MPa) das condições experimentais estabelecidas pelas variáveis "cimento resinoso" e "tratamento de superfície", no fator de envelhecimento "60 dias"......

Tabela 6 - Média dos dados de resistência adesiva (MPa) das condições experimentais estabelecidas pelas variáveis "envelhecimento" e "tratamento de superfície", no fator de cimento resinoso "RelyX ARC"

Tabela 7- Média dos dados de resistência adesiva (MPa) das condições experimentais estabelecidas pelas variáveis "envelhecimento" e "tratamento de superfície", no fator de cimento resinoso "RelyX U100".....

Tabela 8- Média dos dados de resistência adesiva (MPa) das condições experimentais estabelecidas pelas variáveis "envelhecimento" e "tratamento de superfície", no fator de cimento resinoso "Panavia F"

Tabela 9- $\quad$ Análise dos padrões de fratura, conforme o grupo experimental 


\section{LISTA DE ABREVIATURAS E SIGLAS}

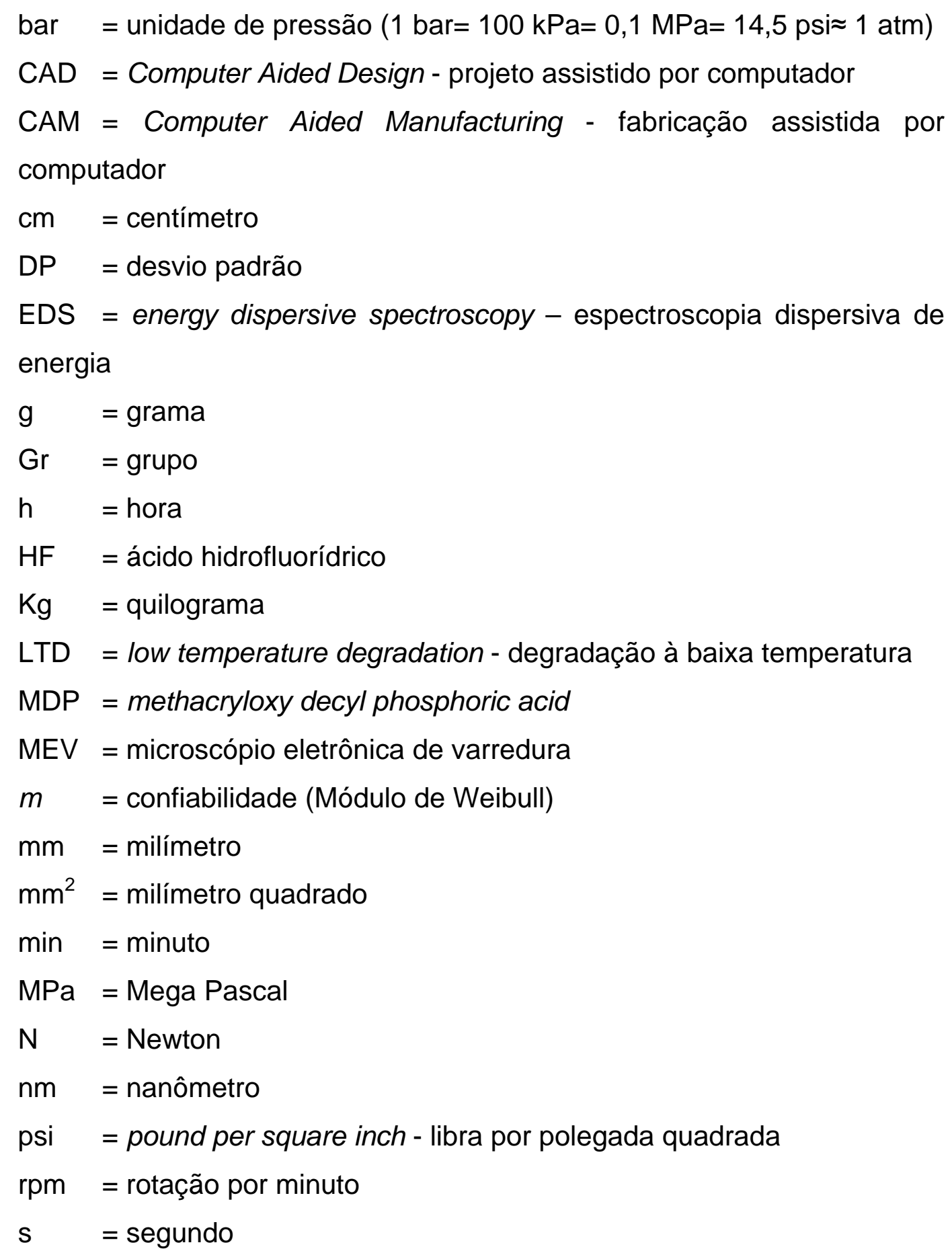




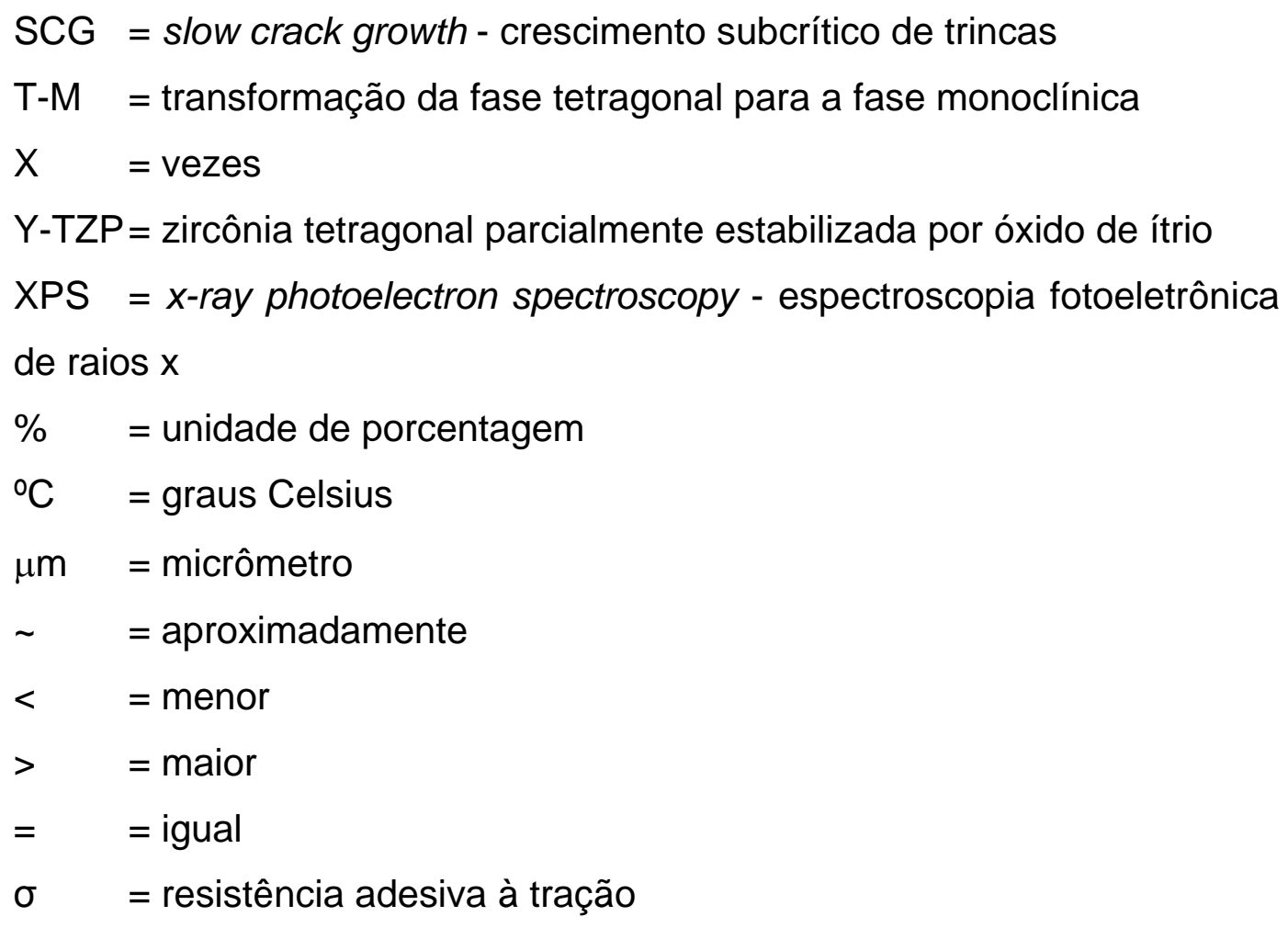


Castro HL. Avaliação de três cimentos resinosos na resistência de união entre dentina e uma cerâmica de zircônia estabilizada por ítria. [dissertação]. São José dos Campos: Faculdade de Odontologia de São José dos Campos, UNESP - Univ Estadual Paulista; 2010.

\section{RESUMO}

Objetivou-se avaliar a resistência à tração $(\sigma)$ da união de três sistemas de cimentação resinosa de ativação dual (RelyX ARC, RelyX U100 e Panavia F) entre a dentina e uma cerâmica à base de zircônia estabilizada por óxido de ítrio (In-Ceram YZ, Vita Zanhfabrik) com diferentes tratamentos de superfície. A superfície oclusal de 54 terceiros molares humanos hígidos foi exposta e condicionada conforme as instruções de cada cimento. Cinqüenta e quatro blocos cerâmicos foram planificados e sinterizados $(6,4 \mathrm{~mm} \times 6,4 \mathrm{~mm} \times 4,8 \mathrm{~mm})$. Após, foram divididos em dois grupos conforme o tipo de tratamento de superfície: jateamento com óxido de alumínio $\leq 50 \mu \mathrm{m}$ ou silicatização (CoJet, 3M ESPE)(24-28 psi). A cimentação à dentina foi realizada de acordo com as instruções de cada fabricante. Assim, foram constituídos 6 grupos. Os conjuntos foram armazenados em água destilada à $37^{\circ} \mathrm{C}$ por $24 \mathrm{~h}$ e cortados no sentido x e y, 9 corpos de prova (cp) por conjunto foram obtidos em média (área adesiva de $\pm 1 \mathrm{~mm}^{2}$ ). Os $\mathrm{cp}$ de cada conjunto foram divididos aleatoriamente em 3 condições de armazenagem: ensaio imediato; 60 dias de armazenagem em água destilada $\left(37^{\circ} \mathrm{C}\right)$ e termociclagem $\left(10.000 x, 5^{\circ} \mathrm{C}-55^{\circ} \mathrm{C}\right)(\mathrm{n} \geq 12)$. $\mathrm{O}$ ensaio de resistência adesiva por microtração foi realizado numa máquina de ensaio universal (1 mm/min). Nos grupos imediatos RelyX ARC-silicatização e Panavia Fjateamento apresentaram as médias mais altas de $\sigma(13,9$ e 13,0 MPa, respectivamente), seguido do RelyX U100-jateamento (10,2 MPa). Após a termociclagem, o cimento Panavia F-jateamento foi melhor (14,8 MPa) seguido pelo RelyX ARC-silicatização e RelyX U100-jateamento (12,9 e $9,9 \mathrm{MPa}$, respectivamente). Após a armazenagem por 60 dias, os cimentos se comportaram de forma semelhante, onde os grupos que foram silicatizados demonstraram uma tendência a valores mais elevados de $\sigma(\mathrm{MPa})$.

Palavras-chave: Cimentos dentários; Resistência à tração; Cerâmica. 


\section{INTRODUÇÃO}

A busca pela excelência estética fez com que a odontologia restauradora se direcionasse para materiais cada vez mais estéticos e duradouros. Neste sentido a utilização de coroas totais cerâmicas é crescente e sua indicação cada vez mais ampla.

Os materiais restauradores precisam cumprir com os requisitos necessários para suportar as cargas e tensões geradas em serviço, principalmente na região posterior. Entretanto, a maioria das cerâmicas dentais é friável e o estresse de tração resultante de uma carga externa pode levar a propagação catastrófica de trincas (falhas, defeitos) pré-existentes (Seghi et al., 1995). Sua susceptibilidade à falha foi identificada em áreas localizadas de concentração de estresse elevado (Kramer et al., 1999; Scherrer et al., 1999; Jung et al., 2000; Lawn et al., 2001). Conseqüentemente, outras cerâmicas foram desenvolvidas na tentativa de melhorar essas propriedades mecânicas.

Como, por exemplo, as cerâmicas à base de zircônia tetragonal parcialmente estabilizada por óxido de ítrio (Y-TZP - Yttria partially stabilized tetragonal zirconia). A medicina faz uso dessa cerâmica em próteses biomédicas, como por exemplo, na articulação do quadril. $\mathrm{Na}$ odontologia estas cerâmicas foram introduzidas em conjunto com os sistemas CAD/CAM (Denry; Kelly, 2008).

A zircônia é um material polimórfico que existe em três alótropos: a fase monoclínica, estável até aproximadamente $1170^{\circ} \mathrm{C}$, seguido da transformação à fase tetragonal (entre $1170^{\circ} \mathrm{C}$ à $2370^{\circ} \mathrm{C}$ ) e cúbica que existe até seu ponto de fusão à $2713^{\circ} \mathrm{C}$ (Subbarao, 1981; Goff et al., 1999). Esses valores podem variar, dependendo da composição química da zirconia (Della Bona, 2009). 
A transformação da fase tetragonal para a fase monoclínica (T-M) durante o resfriamento é acompanhada por um aumento substancial de volume $(\sim 4,5 \%)$ (Kelly \& Denry, 2008). Esta transformação T-M é reversível e inicia-se em torno de $950^{\circ} \mathrm{C}$ no resfriamento (Denry e Kelly, 2008). A zircônia estabilizada com óxidos como $\mathrm{CaO}, \mathrm{MgO}, \mathrm{Y}_{2} \mathrm{O}_{3}$ ou $\mathrm{CeO}_{2}$ consegue reter a sua estrutura tetragonal à temperatura ambiente $\mathrm{e}$, conseqüentemente, o controle do estresse induzido da transformação T-M, sendo muito eficiente no impedimento da propagação da trinca aumentando sua resistência (Garvie et al., 1972; Garvie et al., 1975; Heuer et al., 1986; Della Bona, 2009).

Algumas propriedades mecânicas da zircônia são as mais altas relatadas para uma cerâmica dental, apresentando altos valores de resistência à fratura $(>1000 \mathrm{MPa})$ e de tenacidade (6-10 $\mathrm{MPa} \cdot \mathrm{m}^{0,5}$ ) quando comparados às cerâmicas convencionais (Kosmac et al., 1999; Lawn et al., 2002; Guazzato et al., 2004; Deville et al., 2006). Isto possibilita a realização de próteses parciais fixas posteriores com maior previsibilidade (Della Bona, 2009).

Um problema aparente das cerâmicas a base de zircônia é a degradação à baixa temperatura (LTD - low temperature degradation), sendo esse um fenômeno bem documentado e agravado notavelmente pela presença da água (Sato et al., 1985; Chevalier et al., 1999; Guo, 1999). As conseqüências deste processo de envelhecimento são múltiplas e incluem a degradação da superfície com desprendimento de grãos e a formação de microtrincas, assim como a diminuição da resistência (Denry; Kelly, 2008). Esse tipo de evento ocorreu nas próteses ortopédicas, onde a cerâmica era submetida a processos de esterilização na presença de calor e umidade (o que não ocorre com as cerâmicas dentais) (Della Bona, 2009).

Kosmac et al. (2000) e Sundh et al. (2005) relataram que o tratamento térmico (annealing) à $900^{\circ} \mathrm{C}$ por $1 \mathrm{~h}$ ou os tratamento térmicos relativamente curtos na escala de temperatura de $900-1000^{\circ} \mathrm{C}$ 
induzem a transformação reversa da fase monoclínica para tetragonal novamente. Este fenômeno foi acompanhado pelo relaxamento da tensão compressiva na superfície e uma diminuição na resistência à flexão. A queima da cerâmica de cobertura durante a fabricação de restaurações dentais provavelmente promove a transformação reversa com as conseqüências listadas anteriormente. Além disso, a reversibilidade da transformação não deve ser confundida como um mecanismo para "curar" as falhas introduzidas previamente.

Um problema relatado no desempenho das cerâmicas de zircônia é a pobre adesão aos cimentos resinosos. Para uma adesão confiável entre cerâmicas convencionais (ácido sensíveis) e cimentos resinosos é necessário um pré-tratamento de superfície. No entanto, nem o condicionamento com ácido fluorídrico nem a silanização garantem uma adesão satisfatória entre resina e zircônia, devido ao alto teor cristalino e escassa fase vítrea (abaixo de 1\%) (Bottino et al., 2005; Kim et al., 2005; Amaral et al., 2006; Atsu et al., 2006; Della Bona, 2009). Como conseqüência, vários protocolos de cimentação estão sendo propostos para modificar as propriedades de superfície da zircônia, por meio de métodos de microabrasão (Blatz et al., 2004; Özcan e Vallittu, 2003; Valandro et al., 2006; Kumbuloguo et al., 2006; Wolfart et al., 2007). Esses métodos, contudo, foram criticados por, supostamente, induzirem o crescimento subcrítico de trincas (SCG - slow crack growth) (Zhang et al. 2004; Deville et al., 2006). Porém, os resultados em testes mecânicos ainda são os mais altos em comparação às outras cerâmicas de infraestrutura, sugerindo um desempenho superior mesmo após esses tratamentos (Zhang et al., 2004). Além disso, a união entre infra-estrutura a base de zircônia e cimento resinoso, na cimentação adesiva, funciona de forma diferente aos testes laboratoriais onde os corpos-de-prova de infra-estrutura a base de zircônia são avaliados de forma isolados (Della Bona, 2009). 
Esse desempenho foi confirmado por Sailer et al., em 2007, que apresentaram resultados clínicos satisfatórios com próteses parciais fixas posteriores com infra-estrutura em zircônia cimentados com cimentos resinosos (Variolink II ou Panavia TC).

Embora a cimentação não-adesiva das restaurações cerâmicas a base de zircônia (fosfato de zinco ou cimentos de ionômero de vidro modificados por resina) possa fornecer uma adequada fixação clínica, a cimentação adesiva é preferível para garantir uma melhor conservação e adaptação marginal (Atsu et al., 2006; Burke et al., 2002; Derand et al., 2005).

Segundo Oyagüe et al., 2009a, cimentos com potencial para serem utilizados com a zircônia são baseados no bisphenol $A$ diglycidylether methacrylate (Bis-GMA), e monômeros do tipo 4methacryloxyethyl trimellitate anhydride ou methacryloxy decyl phosphoric acid (MDP), pois apresentam uma resistência de união melhor que outros cimentos e não há necessidade de tratamento de superfície. Porém, o dilema permanece para os clínicos, pois os cimentos e os fabricantes de cerâmica não informam um único protocolo de cimentação, apenas apresentam alternativas para que o clínico faça a sua escolha.

Sabendo que a seleção do cimento é um fator de fundamental importância para garantir uma resistência adesiva adequada a zircônia, agentes de cimentação com monômero fosfato têm sido propostos na literatura com resultados satisfatórios (Oyagüe et al., 2009a; Oyagüe et al., 2009b; Valandro et al., 2005; Valandro et al., 2006; Valandro et al., 2007; Wolfart et al., 2007).

Cimentos auto-adesivos de passo único foram igualmente propostos para cimentação de restaurações à base de zircônia (Ernst et al., 2005). A matriz resinosa destes sistemas consiste de um ácido metacrilato multifuncional que reage com o substrato e contribui para o mecanismo de adesão (De Munck et al., 2004), porém há pouca informação disponível. 
Enquanto não houver um consenso e um conceito bem sedimentado na literatura sobre o método de condicionamento mais apropriado para uma adesão adequada do cimento à cerâmica a base de zircônia, bem como da durabilidade da adesão a longo prazo, ficam lacunas quanto aos procedimentos de cimentação.

Diante do exposto, o objetivo neste estudo foi investigar a influência dos tratamentos de superfície de uma cerâmica a base de zircônia estabilizada por óxido de ítrio na resistência adesiva a cimentos resinosos, com características diferentes, imediatamente após a cimentação e após o envelhecimento. 


\section{REVISÃO DA LITERATURA}

\subsection{Evolução dos sistemas adesivos e dos cimentos resinosos}

Os primeiros relatos do condicionamento do esmalte dental com ácido fosfórico foram de Buonocore (1955), em que o autor verificou a alteração da morfologia superficial do esmalte criando microporosidades que melhoraram a união entre a resina e o esmalte dental.

A odontologia adesiva evoluiu muito com a incorporação de partículas de carga às resinas (Bowen, 1963), a adição de novas técnicas e materiais para o condicionamento do órgão dental (Fusayama et al., 1979; Nakabayashi et al.,1982).

Pashley et al., em 1992, evidenciaram a necessidade de se aprimorar os agentes condicionadores e primers. As possíveis desvantagens causadas pelo condicionamento ácido, como o aumento da permeabilidade dentinária, da umidade superficial, do potencial de irritação pulpar, da desnaturação do colágeno e de uma discrepância entre profundidade de desmineralização e capacidade de penetração do agente adesivo foram relatados no trabalho. Os autores concluíram que foi vantajosa a simplificação da técnica com a combinação de agentes condicionadores e primers, reduzindo a concentração ácida, o tempo de aplicação, bem como minimizando a microinfiltração.

Watanabe e Nakabayashi, em 1993, desenvolveram um primer auto-condicionante para adesão em esmalte e dentina simultaneamente, o qual reduziu o tempo de trabalho, eliminando o passo 
de lavagem do ácido, além de evitar o risco de colapso das fibras de colágeno dentinário.

Em 1994, Watanabe e Nakabayashi descreveram métodos utilizados para mensurar a união de compósitos sobre a dentina. Os métodos mais utilizados foram o teste de tração, o de cisalhamento e o de "push-out". Os autores relataram que o teste de tração deve ser o de eleição, apesar de ser crítica a execução do teste, visto que a interface a ser testada deve estar perpendicular a força de tração. Já os testes de cisalhamento, a fratura parece sempre começar no ponto em que o bisel, aplicador da carga, atinge a amostra, podendo mascarar a fratura (Della Bona; van Noort, 1995).

Van Meerbeek et al. (1994) avaliaram, in vivo, a efetividade clínica de dez sistemas adesivos em restaurações classe V. Foram utilizados sistemas de um (auto-condicionantes) e dois ou mais passos clínicos (convencionais). Os autores concluíram que os sistemas que promoveram a remoção da smear layer e a desmineralização da dentina (convencionais) mostraram uma evolução clínica melhor do que aqueles que modificaram a camada desordenada de colágeno sem remoção completa da smear layer. A retenção após um ano foi registrada como perfeita para Clearfil Liner Bond e Scotchbond Multi-Purpose.

Sano et al., em 1994, compararam in vitro a relação entre a área de superfície e a resistência de união entre dentina e dois materiais restauradores, por meio do teste de tração. Foram utilizados 20 molares humanos extraídos. O tecido dentinário foi exposto através de um corte realizado em cortadeira com disco diamantado sob refrigeração à água. Os dentes foram polidos com lixas de SiC (carbeto de silício) de granulação 600 e tratados com um dos 3 tipos de materiais utilizado no teste (Scotchbond Multi Purpose, Clearfil Liner Bond 2 e Vitremer). Após construído um bloco de material restaurador (resina ou ionômero de vidro), fatias de $0,5 \mathrm{~mm}$ a $3 \mathrm{~mm}$ de espessura foram obtidas através de cortes realizados ao longo eixo do dente e, com o uso de uma ponta 
diamantada superfina, foi realizado um corte ("estrangulamento") na região da união, com aproximadamente 0,5 $\mathrm{mm} \times 0,5 \mathrm{~mm}$ a $3 \mathrm{~mm} \times 3 \mathrm{~mm}$ de área seccional, deixando os corpos-de-prova com a forma de ampulheta. Cada corpo-de-prova foi posicionado e unido com cola a base de cianoacrilato a um dispositivo de teste (Bencor Multi-T) acoplado a máquina de ensaios universal. O teste foi realizado com uma velocidade de $1 \mathrm{~mm} / \mathrm{min}$. Os resultados demonstraram que houve relação inversa entre a resistência de união e área de adesão, além de permitir várias medições em um mesmo dente. Os autores concluíram que o teste de tração com menor área de adesão produziu resultados mais confiáveis, sendo denominado de teste de microtração.

Della Bona e Van Noort, em 1995, verificaram o efeito da distribuição de esforços durante a realização dos testes de resistência ao cisalhamento sobre uma cerâmica, utilizando a análise de estresse por elemento finito, bem como a análise do tipo de falha ocorrida com os diferentes tipos de testes. Para isso, foram confeccionadas amostras de cerâmica e resina composta. No grupo A, foram construídos cilindros de resina composta sobre a base de cerâmica; no grupo $B$, a base era de resina composta e o cilindro de cerâmica; e no grupo $\mathrm{C}$, tanto a base quanto o cilindro foram construídos com resina composta. Para o ensaio de cisalhamento, o carregamento nos cilindros foi realizado com um cinzel posicionado o mais próximo possível da interface adesiva. Paralelamente, neste estudo, os autores também verificaram a resistência de união à tração para os mesmos materiais. Os resultados demonstraram que os valores de resistência ao cisalhamento para as amostras do grupo $A$ foi inferior estatisticamente aos valores dos grupos B e C. Quanto ao tipo de falha ocorrida, metade das amostras do grupo A tiveram falha coesiva na base de cerâmica e a outra metade falha adesiva. No grupo B, 80\% das falhas foram coesivas na base de resina composta e os $20 \%$ restantes foram falhas adesivas. No grupo C, 100\% das amostras tiveram falha coesiva na base de resina composta. Já no teste de tração, as falhas 
sempre ocorreram na interface adesiva e isso levou os autores a concluir que o teste de tração seria o mais indicado, já que o teste de cisalhamento pareceu ser inadequado para mensurar a resistência de união da interface cerâmica/resina composta. Pequenas variações neste tipo de teste como geometria da amostra, ponto de carregamento e tipo de carregamento, fornecem valores de resistência de união diferentes, fato este atribuído a não uniformidade dos esforços induzidos na interface durante o carregamento. Sendo assim, o teste de tração teria um arranjo menos complexo e mais apropriado para se avaliar a resistência de união da interface cerâmica/resina composta.

Em 1998, van Meerbeek et al. realizaram uma revisão de literatura sobre o desempenho clínico dos adesivos dentinários. Os sistemas adesivos foram classificados em relação à smear layer. O primeiro grupo de sistemas adesivos remove completamente a smear layer e são apresentados em um ou dois frascos, dependendo, respectivamente, da aplicação combinada ou separada do primer e do agente adesivo. O segundo grupo modifica a smear layer ao invés de removê-la, denominados de sistemas auto-condicionantes. Este contém um monômero acídico Phenyl-P e HEMA para, simultaneamente, condicionar e tratar tanto o esmalte quanto a dentina. De acordo com os autores, além da simplicidade, o segundo grupo promove a desmineralização superficial da dentina, a penetração simultânea de monômeros, e pode ser polimerizado in situ.

Em 2002, Lopes et al. realizaram uma revisão de literatura sobre adesão dentária no que se refere ao estado presente e perspectivas futuras. Os autores afirmaram que duas técnicas adesivas distintas são as mais proeminentes: condicionamento total e os sistemas auto-condicionantes. Enquanto os adesivos com condicionamento total já demonstraram sua eficácia tanto in vitro como em situações clínicas, os sistemas auto-condicionantes ainda necessitam provar sua eficácia, os quais estão evoluindo rapidamente, porém seus resultados ainda não são 
suficientemente previsíveis, mas alguns sistemas, como o Prompt L-Pop (3M ESPE), que é um adesivo auto-condicionante, e o Clearfil SE Bond (Kuraray), que é um sistema com um primer auto-condicionante, alcançaram resultados positivos na união às estruturas dentárias. No entanto, mais estudos são necessários para confirmar a eficiência desses sistemas.

Em 2004, Behr et al. compararam in vitro a adaptação marginal de um cimento resinoso auto-adesivo de apenas um passo clínico (RelyX Unicem), com cimentos já estabelecidos e seus correspondentes sistemas adesivos. Coroas totalmente cerâmicas foram cimentadas a molares humanos com o cimento auto-adesivo (sem e com a etapa de tratamento da superfície dentinária), um cimento que remove a camada de smear layer (convencional) e um cimento resinoso com sistema adesivo que dissolve a smear layer (sistema adesivo autocondicionante). Os resultados indicaram que o cimento auto-adesivo sem pré-tratamento proporcionou adaptação marginal em dentina similar aos demais agentes de cimentação.

Piwowarczyk et al., em 2004, determinaram a resistência adesiva ao cisalhamento, in vitro, de agentes cimentantes a algumas ligas metálicas e cerâmicas odontológicas: alumina densamente sinterizada; cerâmica reforçada com leucita; e cerâmica a base de dissilicato de lítio. As superfícies da liga e da cerâmica de alumina foram jateadas com partículas de óxido de alumínio $(100 \mu \mathrm{m})$ com pressão de 2,8 bar, a uma distância de $10 \mathrm{~mm}$, durante 10 segundos. As superfícies das demais cerâmicas sofreram condicionamento com ácido hidrofluorídrico e aplicação de silano. Concluíram que, após 14 dias de armazenamento em água e termociclagem, apenas o cimento auto-adesivo RelyX Unicem e dois cimentos resinosos (Panavia F e Compolute) apresentaram forte adesão aos específicos materiais, e os demais cimentos (fosfato de zinco, ionômeros de vidro e ionômeros de vidro modificados resina) apresentaram os menores valores de resistência de união. 
Van Meerbeek et al. (2005) preocupados com a técnica dos adesivos auto-condicionantes de um passo clínico, discutiram os principais pontos negativos inerentes a estes sistemas. Assim, consideraram que, além da formação da camada híbrida, os adesivos auto-condicionantes poderiam oferecer a vantagem adicional de formar uma interação química entre os monômeros funcionais e a hidroxiapatita residual. Contudo, os adesivos auto-condicionantes de um passo técnico são comumente associados com uma baixa resistência de adesão, a qual poderia ser atribuída em parte à dissolução de monômeros hidrofílicos e hidrofóbicos em uma relativamente alta concentração de solventes. Dentro desta mistura instável, a presença da água também é essencial como um meio de ionização para desencadear a atividade autocondicionante do adesivo. Por serem altamente hidrofílicos, os adesivos auto-condicionantes de um único passo têm sido reportados como uma membrana semipermeável, permitindo a passagem de fluidos e comprometendo seriamente a durabilidade de união. Entretanto, empregando-se uma técnica apropriada de secagem ou de evaporação do solvente a efetividade de união seria aumentada, por remover substancialmente a quantidade de água destes adesivos.

Schulze et al. (2005) estudaram o sistema adesivo com primer auto-condicionante (Clearfil SE Bond, Kuraray) em comparação ao adesivo mono-componente com condicionamento ácido prévio (Single Bond, 3M ESPE), no que se refere à umidade da superfície dentária. Os resultados demonstraram que o Clearfil SE Bond não demonstrou alterações entre os grupos, enquanto que o Single Bond apresentou diferenças significantes entre os grupos, especialmente após a secagem da superfície, confirmando a sensibilidade da técnica.

Abo-Hamar et al. (2005) avaliaram, in vitro, a resistência ao cisalhamento de um cimento auto-adesivo em esmalte e dentina, comparando-o a quatro agentes cimentantes (três resinosos e um de ionômero de vidro). As amostras foram submetidas à termociclagem, 
sendo que a resistência adesiva do cimento auto-adesivo após a termociclaglem, em esmalte, diminui significativamente, mas ainda permaneceu estatisticamente superior ao grupo do cimento de ionômero de vidro. Em dentina, a resistência adesiva do cimento auto-adesivo foi estatisticamente semelhante aos outros cimentos resinosos, porém significativamente superior ao cimento de ionômero de vidro. Os autores afirmaram que o tipo de substrato afeta a resistência adesiva dos cimentos testados, sendo que o cimento auto-adesivo não é o ideal para cimentação de inlays e coroas parciais, onde uma considerável área de esmalte está presente. Porém, concluíram que o cimento auto-adesivo, que tem o processo de cimentação simplificado, pode ser considerado uma alternativa aos sistemas utilizados para cerâmicas e restaurações de bases metálicas, nos casos em que pouco ou nenhum esmalte é encontrado.

De Munck et al. (2005) realizaram uma revisão crítica da literatura com relação à durabilidade de união entre os tecidos dentários e os adesivos resinosos, enfocando métodos e resultados. Os autores relatam os tipos de envelhecimento como estocagem, termociclagem, cargas oclusais e estudos de degradação in vivo. O envelhecimento mais comumente utilizado é a estocagem dos corpos-de-prova em ambiente úmido a $37^{\circ} \mathrm{C}$, por um período específico. A maioria dos estudos demonstra diminuição dos valores de resistência após a armazenagem, que é causada, possivelmente, pela degradação por hidrólise da interface entre os componentes (principalmente da resina e/ou colágeno). Mas, a água pode infiltrar e diminuir as propriedades mecânicas da matriz polimérica, dilatando e reduzindo as forças entre as cadeias poliméricas (processo chamado de plastificação). Além disso, alguns componentes da interface como monômeros residuais e produtos resultantes dos processos de envelhecimento podem enfraquecer a adesão entre os materiais. A água é a solução geralmente utilizada nos estudos, sendo que saliva artificial também pode ser utilizada demonstrando resultados 
similares. Os autores relataram que o envelhecimento por termociclagem é outro meio bastante utilizado, sendo que 500 ciclos $\left(5^{\circ} \mathrm{C}-55^{\circ} \mathrm{C}\right)$ é o mínimo que a norma ISO TR 11450 (1994) recomenda. O efeito da termociclagem pode ocorrer de duas maneiras: (1) a água quente pode acelerar a hidrólise dos componentes da interface e subseqüente absorção de água e remoção dos produtos da degradação ou oligômeros mal polimerizados; ou (2) devido a um coeficiente de expansão térmico linear mais alto do material restaurador em relação aos tecidos dentais. Os repetitivos estresses de contração/expansão que são gerados na interface podem levar a formação de trincas que propagam nas interfaces adesivas, e, quando uma falha ou lacuna (gap) é criada a sua evolução de tamanho pode levar a penetração de fluídos orais, processo conhecido como "percolação". Os autores concluíram que a termociclagem é fortemente dependente do tamanho da interface adesiva, sendo que para palitos de microtração a termociclagem diminuiu significantemente a resistência adesiva, suportando a hipótese que a termociclagem acelera a degradação química da interface. Gale e Darvell (1999), sugeriram, após uma detalhada revisão de literatura, que 10.000 termociclos pode ser considerado como o uso clínico durante um ano.

Em 2008, Holderegger et al. avaliaram, in vitro, a resistência adesiva (teste de cisalhamento) de um cimento auto-adesivo, em dentina humana, comparado a três cimentos resinosos convencionais. Testaram a influência da termociclagem e do operador na capacidade e qualidade da adesão. Os autores constataram que o cimento autoadesivo exibiu os menores valores de resistência adesiva, porém foi o que menos alterou com relação a variação de operador e à termociclagem. 


\subsection{Adesão entre zircônia densamente sinterizada parcialmente estabilizada por óxido de ítrio (Y-TZP) e cimentos resinosos}

A reabilitação oral através de próteses livre de metal é crescente, e as exigências estéticas e funcionais estão sendo priorizadas. Sendo assim, as próteses com infra-estrutura à base de Y-TZP estão sendo utilizadas devido as suas excelentes propriedades mecânicas (Della Bona, 2009; Deville et al., 2006; Guazzato et al., 2004; Kosmac et al., 1999; Lawn et al., 2002).

Porém, com o aumento das propriedades mecânicas das cerâmicas surgiram dificuldades para a adesão aos cimentos resinosos. Técnicas de tratamento de superfície e materiais estão sendo propostos para o aumento da durabilidade de união entre cerâmicas Y-TZP e cimentos resinosos, bem como a relação entre esses tratamentos e a resistência da cerâmica (Della Bona, 2009).

Em 1999, Kosmac et al. avaliaram o efeito do polimento e do jateamento na microestrutura, na resistência à flexão biaxial e na confiabilidade (módulo de Weibull) de 2 cerâmicas de Y-TZP. Os autores concluíram que o jateamento aumentou a resistência à flexão da zircônia, já o polimento promoveu diminuição da resistência e redução da confiabilidade.

Em 2000, Tinschert et al., usando teste de flexão em quatro pontos, avaliaram a resistência flexural e a confiabilidade de algumas cerâmicas odontológicas, considerando a fresagem mecânica (CAD-CAM) e o processamento tradicional em laboratório. Foi verificado que as cerâmicas fresadas por CAD-CAM (Cerec Mark II e Zirconia-TZP, Vita Zanhfabrik, Alemanha) atingiram valores de $m$ maiores que 18 (análise de Weibull), sendo consideradas mais confiáveis.

Zhang et al., em 2004, verificaram o efeito do jateamento em uma cerâmica Y-TZP e em uma cerâmica densamente sinterizada de 
alumina. As superfícies foram polidas ou jateadas (partículas de óxido de alumínio de $50 \mu \mathrm{m}$, por $5 \mathrm{~s}$ a uma distância de $10 \mathrm{~mm}$, com uma pressão de 40 psi) e submetidas aos testes de fadiga cíclica e dinâmica. As cerâmicas polidas apresentaram, predominantemente, desenvolvimento subcrítico de trincas. Já as jateadas apresentaram uma diminuição da resistência em ambos os testes (dinâmico e cíclico), proveniente dos defeitos iniciais causados pelo jateamento. Porém, os resultados ainda são os mais altos em comparação às outras cerâmicas de infra-estrutura, sugerindo um desempenho superior mesmo após esses tratamentos.

Em 2005, Sundh et al. avaliaram o efeito do tratamento térmico e a aplicação de uma cerâmica de cobertura na resistência à fratura de uma cerâmica Y-TZP após o teste de fadiga. Os autores concluíram que apesar do tratamento térmico e da aplicação de uma cerâmica de cobertura terem diminuído os valores de resistência, os resultados ainda indicam que esse material apresenta propriedades potenciais para restaurações totalmente cerâmicas.

Em 2005, Guazzato et al. avaliaram a influência do jateamento, desgaste com ponta diamantada e polimento antes e após tratamento térmico, na resistência à flexão de uma cerâmica de Y-TZP. Os corpos-de-prova foram divididos em quatro grupos, de acordo com o tratamento de superfície (jateamento, polimento, desgaste paralelo ao eixo de tração, desgaste perpendicular ao eixo de tração). Vinte corposde-prova de cada grupo foram submetidos a tratamento térmico, simulando as temperaturas de cocção da cerâmica de cobertura e glaze (dois ciclos: $930^{\circ} \mathrm{C}$ e $910^{\circ} \mathrm{C}$ por $1 \mathrm{~min}$ ). Após o tratamento, foi realizado o teste de resistência à flexão de três pontos e a análise de difração de raios $X$ foi utilizada para estimar a quantidade relativa de fase monoclínica. A confiabilidade da força foi avaliada através da distribuição de Weibull. Os seguintes valores de força e conteúdo relativo de fase monoclínica de zircônia foram obtidos, respectivamente, para cada grupo: jateamento (1540 MPa; 9,5\%); desgaste paralelo (1330 MPa; 8,3\%); 
desgaste perpendicular (1525 MPa; 8,3\%), desgaste paralelo e tratamento térmico (1225 MPa; conteúdo monoclínico não detectado); desgaste perpendicular e tratamento térmico (1185 MPa; conteúdo monoclínico não detectado); polida e com tratamento térmico (1165 MPa; conteúdo monoclínico não detectado); polido (1095 MPa; 0,8\%); jateamento e com tratamento térmico (955 $\mathrm{MPa} ; 0,3 \%)$. Os autores concluíram que o jateamento e o desgaste podem ser recomendados para aumentar a resistência da cerâmica Y-TZP, desde que não sejam seguidas por tratamento térmico. Fino polimento pode remover a camada de compressão e, portanto, diminuir a resistência à flexão.

Curtis et al. (2006a), avaliaram a influência do jateamento (partículas de alumina de 25, 50 e $110 \mu \mathrm{m}$ ) e do desgaste com ponta diamantadas (fina: cristais de 20-40 $\mu \mathrm{m}$; grossa: cristais de 125-150 $\mu \mathrm{m}$ ) na resistência à flexão biaxial (análise de Weibull), rugosidade, dureza e na composição de fase. Nos grupos controle, tanto a seco quanto armazenado em água por 24 horas, os discos cerâmicos não sofreram tratamento após a sinterização. Não houve diferença estatisticamente significante $(p>0,05)$ na resistência à flexão dos grupos jateados com relação aos grupos controle seco e armazenado em água por 24 horas. Entretanto, um aumento significante da confiabilidade $(m)$, através do módulo de Weibull, foi identificado para os grupos jateados e armazenados a seco e em água destilada com relação ao grupo controle. O desgaste com ponta diamantada de granulação grossa diminuiu significantemente os valores na resistência biaxial comparado com o grupo controle e aumentaram a rugosidade da superfície. Já com as pontas diamantadas de granulação mais fina não houve diferença estatística. A combinação da redução da rugosidade e a formação de uma área de tensão compressiva devido ao jateamento aumentaram o $m$ na resistência à flexão da cerâmica.

Regimes de carga mastigatória também foram avaliados por Curtis et al. (2006b). Examinou-se a influência da carga mastigatória 
simulada a coroas ou pontes posteriores totalmente cerâmicas que estão sujeitas a esses esforços. Discos da cerâmica Y-TZP (Lava, 3M ESPE) foram confeccionados para os testes de resistência à flexão biaxial. $\mathrm{O}$ teste de dureza também foi aplicado em vários pontos próximos à aplicação da carga cíclica. Os autores notaram um aumento da dureza em áreas localizadas próximas a aplicação de carga, sugestivas do mecanismo de transformação de fase (T-M) da cerâmica, devido a geração de áreas de compressão onde ocorreram forças de tensão no momento da carga.

Papanagiotou et al., em 2006, avaliaram a possível degradação, ao envelhecimento a baixa temperatura e a diferentes tratamentos de superfície, de uma cerâmica de Y-TZP (Vita in-Ceram YZ, Vita Zahnfabrik). As superfícies cerâmicas receberam os seguintes tratamentos: sem tratamento (controle); fervura em água por $24 \mathrm{~h}$ ou por 7 dias; armazenagem em ambiente umidificado à $250^{\circ} \mathrm{C}$ por $6 \mathrm{~h}$, por $24 \mathrm{~h}$, ou por 7 dias; polimento; jateamento (partículas de óxido de alumínio de $50 \mu \mathrm{m})$; jateamento e fervura em água por 7 dias. Foram realizados testes de resistência à flexão em 3 pontos, análise de Weibull, microscopia eletrônica de varredura, análise de difração de raio-X (para detectar a mudança da fase tetragonal para monoclínica), e a espectroscopia dispersiva de energia (EDS) foi utilizada para identificar possíveis mudanças na composição química do material. Os resultados mostraram que a degradação à baixa temperatura e os tratamentos de superfície da cerâmica não reduziram a resistência à flexão da cerâmica. O jateamento com partículas de óxido de alumínio aumentou a resistência flexural da cerâmica.

Atsu et al. (2006) estudaram o efeito do tratamento de superfície na resistência adesiva entre cimentos resinosos e uma cerâmica à base de zircônia com alto conteúdo cristalino (Cercon, Degussa Dental, Alemanha) tratada com diferentes métodos. As superfícies de cimentação da cerâmica foram jateadas com partículas de 
$125 \mu \mathrm{m}$ de óxido de alumínio $\left(\mathrm{Al}_{2} \mathrm{O}_{3}\right)$ e divididas em 6 grupos $(\mathrm{n}=10)$ : Grupo C, sem tratamento (controle); Grupo SIL, silanizadas com agente silano (Clearfil Porcelain Bond Activator, Kuraray); Grupo BSIL, aplicação de um adesivo contendo10-methacryloyloxidecyl dihydrogen phosphate monomer (MDP) e agente silano misturado (Clearfil Liner Bond $2 \mathrm{~V} /$ Porcelain Bond Activator); Grupo SC, silicatização (partículas de $\mathrm{Al}_{2} \mathrm{O}_{3}$ modificadas por sílica de $30 \mu \mathrm{m}$ - Cojet System); Grupo SCSIL, silicatização e silanização; e Grupo SCBSIL, silicatização e aplicação da mistura de um adesivo e agente silano (Clearfil Liner Bond 2V / Porcelain Bond Activator). As cerâmicas tratadas foram cimentadas aos cilindros de resina composta (Z-250) através de um cimento resinoso monômerofosfatado (Panavia F). O teste de cisalhamento foi realizado para aferir a resistência de união dos diferentes tratamentos de superfície. O grupo SCBSIL obteve os maiores valores de resistência, apresentando diferença estatística $(P<0,001)$ dos grupos $C$, SIL e BSIL, mas não apresentou diferença estatisticamente significante entre os grupos SC e SCSIL. Os modos de falha dos grupos C e SIL foram principalmente adesivas entre cerâmica/cimento, já os demais grupos apresentaram principalmente falhas mistas e coesivas. Sendo assim, os autores concluíram que a silicatização e a aplicação da mistura de um adesivo com MDP e agente silano aumentam a resistência ao cisalhamento entre a cerâmica de $\mathrm{Y}$ TZP e um cimento resinoso (Panavia F).

Della Bona et al., em 2007, avaliaram a resistência adesiva à tração e ao cisalhamento de uma cerâmica infiltrada por vidro e reforçada com zircônia (Vita In-Ceram Zircônia - IZ) à resina composta, testando a hipótese de que o sistema de silicatização (Cojet, 3M-ESPE) produz valores maiores de resistência adesiva do que os outros tratamentos de superfície utilizados, quais sejam: HF- ácido hidrofluorídrico a 9,5\% (Ultradent) por 2 min; SB- jateamento com óxido de alumínio $50 \mu \mathrm{m}$ por $10 \mathrm{~s}$; SC- silicatização por $10 \mathrm{~s}$. As superfícies tratadas foram lavadas (com exceção do grupo SC), secadas com jatos 
de ar e uma camada de silano foi aplicada. $\mathrm{O}$ adesivo (Single Bond, 3MESPE) foi aplicado na área de adesão (3,5 $\mathrm{mm}$ de diâmetro) e fotopolimerizado por $10 \mathrm{~s}$. Um cilindro resinoso (Z100, 3M) foi construído em incrementos e fotopolimerizado. Metade dos espécimes de cada grupo $(n=10)$ foram testados para resistência adesiva à tração $\left(\sigma_{t}\right)$ e a outra metade para resistência adesiva ao cisalhamento $\left(\sigma_{s}\right)$. Ambos os testes foram realizados utilizando o aparato Bencor Multi-T em uma máquina de ensaios universal (EMIC DL 2000) com uma velocidade de $1 \mathrm{~mm} / \mathrm{min}$. Os resultados foram analisados estatisticamente por ANOVA e Tukey $(\alpha=0.05)$. Os valores médios e desvio padrão $(\mathrm{MPa})$ para $\sigma_{t}$ foram: HF-

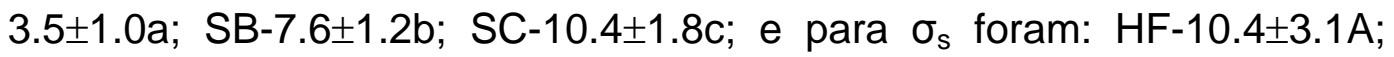
SB-13.9 $\pm 3.1 B ; S C-21.6 \pm 1.7 C \quad(p<0.05)$. Os tratamentos de superfície demonstraram o mesmo ranqueamento estatístico de valores em ambos os testes. A cerâmica IZ tratada com SC demonstrou aumento significativo nos valores médios de resistência adesiva em ambos os testes.

Aboushelib et al., em 2007, propuseram um novo método de preparo da superfície das cerâmicas Y-TZP. O objetivo do estudo foi avaliar a resistência à microtração e a durabilidade de união entre cerâmica e cimento resinoso. O método de preparo consiste no jateamento da superfície (partículas de $110 \mu \mathrm{m}$ de óxido de alumínio) e na aplicação de uma fina camada de um vidro de infiltração de baixa fusão composto por óxidos inorgânicos (sílica 30\%; titânio 13\%; alumina 8\%; potássio $3 \%$; rubídio 1\%; magnésio 1\%). Após a queima em forno na presença de ar à $750^{\circ} \mathrm{C}$, a camada de vidro de infiltração foi condicionada com uma solução de $5 \%$ de ácido hidrofluorídrico por $15 \mathrm{~min}$. Os cimentos Panavia F 2.0 (Kuraray Co Ltd, Japão), RelyX ARC (3M ESPE, EUA) e Bistite II DC (J Morita USA, EUA) foram utilizados para a cimentação, sendo que para o grupo do novo método foi utilizado o cimento Panavia $F$ 2.0. As amostras foram testadas inicialmente ( 24 horas), uma, duas, três semanas e em um mês. Os valores obtidos demonstraram que o método 
de condicionamento cerâmico aliado à um agente cimentante com monômero MDP produz uma união forte e durável.

Studart et al., em 2007, avaliaram a resistência a carga cíclica de três cerâmicas de infra-estrutura indicadas para próteses fixas de 3, 4 e 5 elementos. Uma a base de dissilicato de lítio (Empress 2, Ivoclar Vivadent), uma cerâmica de zirconia infiltrada por vidro (InCeramZirconia, Vita Zahnfabrik) e uma cerâmica Y-TZP (Cercon, Degudent). Os testes de fadiga mecânica e de fratura rápida foram realizados para determinar a distribuição de Weibull e o tempo de vida e resistência inicial de cada infra-estrutura. Os autores concluíram que apesar da notável susceptibilidade à fadiga em água, a Y-TZP foi o material que apresentou maiores condições para a confecção de pontes fixas posteriores livres de metal, devido a sua alta resistência mecânica inicial. Segundo os autores, se seguidas as normas para seleção dos materiais e design das pontes livres de metal, esse material tem um tempo de vida estimado, sobre condições de severa umidade e carga cíclica, de mais de 20 anos.

Özcan et al. (2008a) avaliaram o efeito do jateamento de consultório e laboratorial no condicionamento da superfície de uma cerâmica Y-TZP (Lava, 3M ESPE) cimentados à um cimento resinoso (Panavia F 2.0, Kuraray). Os espécimes foram divididos em 4 grupos: 1jateamento com dispositivo de consultório com partículas de óxido de alumínio de $50 \mu \mathrm{m}$ + aplicação do Alloy Primer (Kuraray, Japão); 2jateamento com dispositivo de consultório com partículas de óxido de alumínio de $50 \mu \mathrm{m}$ + Cesead II Opaque Primer (Kuraray, Japão); 3jateamento com dispositivo de consultório com partículas de óxido de alumínio de $50 \mu \mathrm{m}$ + Silano-Pen + agente silano (Bredent); e 4silicatização (em laboratório) com partículas de óxido de alumínio modificadas por sílica de $110 \mu \mathrm{m}$ (Rocatec) + agente silano (ESPE-Sil, 3M ESPE). As superfícies tratadas receberam um cimento resinoso (Panavia F 2.0). Após a cimentação, os corpos-de-prova foram termociclados (6.000 ciclos de $\left.5^{\circ} \mathrm{C}-55^{\circ} \mathrm{C}\right)$ e o teste de cisalhamento foi realizado. Os 
resultados não indicaram diferença estatística entre os grupos. Entretanto, o desempenho do jateamento com dispositivo de consultório usado para a zircônia é uma alternativa para o tratamento da superfície.

Özcan et al. (2008b) compararam a adesão entre uma cerâmica Y-TZP (LAVA, 3M ESPE, Germany) cimentada a quatro tipos de cimentos resinosos, segundo as instruções dos fabricantes (Panavia $F$ 2.0, Multilink, SuperBond e Quadrant Posterior Dense). O teste de resistência ao cisalhamento foi realizado, sendo que metade das amostras foi testada imediatamente e as demais foram termocicladas (6.000 ciclos $/ 5^{\circ} \mathrm{C}-55^{\circ} \mathrm{C}$ ). A resistência de união foi afetada significativamente após a termociclagem $(p<0,001)$. O cimento Panavia $F$ 2.0 demonstrou os maiores resultados na condição seca. Após a termociclagem, todos as amostras falharam antes do teste. Sendo assim, os autores concluíram que o uso de zircônia não pode ser recomendado para próteses fixas quando a retenção adesiva for necessária.

Tanaka et al., em 2008, investigaram a eficiência da silicatização sobre uma cerâmica a base de zircônia (Katana, Noritake Dental Supply Co. Ltd., Japão). Os corpos-de-prova foram jateados com partículas de $30 \mu \mathrm{m}$ de óxido de alumínio modificadas por sílica (Rocatec ${ }^{\text {TM }}$ Soft, 3M ESPE, USA) ou com partículas de $30 \mu \mathrm{m}$ de óxido de alumínio (Aluminus Oxide, Heraeus Kulzer $\mathrm{GmbH}$, Germany) sob uma pressão de 0,28 MPa a uma distância de $10 \mathrm{~mm}$ por $13 \mathrm{~s} / 1 \mathrm{~cm}^{2}$. Os grupos foram divididos em: AS- jateamento da superfície cerâmica com óxido de alumínio mais aplicação de monômero MDP (MDP: Epricode, Kuraray, Japão); SiC- silicatização mais monômero MDP; ROCsilicatização, silano (Espe ${ }^{\mathrm{TM}}$-sil, 3M ESPE, EUA); mROC- silicatização mais uma mistura de silano e monômero MDP. A superfície cerâmica foi analisada através da espectroscopia com fotoelétrons de raios $\mathrm{x}$ ( $x$-ray photoelectron spectroscopy - XPS), apresentando um aumento de $9,7 \%$ de sílica na superfície da cerâmica. Não houve diferença estatística na média da rugosidade superficial da cerâmica jateada ou silicatizada 
$(p<0,01)$. No teste de cisalhamento, metade das amostras foi testada 24 horas após a cimentação e as demais foram testadas após 10.000 ciclos $\left(5^{\circ} \mathrm{C}-55^{\circ} \mathrm{C}\right)$. O grupo mROC obteve os valores mais altos, sendo que não diminuiu significantemente após a termociclagem $(p<0,01)$. Não ocorreu diferença estatística entre os grupos AS, SiC e ROC. Após a termociclagem a média da resistência ao cisalhamento do grupo AS diminuiu levemente e do grupo $\mathrm{SiC}$ diminuiu significativamente, enquanto o grupo ROC não diminuiu $(p<0,01)$. Microscopia eletrônica de varredura (MEV) foi realizada nas amostras, onde observou-se falhas coesivas somente no grupo mROC, já os demais grupos apresentaram falhas mistas. Sendo assim, os autores concluíram que somente a silicatização da cerâmica a base de zircônia não foi eficiente, devido a alta tenacidade dessa cerâmica. Resultados melhores foram encontrados com a interação da silicatização com um adesivo contendo monômero MDP associado a um agente silano.

Em 2009, Souza avaliou o efeito de diferentes protocolos de jateamento na resistência à flexão biaxial e na estabilidade estrutural de uma cerâmica de Y-TZP. Os grupos experimentais foram formados dependendo dos fatores do estudo, que foram: jateamento (óxido de alumínio de $110 \mu \mathrm{m}$ ou $50 \mu \mathrm{m}$; óxido de sílica: $30 \mu \mathrm{m}$ ou $50 \mu \mathrm{m}$ ); pressão (2,5 bar ou 3,5 bar) e ciclagem mecânica (com e sem). Concluiu que o jateamento com partículas modificadas por sílica (Cojet) de $30 \mu \mathrm{m}$ a uma distância de $10 \mathrm{~mm}$, por 20s a uma pressão de 2,5 bar e 3,5 bar, parecem ser os tratamentos de superfície mais indicados para aumentar a resistência mecânica da cerâmica Y-TZP, já que não foi observado diminuição da resistência após fadiga mecânica. Porém, o tipo de partícula [óxido de alumínio (110 $\mu \mathrm{m}$ ou $50 \mu \mathrm{m})$ ou óxido de silício (partículas de $110 \mu \mathrm{m}$ ou $30 \mu \mathrm{m}$ )], a pressão (2,5 bar ou 3,5 bar) e a ciclagem mecânica (100.000 ciclos, $50 \mathrm{~N}$ e $4 \mathrm{~Hz}$ ) não influenciaram os valores de resistência entre os grupos experimentais. 
Oyagüe et al. (2009a) avaliaram o efeito do condicionamento da superfície na resistência à tração de uma cerâmica a base de óxido de zircônio cimentada a cimentos resinosos duais, com os seguintes tratamentos: (1) jateamento com partículas de óxido de alumínio de $125 \mu \mathrm{m}$ (Supradental, Espanha) a uma distância de 5 mm, por 10 s à uma pressão de 60-100 psi; (2) silicatização com partículas de óxido de alumínio $(50 \mu \mathrm{m})$ modificadas por sílica (Supradental, Espanha); (3) sem tratamento de superfície. Foram confeccionados cilindros de resina composta (Tetric Evo Ceram, Ivoclar-Vivadent) de 19,5 mm de diâmetro e 3,5 mm de altura para a cimentação nos discos cerâmicos. Foram utilizados 3 cimentos resinosos para a cimentação, formando três subgrupos: (1) Calibra (DeTrey Dentsply); (2) Clearfil Esthetic Cement (Kuraray); (3) Relyx Unicem (3M ESPE). A cimentação foi realizada conforme as instruções dos fabricantes, sob uma carga de 1 Kg (1249 $\mathrm{MPa}$ ) durante $5 \mathrm{~min}$ para o início da presa química. Após foram fotoativados (BluePhase, Ivoclar Vivadent; output: $600 \mathrm{mmW} / \mathrm{cm}^{2}$ ) por 40 s em cada lado para atingir um grau adequado de polimerização. Os corpos de prova foram armazenados à temperatura de $37^{\circ} \mathrm{C}$ por $24 \mathrm{~h}$ em um ambiente com $100 \%$ de umidade relativa. Os conjuntos cerâmicacimento-resina foram seccionados verticalmente com um disco de diamante em baixa rotação (Accutom 50, Struers, Denmark), formando corpos de prova com $1 \mathrm{~mm}^{2}$ de área adesiva. Obtendo-se, em média, 25 corpos de prova por grupo. Um dispositivo (Bencor Multi T testing, Danville Engineering, EUA) foi acoplado em uma máquina de ensaios universais (Instron Model 4411, Instron, EUA) para o teste de microtração, com a uma velocidade de $0,5 \mathrm{~mm} / \mathrm{min}$ até a fratura. Os modos de falha foram avaliados em um estereomicroscópio (Olympus SZ-CTV, Olympus Co., Japão) com 40 vezes de ampliação, e classificadas como coesiva (do cimento ou da cerâmica), adesiva (entre o compósito e o cimento ou entre o cimento e a cerâmica) e mista (fratura adesiva e coesiva simultaneamente). Quatro amostras de cada grupo foram analisadas em 
MEV para caracterizar o padrão de fratura. Microscopia de força atômica foi utilizada para avaliar a rugosidade das superfícies tratadas da cerâmica (antes da cimentação). Ocorreram mudanças significativas na superfície cerâmica após o tratamento $(p<0,001)$, sendo que o jateamento apresentou a maior rugosidade $(45,77 \mathrm{~nm})$ seguido de silicatização $(22,10$ $\mathrm{nm})$ e sem tratamento $(9,39 \mathrm{~nm})$. A resistência de união do cimento Clearfil foi significantemente maior que o Relyx Unicem e Calibra, independentemente do tipo de superfície $(p<0,001)$. Fraturas prematuras ocorreram com o cimento Calibra quando cimentado à superfície silicatizada e não tratada. Este estudo recomendou para a cimentação de cerâmicas a base de zircônia a utilização de cimentos com monômerofosfato (Clearfil), sendo que o tratamento de superfície não é necessário.

Oyagüe et al. (2009b) avaliaram a estabilidade hidrolítica de diferentes cimentos resinosos duais em contato com uma cerâmica a base de óxido de zircônio (Cercon Zirconia, Dentsply). Dezoito blocos cerâmicos foram condicionados com: 1 - sem tratamento; 2 - jateamento (partículas de óxido de alumínio de $125 \mu \mathrm{m}$ ); e 3 - silicatização (partículas de óxido de alumínio modificadas por sílica - $50 \mu \mathrm{m}$ ). Foram utilizados 3 cimentos resinosos para a cimentação: Clearfil Esthetic Cement (Kuraray), Relyx Unicem (3M ESPE) e Calibra (Dentsply). Decorridas 24 horas após a cimentação, os conjuntos foram cortados e corpos-de-prova com área de $1 \mathrm{~mm}^{2}$ foram obtidas para a realização do teste de microtração. Metade dos corpos-de-prova de cada subgrupo $(n \cong 25)$ foram testados imediatamente e os demais foram armazenados em água por 6 meses à $37^{\circ}$ C. Após 24 h, o cimento Clearfil mostrou valores de adesão significantemente maiores que os demais cimentos independente do prétratamento cerâmico $(p<0,001)$. Todas as amostras falharam com 0 cimento Calibra exceto quando cimentado à superfície cerâmica jateada. Depois de 6 meses de armazenagem, a resistência à tração diminuiu significantemente. RelyX Unicem não apresentou alteração significante após a estocagem em água. Os espécimes cimentados com Calibra e 
jateados falharam no decorrer dos 6 meses. Alterações micromorfológicas dos cimentos foram evidenciadas após a armazenagem em água. Os autores concluíram que a longevidade da adesão cimento-cerâmica depende mais da seleção do cimento do que do pré-tratamento da superfície cerâmica. Clearfil e RelyX Unicem foram adequados para a cimentação de zircônia.

Kern et al. (2009), avaliaram a resistência à tração entre uma cerâmica Y-TZP (Cercon, DeguDent) com três diferentes tipos de tratamento (polimento com lixa d'água de 600; jateamento com partículas de óxido de alumínio de $50 \mu \mathrm{m}$ com pressão de 0,05 ou 0,25 MPa) cimentados a um cimento resinoso (Multilink Automix, Ivoclar-Vivadent) utilizando 4 condições experimentais de primer: sem aplicação de primer, Metal/Zirconia Primer (Ivoclar-Vivadent), Alloy Primer (Kuraray) ou com Clearfil Ceramic Primer (Kuraray). Os corpos-de-prova foram divididos em duas condições de armazenagem: 3 dias em água ou 150 dias em água mais 37.500 termociclos $\left(5^{\circ} \mathrm{C}-55^{\circ} \mathrm{C}\right)$. O não jateamento da superfície cerâmica resultou no descolamento durante o envelhecimento artificial de 150 dias, independentemente do uso dos primers. A combinação entre jateamento e a utilização de primer melhorou a resistência de união significantemente $(p<0,05)$. $O$ jateamento com baixa pressão $(0,05 \mathrm{MPa})$ reduziu a rugosidade quando comparado ao jateamento com pressão de 0,25 MPa sem afetar a durabilidade de união, promovendo adesividade adequada quando os primers foram aplicados.

Em 2010, Yang et al. apresentaram um estudo utilizando o mesmo delineamento experimental do estudo anterior (Kern et al., 2009) variando apenas o cimento resinoso (RelyX Unicem, 3M ESPE). Concluíram que utilizando esse cimento resinoso auto-adesivo, o jateamento à uma pressão de $0,25 \mathrm{MPa}$ ou a combinação com baixa pressão $(0,05 \mathrm{MPa})$ e a utilização de primers contendo monômero éster fosfato parecem ser úteis para se obter uma união durável a longo prazo entre RelyX Unicem e uma cerâmica Y-TZP. 
Kitayama et al. (2010) avaliaram a resistência à tração da combinação de primers e cimentos resinosos (Bistite II/Tokuso Ceramic Primer; Linkmax/GC Ceramic Primer; RelyX ARC/RelyX Ceramic Primer; Panavia F 2.0/Clearfil Ceramic Primer; Resicem/Shofu Porcelain Primer e Resicem/AZ Primer) à porcelana feldspática (GN-1 Ceramic Block, GC) e a uma Y-TZP (Cercon Base, Degudent). As superfícies cerâmicas foram jateadas com partículas de óxido de alumínio de $70 \mu \mathrm{m}$, a uma pressão de $0,5 \mathrm{MPa}$ por $5 \mathrm{~s}$ à uma distância de $10 \mathrm{~mm}$. Dois modos de falha foram reportados: falha adesiva na superfície cerâmica ou falha coesiva do cimento resinoso. Os autores relataram um aumento significante $(p<0,05)$ da resistência à tração aplicando primers contendo um agente silano à porcelana feldspática (com exceção do AZ Primer). Para a cerâmica YTZP o cimento Resicem e o AZ Primer exibiram aumento significantemente maior que os outros grupos, exceto o Panavia F 2.0 e Clearfil Ceramic Primer. O modo de falha predominante para os grupos condicionados com primer contendo um monômero ácido fosfônico (AZ Primer) ou monômero éster fosfato (Clearfil Ceramic Primer e Tokuso Ceramic Primer) foram falhas coesivas no cimento enquanto que os outros primers apresentaram, predominantemente, falhas adesivas entre a cerâmica Y-TZP e o cimento. Sendo assim, os autores concluíram que o uso de primer contendo um monômero ácido fosfônico ou um monômero éster fosfato aumentam a resistência de união da resina à uma cerâmica Y-TZP. 


\section{PROPOSIÇÃO}

O objetivo neste estudo foi avaliar três cimentos resinosos duais e seus protocolos de cimentação imediatamente, após armazenagem ou ciclagem térmica na resistência de união entre a dentina e uma cerâmica a base de zircônia tetragonal parcialmente estabilizada por óxido de ítrio (Y-TZP) que recebeu diferentes protocolos de tratamento de superfície.

As hipóteses testadas nesse estudo são:

- O cimento auto-condicionante dentinário apresenta uma resistência de união menor do que os demais cimentos avaliados;

- A armazenagem e a ciclagem térmica não reduzem a resistência adesiva de todos os sistemas adesivos avaliados. 


\section{MATERIAIS E MÉTODO}

Os materiais utilizados para a realização dos experimentos nesse estudo estão apresentados no Quadro 1.

Quadro 1 - Tipo de material, nome comercial, número do lote e fabricante dos produtos usados na confecção dos corpos-de-prova.

(continua)

\begin{tabular}{|c|c|}
\hline Material & Nome comercial - lote - fabricante \\
\hline Ácido fosfórico & $\begin{array}{l}\text { Condac } 37 \text { FGM - Ácido fosfórico 37\% } \\
\text { Lote: } 060109 \\
\text { Dentscare Ltda, Joinville, SC, Brasil }\end{array}$ \\
\hline Adesivo & $\begin{array}{c}\text { Super Bonder - Flex Gel } \\
\text { Lote: MAI108V } \\
\text { Hentzel Ltda, Itapevi, SP, Brasil }\end{array}$ \\
\hline Adesivo dentinário & $\begin{array}{c}\text { ED Primer II } \\
\text { Líquido A - Lote: } 262 \mathrm{~A} \\
\text { Líquido B - Lote: 137A } \\
\text { Kuraray Medical Inc, Okayama, Japão }\end{array}$ \\
\hline Adesivo dentinário & $\begin{array}{c}\text { Adper Single Bond } 2 \\
\text { Lote: } 9 X Y B R \\
\text { 3M-ESPE, St Paul, EUA }\end{array}$ \\
\hline
\end{tabular}


(continuação)

\begin{tabular}{|c|c|}
\hline Material & Nome comercial - lote - fabricante \\
\hline Agente de limpeza & $\begin{array}{c}\text { Álcool Isopropílico } \\
\text { Lote: } 16290 \\
\text { Cetus Ind. e Com. Prod. Químicos Ltda, } \\
\text { Santo Amaro, SP, Brasil }\end{array}$ \\
\hline Cerâmica & $\begin{array}{c}\text { VITA In-Ceram YZ 40/15 } \\
\text { Lote: } 15610 \\
\text { Vita Zanhfabrik, Bad Sachingen, Alemanha }\end{array}$ \\
\hline Cimento Resinoso & $\begin{array}{c}\text { Panavia F } \\
\text { Pasta A - Lote: 249D } \\
\text { Pasta B - Lote: 26D } \\
\text { Kuraray Medical Inc., Okayama, Japão }\end{array}$ \\
\hline Cimento Resinoso & $\begin{array}{c}\text { RelyX }{ }^{\text {TM }} \text { ARC (Transparent A1) } \\
\text { Lote: FY8HX } \\
\text { 3M-ESPE, St. Paul, EUA }\end{array}$ \\
\hline Cimento Resinoso & $\begin{array}{c}\text { RelyX }{ }^{\mathrm{TM}} \text { U100 } \\
\text { Lote: } 345682 \\
\text { 3M-ESPE, St Paul, EUA }\end{array}$ \\
\hline Disco Diamantado & $\begin{array}{l}\text { Diamond Wafering Blade No. 11-4254 } \\
\qquad(102 \times 0,3 \mathrm{~mm}) \\
\text { Buehler, Illinois, EUA }\end{array}$ \\
\hline Óxido para jateamento & $\begin{array}{c}\text { Cojet Sand }(30 \mu \mathrm{m}) \\
\text { Lote: } 0006 \\
\text { ESPE Dental AG, Seefeld, Alemanha }\end{array}$ \\
\hline
\end{tabular}


(conclusão)

\begin{tabular}{|c|c|}
\hline Material & Nome comercial - lote - fabricante \\
\hline Óxido para jateamento & Óxido de Alumínio extra fino (45 $\mu \mathrm{m})$ \\
Lote: 26366
\end{tabular}

\subsection{Preparo dos dentes}

Após a aprovação do projeto de pesquisa pelo Comitê de Ética em Pesquisa com Seres Humanos da Faculdade de Odontologia de São José dos Campos (UNESP), sob protocolo número 048/2008$\mathrm{PH} / \mathrm{CEP}$ (em anexo), cinqüenta e quatro molares humanos hígidos foram limpos e armazenados em água destilada à $4^{\circ} \mathrm{C}$ imediatamente após a extração.

Os dentes foram incluídos em resina acrílica quimicamente ativada com o auxílio de um delineador, para que a superfície oclusal dos dentes ficasse o mais paralelo possível da base. A superfície oclusal dos dentes foi abrasionada até expor a dentina (Koibuchi et al., 2001) utilizando um recortador de gesso. Após, os dentes 
foram fixados em uma máquina de corte (Labcut 1010, Extec, EUA) e uma fina fatia $(\sim 1 \mathrm{~mm})$ da superfície oclusal foi removida, através de um corte (disco diamantado com baixa concentração de diamante, Buehler, EUA), deixando o mais paralelo possível a superfície oclusal da base em resina acrílica (Figura 1). Em seguida, essa superfície foi planificada e polida em politriz (Labpol 8-12, Extec, EUA) empregando lixa d'água de granulação 600 (3M, St. Paul, EUA) por 60 s (Lopes et al., 2003), padronizando a formação da lama dentinária.

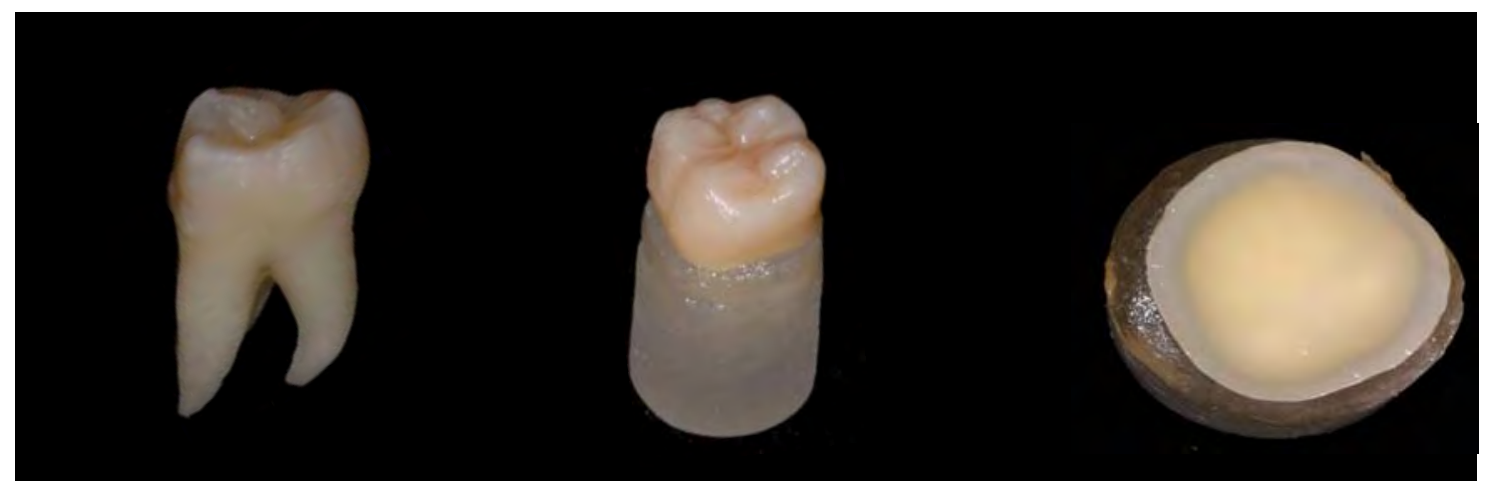

Figura 1 - Inclusão dos dentes em resina acrílica e vista oclusal do conjunto após a exposição da dentina.

\subsection{Preparo dos blocos cerâmicos}

Os blocos cerâmicos Vita In-Ceram YZ - 40/15 (14 mm x $15 \mathrm{~mm} \times 40 \mathrm{~mm}$ ) foram posicionados perpendicularmente ao disco diamantado (Buehler, Illinois, EUA) em uma máquina de corte (Labcut, Extec, EUA) em baixa rotação (200 rpm), sob refrigeração com água, para se obterem blocos de $8 \mathrm{~mm} \times 8 \mathrm{~mm} \times 6 \mathrm{~mm}$. As superfícies dos blocos foram planificadas e polidas em politriz (Labpol 8-12, Extec, EUA) empregando lixa d'água de granulação 1200 (3M, St. Paul, EUA) por 20 s 
em cada face, para se obter uma superfície lisa e uniforme. Após foram submetidos à sinterização em um forno (VITA ZYrcomat - Vita Zanhfabrik, Alemanha) utilizando programa específico da cerâmica, conforme instruções do fabricante.

Considerando que a contração de sinterização da cerâmica é em torno de $20 \%$, os blocos pós-sinterização obtiveram dimensões aproximadas de 6,4 mm x 6,4 mm x 4,8 mm (Figura 2).

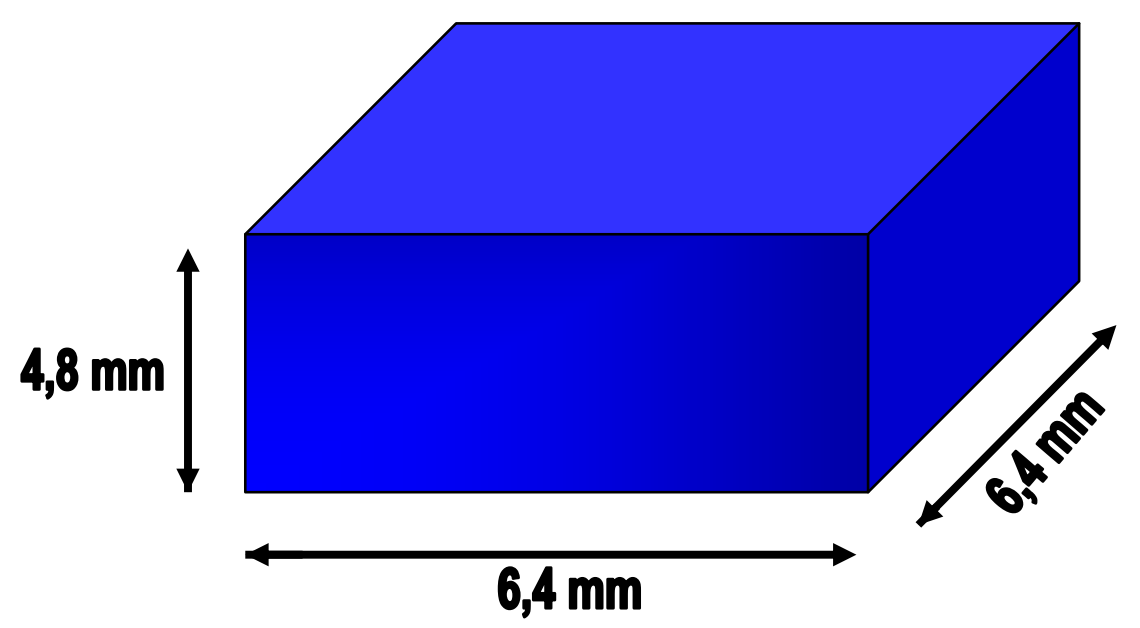

Figura 2 - Representação gráfica das dimensões do bloco cerâmico após sinterização.

\subsection{Tratamento da superfície cerâmica}

Previamente aos processos de jateamento, os blocos cerâmicos foram limpos com álcool isopropílico e após submetidos à limpeza em aparelho sônico (Vitasonic, Vita Zanhfabrik, Alemanha) por 5 min com água destilada. Os blocos foram secos com jato de ar isento de umidade e óleo. Com uma caneta permanente na cor azul, foi realizada 
uma marcação nas superfícies da amostra que não foram jateadas, com o intuito de orientar durante o jateamento e facilitar os procedimentos seguintes.

Os 54 blocos cerâmicos foram divididos em 2 grupos, segundo o tipo de tratamento $(n=27)$ :

Tratamento 1:

Utilizando um microjateador (Cojet Prep, 3M ESPE, St. Paul, EUA), procedeu-se a ativação da superfície com óxido de alumínio $\leq$ $45 \mu \mathrm{m}$ a 10 mm de distância da superfície durante 20 s (24-28 psi).

Tratamento 2:

Com o mesmo microjateador, ativou-se a superfície cerâmica com CoJet $^{\mathrm{TM}}$ Sand a uma distância de $10 \mathrm{~mm}$ da superfície durante 20 s (silicatização) (24-28 psi).

Após, as superfícies foram limpas com jato de ar, isento de umidade e óleo, por 15 s para a remoção dos resíduos do produto jateado.

Para a padronização da distância e do ângulo de incidência das partículas na superfície a ser jateada $\left(90^{\circ}\right)$, utilizou-se um dispositivo metálico, desenvolvido por Amaral et al. (2008), onde o microjateador permaneceu fixo durante a etapa de jateamento e a amostra estava apoiada na base do dispositivo com o auxílio de uma pinça clínica, para manter a distância $(10 \mathrm{~mm})$ até a ponta do microjateador (Figura 3). 


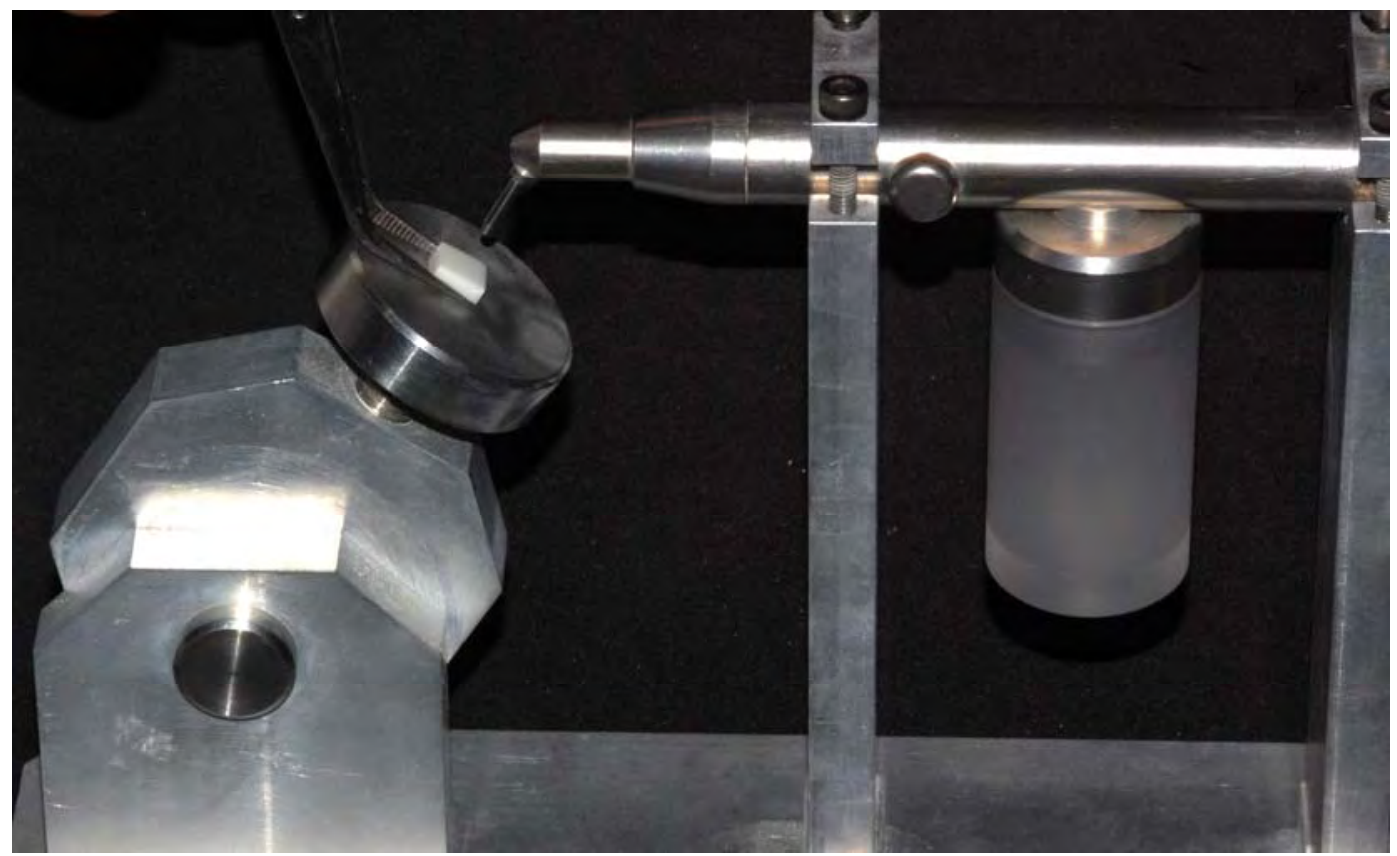

Figura 3 - Microjateador e amostra cerâmica posicionada no dispositivo metálico para padronização dos procedimentos de jateamento.

\subsection{Processos de cimentação}

\subsubsection{RelyX ARC:}

Aplicou-se RelyX ${ }^{\mathrm{TM}}$ ceramic primer para ambos os tratamentos cerâmicos (1 e 2), aguardando 5 s e após secou-se suavemente com jato de ar isento de umidade e óleo, para a total volatilização do solvente.

Ácido fosfórico à 37\% foi aplicado na superfície dentinária por 15 s. Após lavou-se com jato de ar e água por $30 \mathrm{~s}$ e removido o excesso de umidade com papel absorvente.

Duas camadas consecutivas de Single Bond Adhesive foram aplicadas à dentina. Após foi aplicado um suave jato de ar por $5 \mathrm{~s}$, para evitar o excesso de adesivo na superfície preparada. $O$ adesivo foi fotoativado por $10 \mathrm{~s}$. 
Uma medida do cimento (base e catalizador) foi misturada por $10 \mathrm{~s}$ no bloco misturador com espátula adequada (plástica). Uma camada de cimento foi aplicada na superfície de cimentação cerâmica e o bloco cerâmico foi posicionado e pressionado (750 g por $1 \mathrm{~min}$ ) sobre a dentina. O excesso do cimento foi removido com microbrush, imediatamente após o assentamento da cerâmica (Figura 4). Aguardou-se $60 \mathrm{~s}$ e após, as margens da zona de adesão foram fotoativadas por $40 \mathrm{~s}$ em cada face (SmartLite PS/DENTSPLY, Petropolis, Brasil; intensidade: $\left.950 \mathrm{mw} / \mathrm{cm}^{2}\right)$.

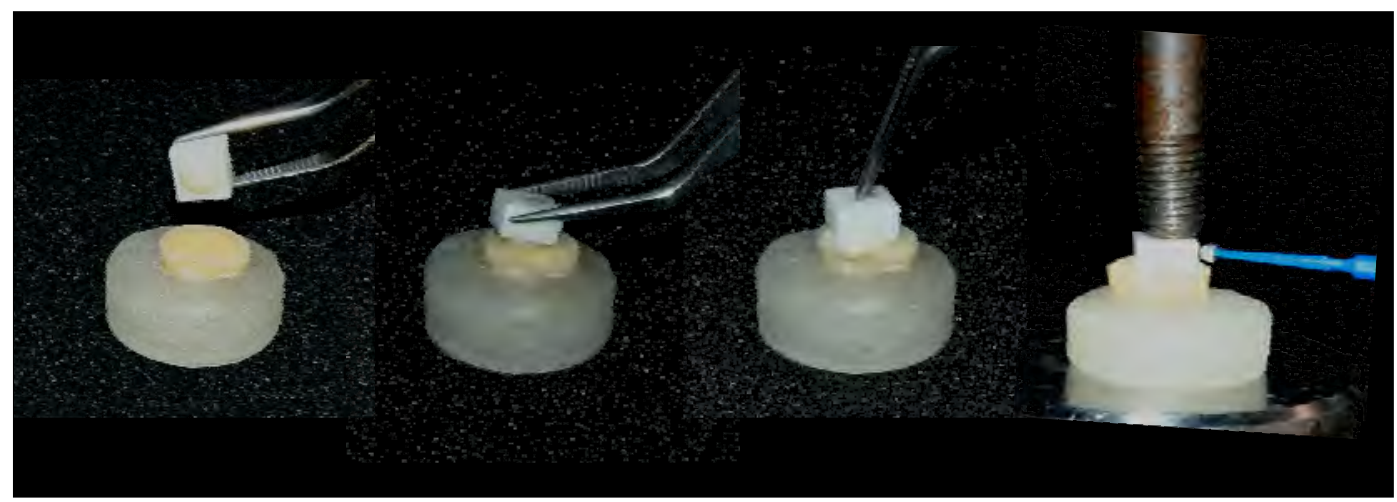

Figura 4 - Cimentação do bloco cerâmico à dentina com aplicação de carga perpendicular $(750 \mathrm{~g})$ e remoção dos excessos.

\subsubsection{RelyX U100:}

Aplicou-se RelyX ${ }^{\mathrm{TM}}$ ceramic primer, para ambos os tratamentos cerâmicos (1 e 2), aguardando 5 s e após secou-se suavemente com jato de ar isento de umidade e óleo, para a total volatilização do solvente.

A superfície dentária foi limpa com pasta de pedra pomes, lavada com jato de ar e água por 30 s e removido o excesso de umidade com papel absorvente.

Uma medida do cimento (base e catalizador) foi misturada por $20 \mathrm{~s}$ no bloco misturador com espátula adequada (plástica). Uma 
camada de cimento foi aplicada na superfície de cimentação cerâmica e o bloco cerâmico foi posicionado e pressionado (750 g por $1 \mathrm{~min}$ ) sobre a dentina. O excesso do cimento foi removido com microbrush, imediatamente após o assentamento da cerâmica. Aguardou-se $60 \mathrm{~s}$ e após, as margens da zona de adesão foram expostas à luz por $40 \mathrm{~s}$ em cada face.

\subsubsection{Panavia F:}

Em um dispositivo plástico, dispensou uma gota de Clearfil Porcelain Bond Activator e uma gota de Clearfil SE Bond Primer, misturando-se com o auxílio de um pincel e aplicando-se sobre a superfície de cimentação cerâmica, da mesma forma para ambos os tratamentos (1 e 2). Aguardou-se 5 min e secou-se suavemente com jato de ar isento de umidade e óleo.

A superfície dentária foi limpa com pasta de pedra pomes por $30 \mathrm{~s}$, lavada com jato de ar e água por $30 \mathrm{~s}$ e removido o excesso de umidade com papel absorvente. Uma gota do Liquido A e uma gota do Liquido $B$ do ED PRIMER II foram misturadas com o auxílio de um pincel e aplicada na superfície dentinária, aguardando-se por 60 s. O excesso de primer foi removido com papel absorvente e após com suave jato de ar isento de óleo e umidade.

Uma mesma quantidade (aproximadamente $10 \mathrm{~mm}$ ) das pastas A e B do cimento resinoso foi espatulada por $20 \mathrm{~s}$. Uma camada de cimento foi aplicada na superfície de cimentação cerâmica e o bloco cerâmico foi posicionado e pressionado (750 g por $1 \mathrm{~min}$ ) sobre a dentina. O excesso do cimento foi removido com microbrush, imediatamente após o assentamento da cerâmica. Aguardou-se 60 s e após, as margens da zona de adesão foram expostas à luz por $40 \mathrm{~s}$ em cada face.

Os 54 conjuntos (dente-cimento-cerâmica) foram divididos em 18 grupos $(n=3)$, considerando o tratamento de superfície (jateamento 
com óxido de alumínio ou Cojet), cimentos resinosos (RelyX U100, RelyX ARC, Panavia F) e envelhecimento (imediato, 60 dias e termociclagem: 10.000 ciclos de $5^{\circ} \mathrm{C}-55^{\circ} \mathrm{C}$ ), apresentados de forma resumida no Quadro 2 (Pág. 61).

\subsection{Obtenção dos corpos-de-prova}

Após a cimentação, os conjuntos dente-cimento-cerâmica foram armazenados em água destilada à $37^{\circ} \mathrm{C}$ por 24 horas. Os conjuntos foram fixados em uma cortadeira de precisão (Isomet 1000, Buehler, EUA) de tal modo que a interface de cimentação ficasse perpendicular ao disco diamantado de corte (Diamond Wafering Blade, Buehler, EUA). Os cortes foram realizados em baixa rotação $(250 \mathrm{rpm})$ e sob refrigeração constante de água, para se obter cortes homogêneos nos eixos $\mathrm{X}$ e $\mathrm{Y}$. A primeira secção, mais externa e de aproximadamente $1 \mathrm{~mm}$, foi descartada, devido à possibilidade de haver excesso ou ausência de cimento ou irregularidades na interface, que poderiam influenciar nos resultados (Della Bona et al., 2000; Della Bona, 2009).

Primeiramente foi cortada somente a zircônia no eixo $X$, até chegar próximo da interface de cimentação, deixando pelo menos 0,5 $\mathrm{mm}$ de zircônia sem cortar. Os cortes na zircônia foram realizados espaçando 1,4 mm entre um corte e outro, visto que o disco de diamante tem uma espessura de $0,3 \mathrm{~mm}$. A posição do primeiro corte realizado foi marcada, para que num segundo momento voltasse exatamente naquela região para terminar o corte.

Após a realização dos cortes parciais no eixo $X$, a amostra foi girada em $90^{\circ}$ e foram realizados os cortes no eixo $Y$ (somente em zircônia). Sendo que o último corte foi realizado até o fim, ou seja, até penetrar $\pm 5 \mathrm{~mm}$ na dentina. Depois deste corte, retornou-se 
cortando no mesmo eixo, repetindo os exatos locais de corte até a dentina. Completados os cortes até a dentina no eixo $\mathrm{Y}$, girou-se novamente o dispositivo de corte em $90^{\circ}$ e ajustou-se a máquina de corte na posição exata do primeiro corte do eixo X. Procederam-se os cortes até dentina no eixo $X$, sendo estes realizados com velocidade de $200 \mathrm{rpm}$ (Figura 5).

Com os eixos $\mathrm{X}$ e $\mathrm{Y}$ cortados, procedeu-se o corte da base, ou seja, o corte da dentina para soltar os corpos-de-prova em forma de barra (200 rpm). 

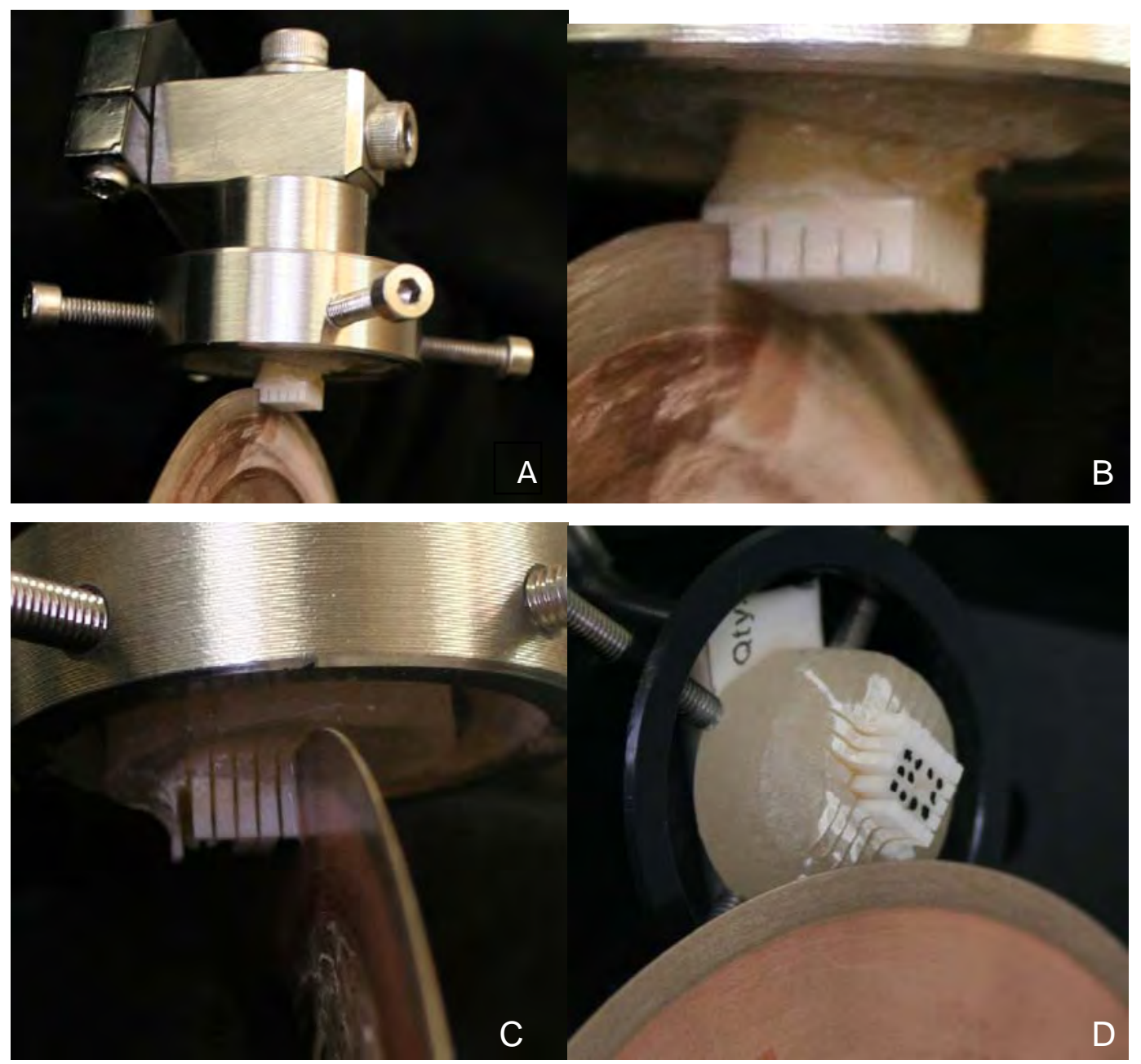

Figura 5 - Imagens representativas do corte dos conjuntos cerâmica-cimento-dente para obtenção dos corpos-de-prova em forma de barra. A e B-corte somente da zircônia nos eixos X e Y. C- Finalização dos cortes. D- corte final da base dos corpos-de-prova soltando os mesmos da dentina.

Características dos corpos-de-prova (cp):

1. barras em forma retangular com a interface não-usinada (nontrimmed);

2. interface adesiva mais quadrangular possível $( \pm 1 \mathrm{~mm} \times \pm 1 \mathrm{~mm})$ com área de, aproximadamente, $1 \mathrm{~mm}^{2}$;

3. comprimento médio de $8 \mathrm{~mm}$, e mínimo de $6 \mathrm{~mm}$ (Della Bona et al., 2000; Amaral et al., 2006). 


\subsection{Ciclagem térmica e armazenagem}

Os cp foram submetidos às condições de armazenagem e termociclagem da seguinte forma:

a. Sem armazenagem e termociclagem (imediato)

- Cp foram submetidos ao teste de microtração imediatamente após os cortes;

b. Com 60 dias de armazenagem - Cp foram armazenados em água destilada à $37^{\circ} \mathrm{C}$ (Estufa de Cultura 502, Fanen, São Paulo, Brasil) até completar 60 dias da data de cimentação (Figura $6)$;

c. Termociclagem (10.000 ciclos) - Cp sofreram ciclagem térmica com os seguintes parâmetros: número de ciclos: 10.000; temperaturas: $5^{\circ} \mathrm{C}-$ $55^{\circ} \mathrm{C}$ com $30 \mathrm{~s}$ em cada banho e $2 \mathrm{~s}$ de transição entre os banhos (Figura 7).

Três conjuntos (dente-cimento-cerâmica) foram designados para cada condição e de onde foram obtidos aproximadamente $9 \mathrm{cp}$, por conjunto, totalizando para cada grupo experimental 27 repetições (cp). Portanto, foram constituídos 18 grupos, considerando os fatores "cimento resinoso" (em 3 níveis), preparo da superfície cerâmica (em 2 níveis) e "armazenagem e termociclagem" em (3 níveis) (Quadro 2).

A água destilada, dos seis grupos armazenados por 60 dias, foi trocada a cada $72 \mathrm{~h}$, para evitar a proliferação de microorganismos. 


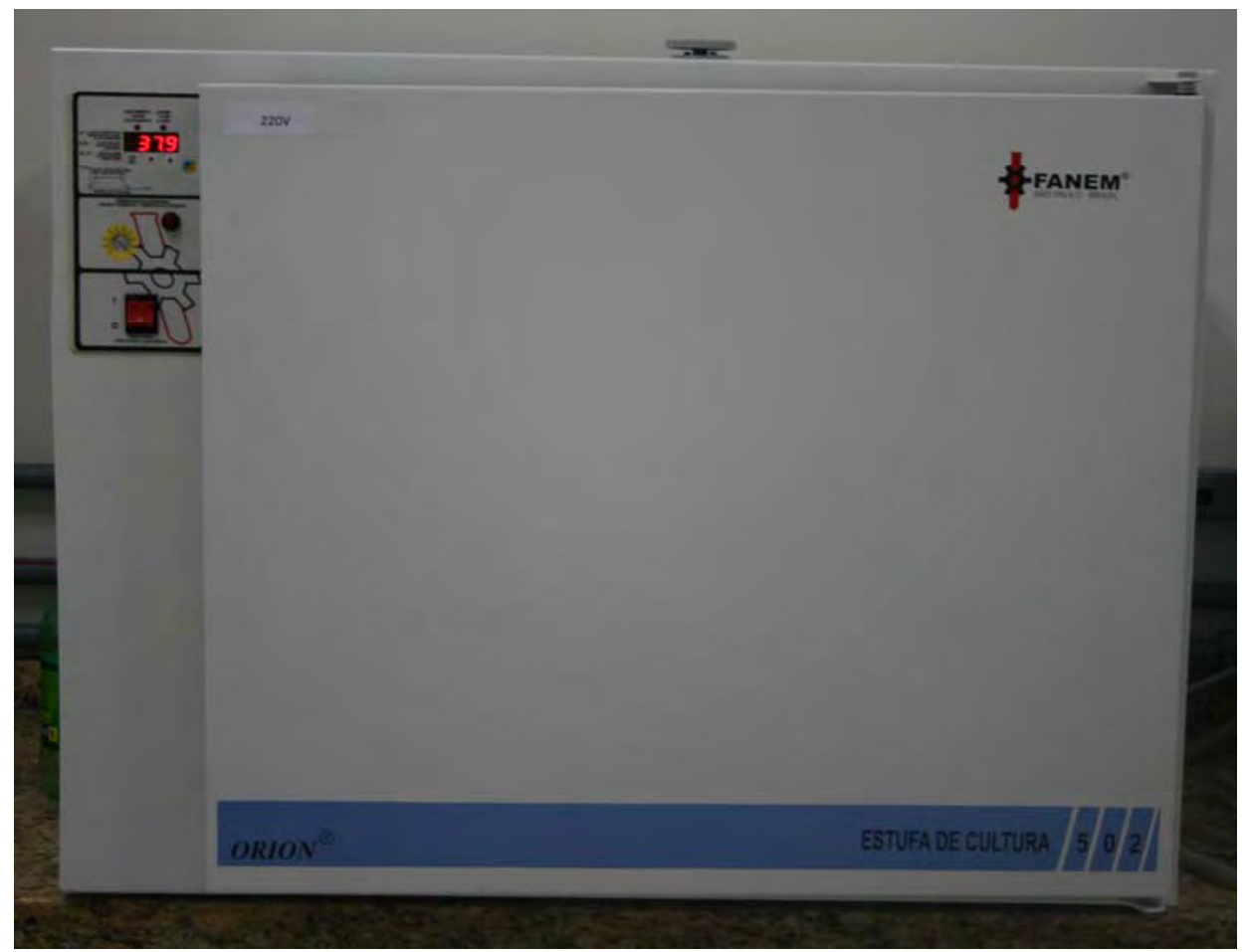

Figura 6 - Estufa bacteriológica onde os corpos-de-prova ficaram armazenados em água à uma temperatura média de $37^{\circ} \mathrm{C}$.

Os dois compartimentos da termocicladora (Banho para teste cíclico; Série 521-4D, Nova Ética Ind., Com. e Serviços Ltda, Vargem Grande Paulista, SP) foram abastecidos com água destilada, deixando aproximadamente $5 \mathrm{~cm}$ de margem de segurança entre a água e a borda, antes de iniciar os procedimentos de termociclagem (Figura 7). 

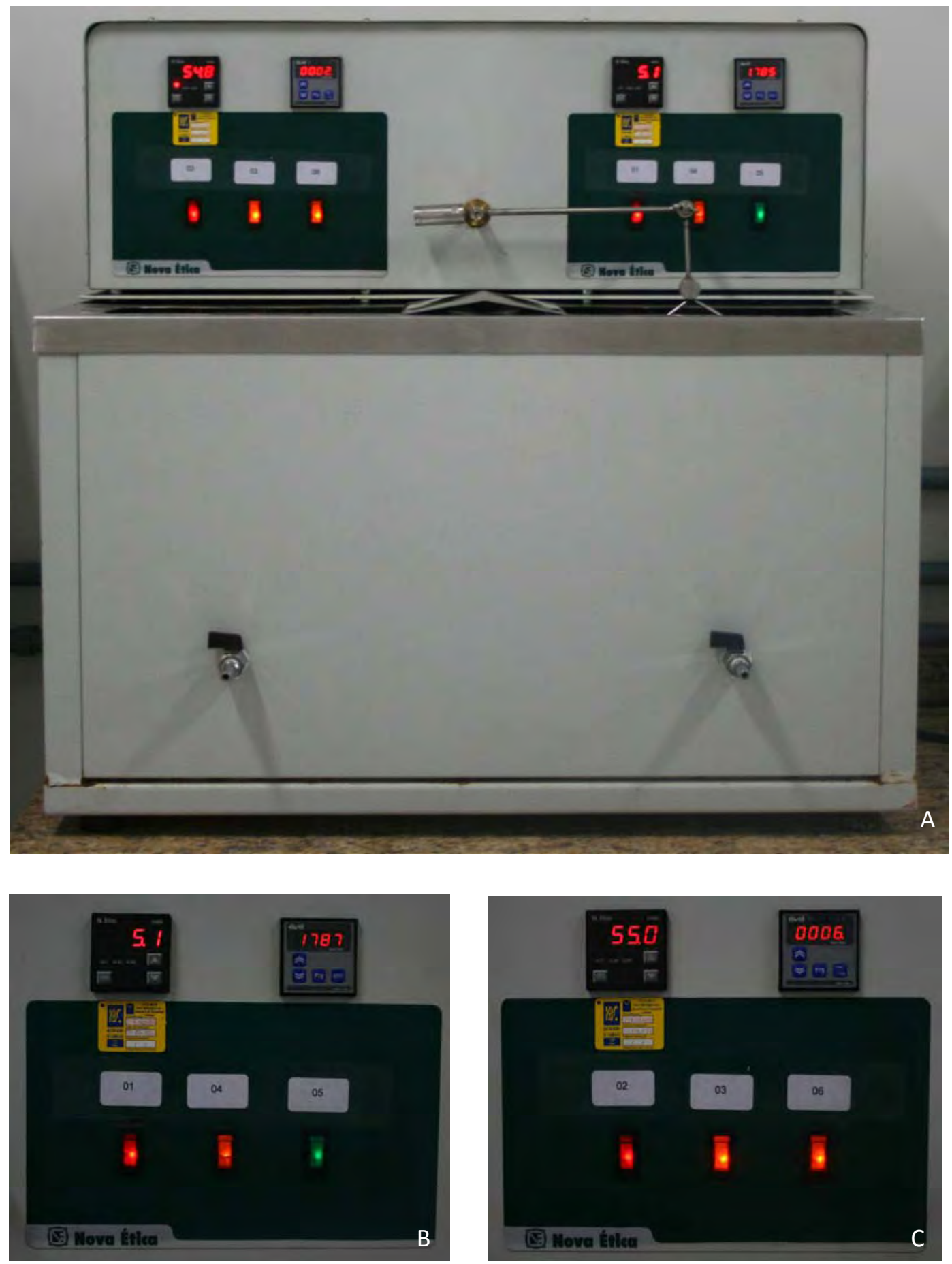

Figura 7 - A: Equipamento para termociclagem. B e C: controladores de temperatura, número de ciclos e tempo de banho. Liga-se, primeiramente, os botões $1 \mathrm{a}$ 5 e aguarda-se que a máquina alcance as temperaturas desejadas para ligar o botão 6 . 
Quadro 2 - Grupos experimentais conforme os fatores do estudo.

\begin{tabular}{|c|c|c|c|}
\hline $\begin{array}{l}\text { Cimento } \\
\text { resinoso }\end{array}$ & $\begin{array}{l}\text { Tipo de Tratamento } \\
\text { da superfície } \\
\text { cerâmica }\end{array}$ & $\begin{array}{c}\text { Condição de } \\
\text { envelhecimento }\end{array}$ & Grupos \\
\hline \multirow{6}{*}{ RelyX U100 } & \multirow{3}{*}{ Jateamento + silano* } & Imediato & Gr 1 \\
\hline & & Armazenagem & Gr 7 \\
\hline & & Termociclagem & Gr 13 \\
\hline & \multirow{3}{*}{ Silicatização + silano* } & Imediato & Gr 2 \\
\hline & & Armazenagem & Gr 8 \\
\hline & & Termociclagem & Gr 14 \\
\hline \multirow{6}{*}{ RelyX ARC } & \multirow{3}{*}{ Jateamento + silano* } & Imediato & Gr 3 \\
\hline & & Armazenagem & Gr 9 \\
\hline & & Termociclagem & Gr 15 \\
\hline & \multirow{3}{*}{ Silicatização + silano* } & Imediato & Gr 4 \\
\hline & & Armazenagem & Gr 9 \\
\hline & & Termociclagem & Gr 16 \\
\hline \multirow{6}{*}{ Panavia F } & \multirow{3}{*}{ Jateamento +silano** } & Imediato & Gr 5 \\
\hline & & Armazenagem & Gr 10 \\
\hline & & Termociclagem & Gr 17 \\
\hline & \multirow{3}{*}{ Silicatização + silano** } & Imediato & Gr 6 \\
\hline & & Armazenagem & Gr 11 \\
\hline & & Termociclagem & Gr 18 \\
\hline
\end{tabular}

${ }^{*}$ RelyX ${ }^{\mathrm{TM}}$ ceramic primer

** Clearfil Porcelain Bond Activator + Clearfil SE Bond Primer 


\subsection{Ensaio de microtração}

A área de todos os cp foi mensurada antes da execução do ensaio, com o auxílio de um paquímetro digital (Starret Indústria e Comércio Ltda, Itu, SP, Brasil) com precisão de centésimo de milímetro. A mesma área foi conferida após a fratura, no caso da fratura não ocorrer no mesmo local mensurado inicialmente.

Em seguida, cada cp foi fixado com adesivo cianoacrilato gel nas hastes de um dispositivo para ensaio de microtração (OD03d Odeme Equipamentos Médico e Odontológicos Ltda, Joaçaba/SC, Brasil) (Figura 8). Os cp foram posicionados seguindo o longo eixo do dispositivo, a fim de minimizar as forças de torção na zona adesiva, sempre com a cerâmica unida a garra superior do dispositivo. Somente as extremidades do $\mathrm{cp}$ foram fixadas, permanecendo livre a zona adesiva (tomando muito cuidado para não escorrer cola próximo da interface, se isto ocorresse o cp era excluído). O dispositivo estava fixado numa máquina de ensaio universal (EMIC DL-1000, São José dos Pinhais, Brasil), com uma célula de carga de $10 \mathrm{kgf}$ e velocidade de $1 \mathrm{~mm} / \mathrm{min}$ até que ocorresse 0 rompimento da união (Della Bona et al., 2000; Amaral et al., 2006). 


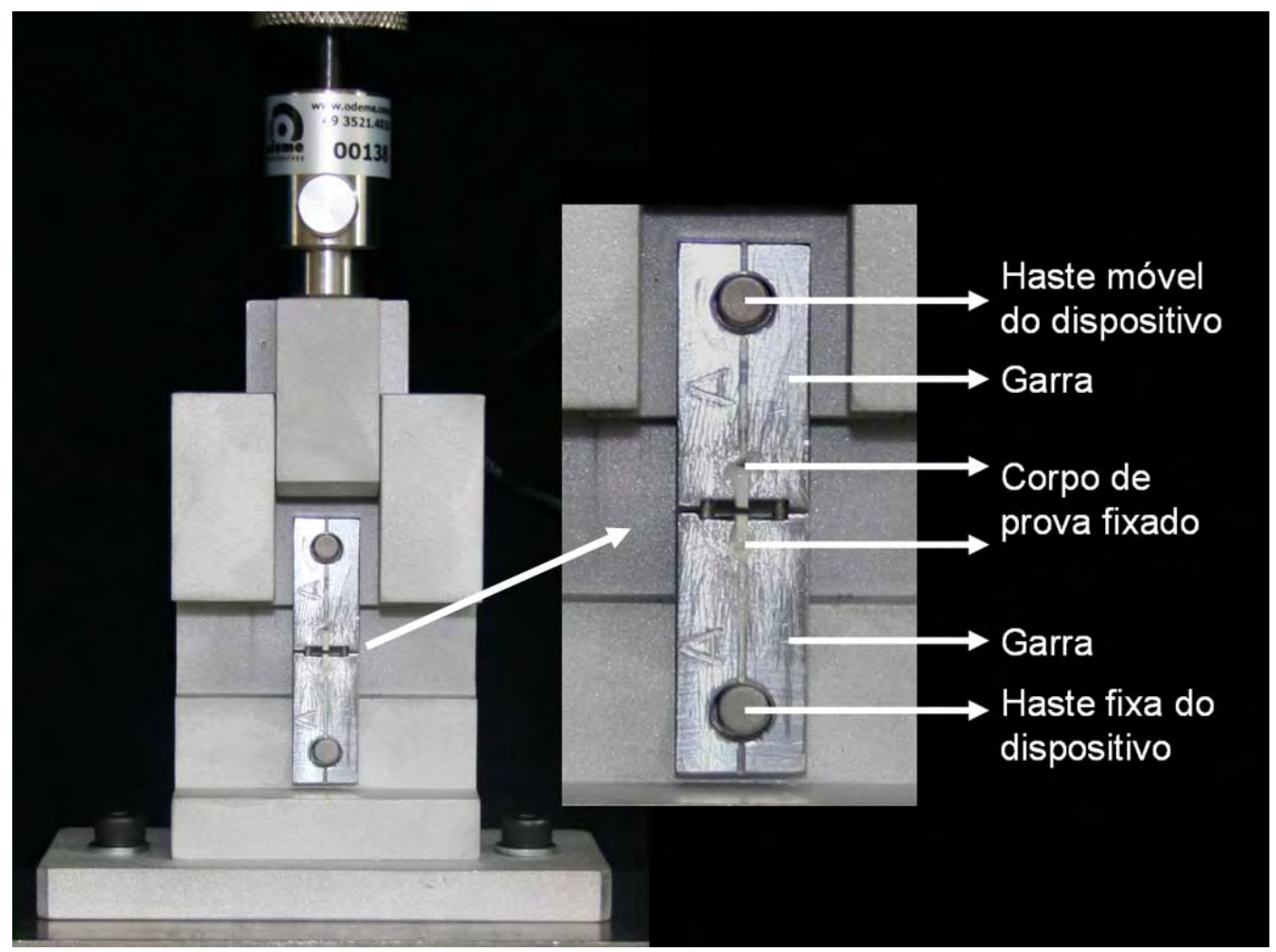

Figura 8 - Dispositivo para ensaio de microtração (OD03d - Odeme Equipamentos Médico e Odontológicos Ltda, Joaçaba/SC, Brasil). Corpo de prova fixado nas garras do dispositivo após a realização do teste (cp fraturado).

A resistência de união foi calculada usando $R=F / A$, onde " $R$ " é a resistência, " $F$ " é a carga de fratura (em N) do cp e "A" a área da zona de adesão do cp (em $\left.\mathrm{mm}^{2}\right)$.

\subsection{Avaliação do modo de falha}

Todos os cp ensaiados foram examinados sob microscopia óptica (Measuring Microscope MF, Mitutoyo, Japão), conectado a câmera digital (Quick Scope, Mitutoyo, Japão) e programa de computador (QSPAK VUE V.1.0). Foi usado aumentos de 30x a 200x para determinação do padrão de falha nas interfaces cerâmica-cimento-dente. 
Algumas amostras de cada grupo experimental foram selecionadas e analisadas em microscópio eletrônico de varredura (Jeol-JSM-5310, Jeol, Japão) com aumentos de 75x a 5.000x, aceleração de 20 kV, distância média de trabalho de $8 \mathrm{~mm}$ e largura do feixe de elétrons de $11 \mathrm{~mm}$ (Figura 9). Para isso, as superfícies de fratura foram fixadas sobre uma base de alumínio (stub) usando uma fita adesiva dupla-face e metalizadas com ouro-paládio em equipamento específico (Polaron SC 7620 Sputter Coater, Quorum Technologies, Newhaven, UK) usando os seguintes parâmetros: tempo: $130 \mathrm{~s}$, corrente de 10-15 mA, vácuo de 130 mTorr, taxa de metalização: $3,5 \mathrm{~nm} / \mathrm{min}$, resultando em uma camada de $\mathrm{Pd}-\mathrm{Au}$ de, aproximadamente, $80 \AA$.

As falhas foram classificadas (Della Bona et al., 2003): 1) adesiva (ADES-CC): falhas adesivas na interface entre cimento e cerâmica; 2) adesiva (ADES-cd): falha adesiva na interface entre cimento e dentina; 3) fratura coesiva do cimento (COES-cim); 4) fratura coesiva na cerâmica (COES-cer); e 5) fratura coesiva na dentina (COES-den).

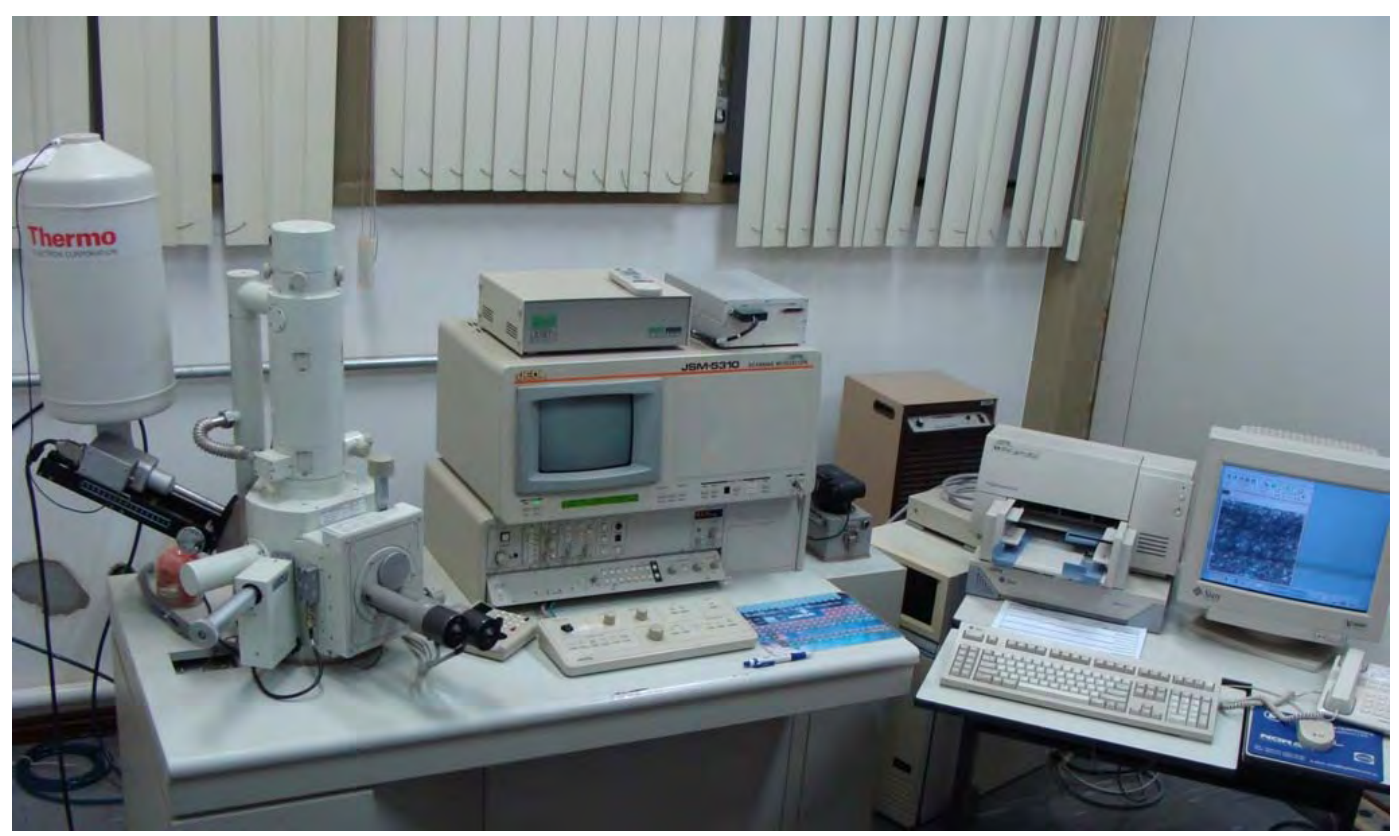

Figura 9 - Vista frontal do microscópio eletrônico de varredura (Jeol-JSM-5310, Jeol, Japão). 


\subsection{Análise estatística}

Os fatores do estudo foram: tratamento da superfície cerâmica (2 níveis), cimentos resinosos (3 níveis) e condição de armazenagem (3 níveis), obtendo-se 18 grupos experimentais. Os dados foram submetidos à análise estatística. Para tanto, foi utilizado o Programa Statistix 8.0 for Windows (Analytical Software Inc, Tallahassee, EUA) e Minitab 15.1.1.0 (Minitab Inc, EUA). 


\section{RESULTADOS}

Para obtenção das médias de resistência à tração dos grupos experimentais, foi realizada a média aritmética dos valores obtidos em cada grupo.

As médias e desvio padrão (DP) para cada grupo avaliado estão apresentados na tabela 1.

Tabela 1 - Valores da média e desvio padrão de resistência à tração (MPa) de todos os grupos experimentais desse estudo

(continua)

\begin{tabular}{cccc}
\hline $\begin{array}{c}\text { Cimento } \\
\text { resinoso }\end{array}$ & $\begin{array}{c}\text { Tratamento da } \\
\text { superfície cerâmica }\end{array}$ & $\begin{array}{c}\text { Condição de } \\
\text { envelhecimento }\end{array}$ & $\begin{array}{c}\text { Média } \pm \text { DP } \\
\text { (MPa) }\end{array}$ \\
\hline & Jateamento + silano* & Armazenagem & $5,83 \pm 2,76$ \\
& & Termociclagem & $1,86 \pm 0,56$ \\
RelyX ARC & & Imediato & $13,93 \pm 6,00$ \\
& Silicatização + silano* & Armazenagem & $10,43 \pm 5,35$ \\
& & Termociclagem & $12,96 \pm 4,77$
\end{tabular}


Tabela 1 - Valores da média e desvio padrão de resistência à tração (MPa) de todos os grupos experimentais desse estudo.

(continuação)

\begin{tabular}{cccc}
\hline $\begin{array}{c}\text { Cimento } \\
\text { resinoso }\end{array}$ & $\begin{array}{c}\text { Tratamento da } \\
\text { superfície cerâmica }\end{array}$ & $\begin{array}{c}\text { Condição de } \\
\text { envelhecimento }\end{array}$ & $\begin{array}{c}\text { Média } \pm \text { DP } \\
\text { (MPa) }\end{array}$ \\
\hline & Jateamento + silano* & Armazenagem & $7,09 \pm 3,91$ \\
& & Termociclagem & $9,87 \pm 3,64$
\end{tabular}

RelyX U100

$$
\text { Imediato } \quad 6,03 \pm 3,04
$$

Silicatização + silano*

Armazenagem

$10,38 \pm 5,49$

Termociclagem

$7,24 \pm 4,35$

Imediato

$13,04 \pm 3.98$

Jateamento +silano**

Armazenagem

$6,89 \pm 3,31$

Termociclagem

$14,78 \pm 6,57$

\section{Panavia F}

Imediato

$9,72 \pm 4,73$

Silicatização + silano**
Armazenagem

$10,25 \pm 3,36$

Termociclagem 
Os dados de resistência adesiva dos grupos estão graficamente representados na Figura 10.

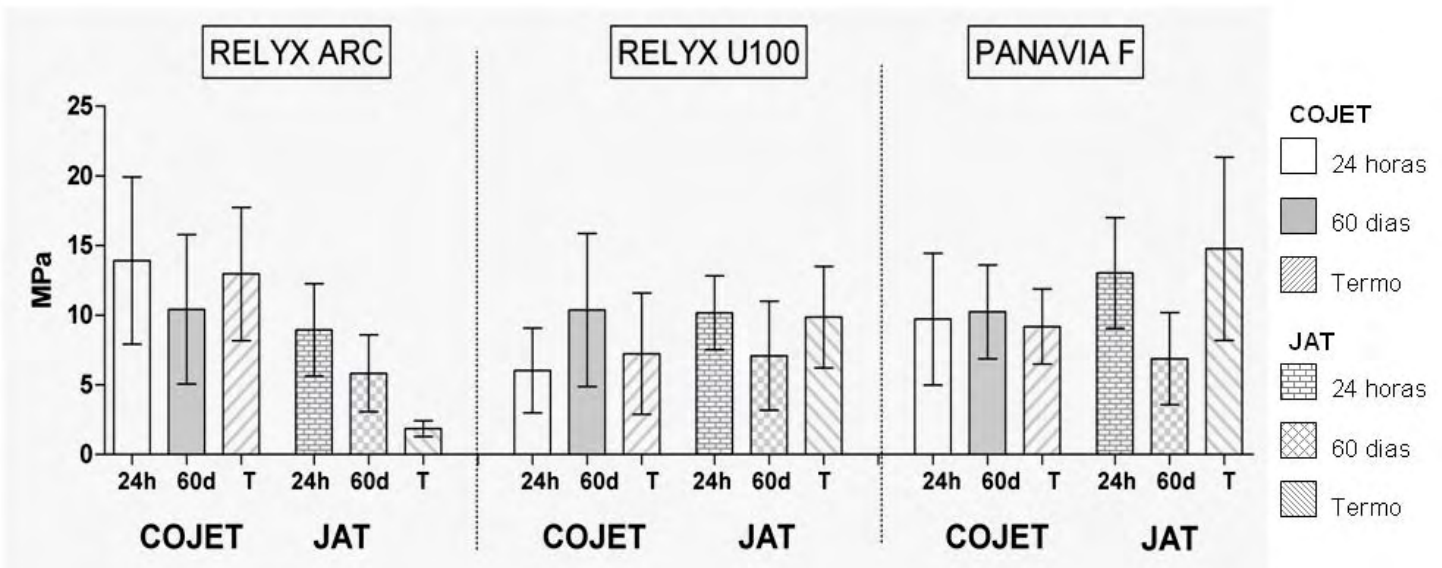

Figura 10 - Gráfico de colunas (média \pm desvio padrão) dos dados de resistência adesiva (MPa) para as 18 condições experimentais.

Para avaliar estatisticamente o relacionamento entre os grupos experimentais, os resultados foram submetidos ao modelo estatístico ANOVA 3-fatores, representada na tabela 2.

Tabela 2 - ANOVA 3-fatores dos resultados de resistência adesiva

\begin{tabular}{lccccc}
\hline \multicolumn{1}{c}{ Fatores } & DF & SS & MS & F & P* \\
\hline Cimento (C) & 2 & 284,50 & 142,252 & 8,19 & 0,0003 \\
Tratamento de & 1 & 143,04 & 143,042 & 8,24 & 0,0043 \\
Superfície (TS) & & & & & \\
Envelhecimento (E) & 2 & 196,61 & 98,303 & 5,66 & 0,0038 \\
C*TS & 2 & 1376,92 & 688,460 & 39,64 & 0,00001 \\
C*E & 4 & 425,76 & 106,441 & 6,13 & 0,0001 \\
TS*E & 2 & 319,29 & 159,647 & 9,19 & 0,0001 \\
C*TS*E $^{*}$ Resíduo & 4 & 638,99 & 159,749 & 9,20 & 0,00001 \\
Total & 363 & 6303,77 & 17,366 & & \\
\hline${ }^{*} \mathrm{p}<0,05$ & 380 & & & & \\
\hline
\end{tabular}


Através da tabela ANOVA 3-fatores é possível perceber que os fatores "cimento resinoso", "tratamento de superfície" e "envelhecimento" foram estatisticamente significantes. A interação desses fatores também foi significante.

Para melhor entendimento dos resultados, os testes comparativos foram divididos conforme o fator "envelhecimento" (tabelas 3, 4 e 5) e segundo o fator "cimento resinoso" (tabelas 6, 7 e 8). Para isto, foram realizados testes de comparação múltipla de Tukey $(\alpha=0,05)$.

Tabela 3 - Média dos valores de resistência adesiva (MPa) das condições experimentais estabelecidas pelas variáveis "cimento resinoso" e "tratamento de superfície", no fator de envelhecimento "24 horas", além dos grupamentos estatísticos

\section{4 horas}

\begin{tabular}{lccc}
\hline Cimento Resinoso & $\begin{array}{c}\text { Tratamento de } \\
\text { Superfície }\end{array}$ & Média (MPa) & $\begin{array}{c}\text { Grupos } \\
\text { Homogêneos }\end{array}$ \\
\hline Rely X ARC & Silicatização & 13,93 & $\mathrm{~A}$ \\
Panavia F & Jateamento & 13,04 & $\mathrm{AB}$ \\
RelyX U100 & Jateamento & 10,18 & $\mathrm{BC}$ \\
Panavia F & Silicatização & 9,72 & $\mathrm{BC}$ \\
RelyX ARC & Jateamento & 8,94 & $\mathrm{C}$ \\
RelyX U100 & Silicatização & 6,03 & $\mathrm{C}$ \\
\hline *letras iguais indicam & semelhança estatística; letras diferentes indicam diferença \\
significante. & & &
\end{tabular}


Tabela 4 - Média dos valores de resistência adesiva (MPa) das condições experimentais estabelecidas pelas variáveis "cimento resinoso" e "tratamento de superfície", no fator de envelhecimento "termociclagem", além dos grupamentos estatísticos

\begin{tabular}{lccc}
\hline \multicolumn{4}{c}{ Termociclagem (10.000) } \\
\hline Cimento Resinoso & $\begin{array}{c}\text { Tratamento de } \\
\text { Superfície }\end{array}$ & Média (MPa) & $\begin{array}{c}\text { Grupos } \\
\text { Homogêneos }\end{array}$ \\
\hline Panavia F & Jateamento & 14,78 & A \\
RelyX ARC & Silicatização & 12,96 & AB \\
RelyX U100 & Jateamento & 9,87 & BC \\
Panavia F & Silicatização & 9,19 & BC \\
RelyX U100 & Silicatização & 7,24 & C \\
RelyX ARC & Jateamento & 1,86 & D \\
\hline *letras iguais indicam & semelhança estatística; letras diferentes indicam diferença \\
significante. & & &
\end{tabular}

Tabela 5 - Média dos valores de resistência adesiva (MPa) das condições experimentais estabelecidas pelas variáveis "cimento resinoso" e "tratamento de superfície", no fator de envelhecimento "60 dias", além dos grupamentos estatísticos

60 dias

\begin{tabular}{lccc}
\hline Cimento Resinoso & $\begin{array}{c}\text { Tratamento de } \\
\text { Superfície }\end{array}$ & Média (MPa) & $\begin{array}{c}\text { Grupos } \\
\text { Homogêneos }\end{array}$ \\
\hline RelyX ARC & Silicatização & 10,42 & $\mathrm{~A}$ \\
RelyX U100 & Silicatização & 10,38 & $\mathrm{~A}$ \\
Panavia F & Silicatização & 10,25 & $\mathrm{~A}$ \\
RelyX U100 & Jateamento & 7,09 & $\mathrm{AB}$ \\
Panavia F & Jateamento & 6,89 & $\mathrm{AB}$ \\
RelyX ARC & Jateamento & 5,83 & $\mathrm{~B}$ \\
\hline *letras iguais indicam & semelhança estatística; letras diferentes indicam diferença \\
significante. & & &
\end{tabular}


Os cimentos resinosos, com relação ao envelhecimento, são visualizados graficamente na figura 11. Na condição 60 dias de armazenagem, os cimentos se comportaram de forma semelhante segundo o tratamento de superfície, sendo que a silicatização demonstrou valores maiores de $\sigma$.

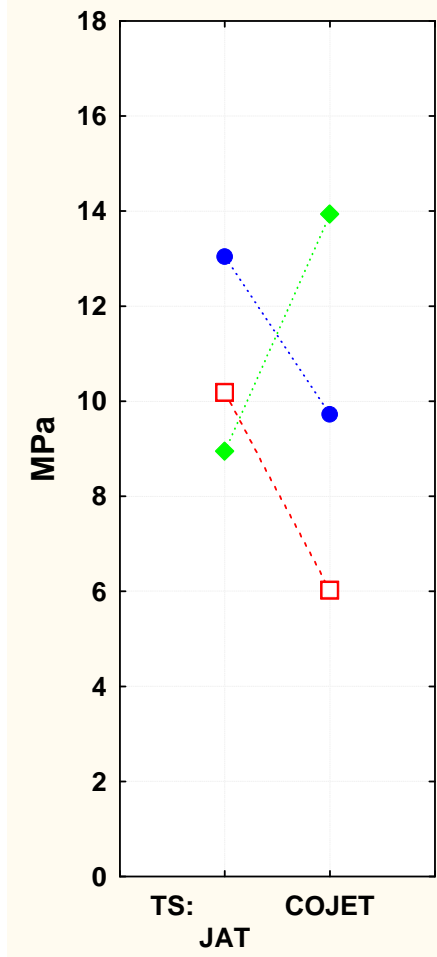

A: $24 h$

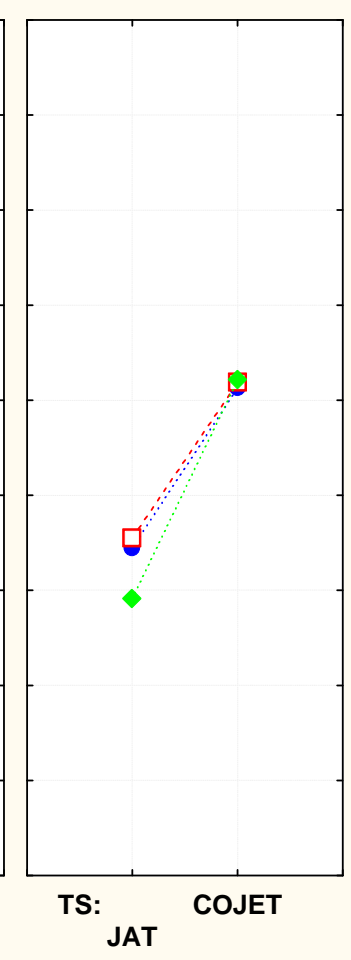

A: 60d

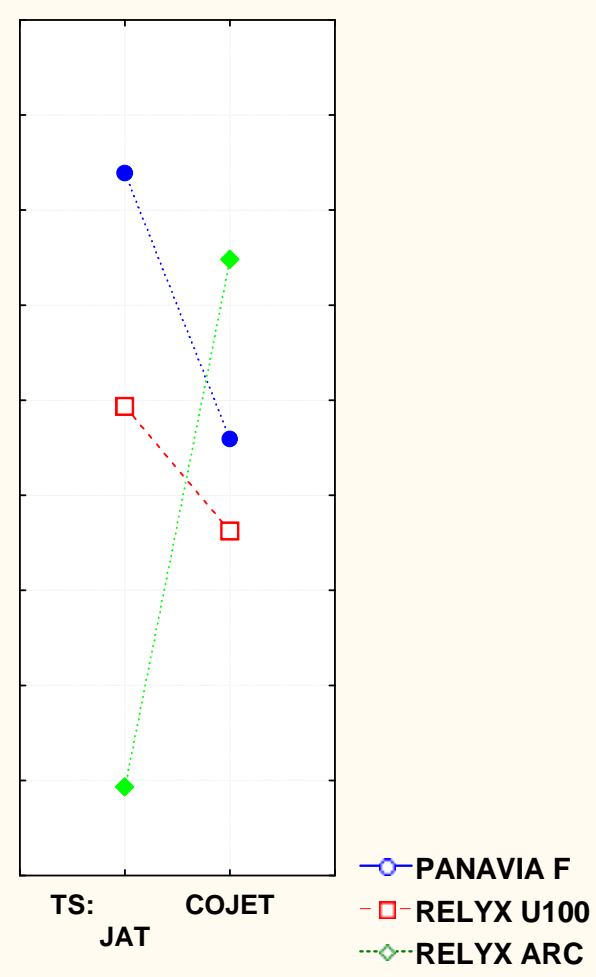

A: TERMO

Figura 11 - Efeito do cimento resinoso. Gráfico de médias segundo as condições experimentais.

O tipo de tratamento de superfície cerâmico pode ser visualizado graficamente de acordo com o tipo de envelhecimento na figura 12, sendo que a silicatização (Cojet) demostrou maiores valores de $\sigma$ após o envelhecimento de 60 dias, independente do cimento resinoso. 

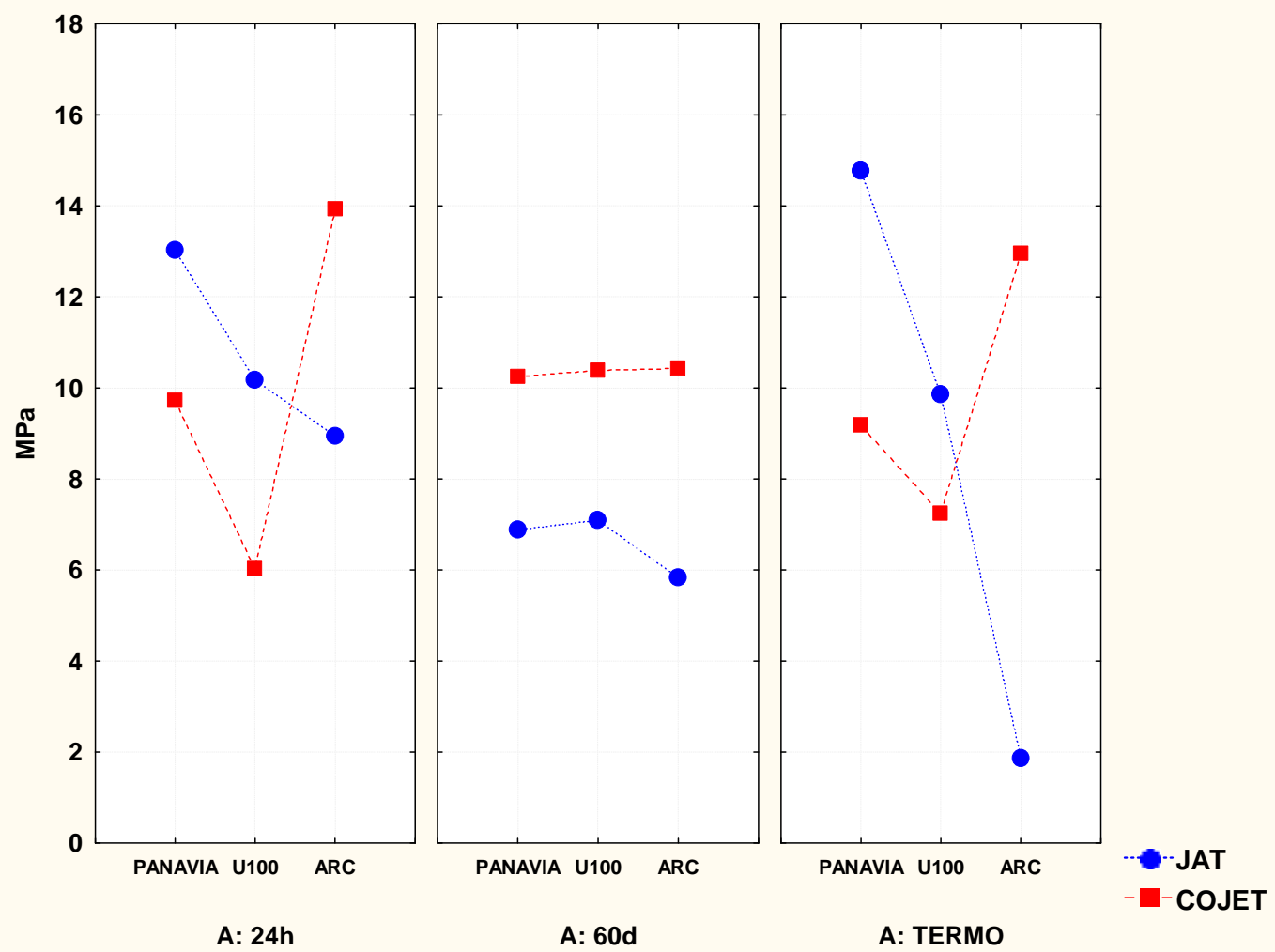

Figura 12 - Efeito do tratamento de superficie. Gráfico de médias segundo as condições experimentais.

Para a condição "cimento resinoso" foram realizados testes comparativos também, para verificar se os cimentos resinosos sofreram com as condições de envelhecimento e tratamento de superfície. Para isto, foram realizados testes de comparação múltipla de Tukey (tabelas 6, 7 e 8). 
Tabela 6 - Média dos valores de resistência adesiva (MPa) das condições experimentais estabelecidas pelas variáveis "envelhecimento" e "tratamento de superfície", no fator de cimento resinoso "RelyX ARC", além dos grupamentos estatísticos

\begin{tabular}{cccc}
\hline \multicolumn{4}{c}{ RelyX ARC } \\
$\begin{array}{c}\text { Tratamento de } \\
\text { Superfície }\end{array}$ & Envelhecimento & Média (MPa) & $\begin{array}{c}\text { Grupos } \\
\text { Homogêneos }\end{array}$ \\
\hline Silicatização & $24 \mathrm{~h}$ & 13,93 & $\mathrm{~A}$ \\
Silicatização & Termociclagem & 12,96 & $\mathrm{~A}$ \\
Silicatização & 60 dias & 10,43 & $\mathrm{AB}$ \\
Jateamento & $24 \mathrm{~h}$ & 8,94 & $\mathrm{BC}$ \\
Jateamento & 60 dias & 5,83 & $\mathrm{CD}$ \\
Jateamento & Termociclagem & 1,86 & $\mathrm{D}$ \\
\hline *letras iguais indicam & semelhança estatística; letras diferentes indicam diferença \\
significante. & & &
\end{tabular}

Tabela 7- Média dos resultados de resistência adesiva (MPa) das condições experimentais estabelecidas pelas variáveis "envelhecimento" e "tratamento de superfície", no fator de cimento resinoso "RelyX U100", além dos grupamentos estatísticos

RelyX U100

\begin{tabular}{cccc}
\hline $\begin{array}{c}\text { Tratamento de } \\
\text { Superfície }\end{array}$ & Envelhecimento & Média (MPa) & $\begin{array}{c}\text { Grupos } \\
\text { Homogêneos }\end{array}$ \\
\hline Silicatização & 60 dias & 10,38 & $\mathrm{~A}$ \\
Jateamento & $24 \mathrm{~h}$ & 10,18 & $\mathrm{AB}$ \\
Jateamento & Termociclagem & 9,87 & $\mathrm{AB}$ \\
Silicatização & Termociclagem & 7,24 & $\mathrm{AB}$ \\
Jateamento & 60 dias & 7,09 & $\mathrm{AB}$ \\
Silicatização & $24 \mathrm{~h}$ & 6,03 & $\mathrm{~B}$ \\
\hline *letras iguais indicam & semelhança estatística; letras diferentes indicam diferença \\
significante. & & &
\end{tabular}


Tabela 8 - Média dos valores de resistência adesiva (MPa) das condições experimentais estabelecidas pelas variáveis "envelhecimento" e "tratamento de superfície", no fator de cimento resinoso "Panavia F", além dos grupamentos estatísticos

\begin{tabular}{cccc}
\hline \multicolumn{4}{c}{ Panavia F } \\
\hline $\begin{array}{c}\text { Tratamento de } \\
\text { Superfície }\end{array}$ & Envelhecimento & Média (MPa) & $\begin{array}{c}\text { Grupos } \\
\text { Homogêneos }\end{array}$ \\
\hline Jateamento & Termociclagem & 14,78 & $\mathrm{~A}$ \\
Jateamento & $24 \mathrm{~h}$ & 13,04 & $\mathrm{AB}$ \\
Silicatização & 60 dias & 10,25 & $\mathrm{~B}$ \\
Silicatização & $24 \mathrm{~h}$ & 9,72 & $\mathrm{BC}$ \\
Silicatização & Termociclagem & 9,19 & $\mathrm{BC}$ \\
Jateamento & 60 dias & 6,89 & $\mathrm{C}$ \\
\hline *letras iguais indicam & semelhança estatística; letras diferentes & indicam diferença \\
significante. & & &
\end{tabular}

Os valores médios dos grupos silicatizados foram maiores do que os jateados após 60 dias em água (Figura 12),

Considerando cada uma das condições de envelhecimento, o cimento resinoso RelyX ARC mostrou valores médios de resistência adesiva significativamente maiores quando a silicatização foi utilizada (Tabela 6).

O jateamento e termociclagem mostrou o maior valor de resistência adesiva quando o cimento Panavia $F$ foi utilizado. Os grupos silicatizados não apresentaram qualquer diferença significativa quando esse cimento foi usado (Tabela 8).

A análise das superfícies fraturadas está disposta na tabela 9. As falhas foram classificadas como descrito anteriormente. 


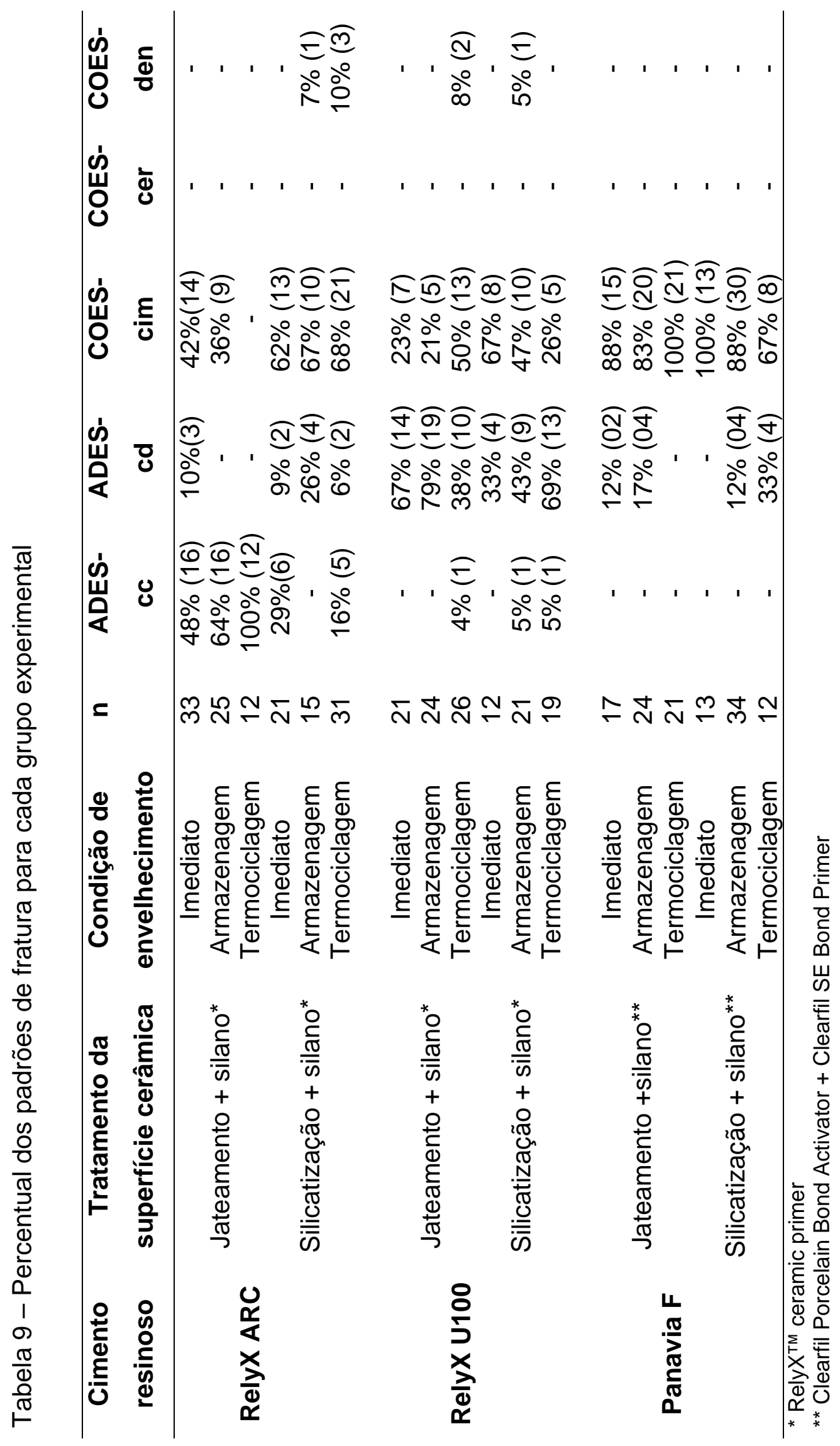


Uma quantidade representativa de $\mathrm{cp}$ de cada grupo experimental foi selecionada e analisada em microscópio eletrônico de varredura com aumentos de $75 \mathrm{x}$ a 5.000x. Fotomicrografias representativas de cada modo de falha seguem abaixo (Figuras 13, 14, 15).

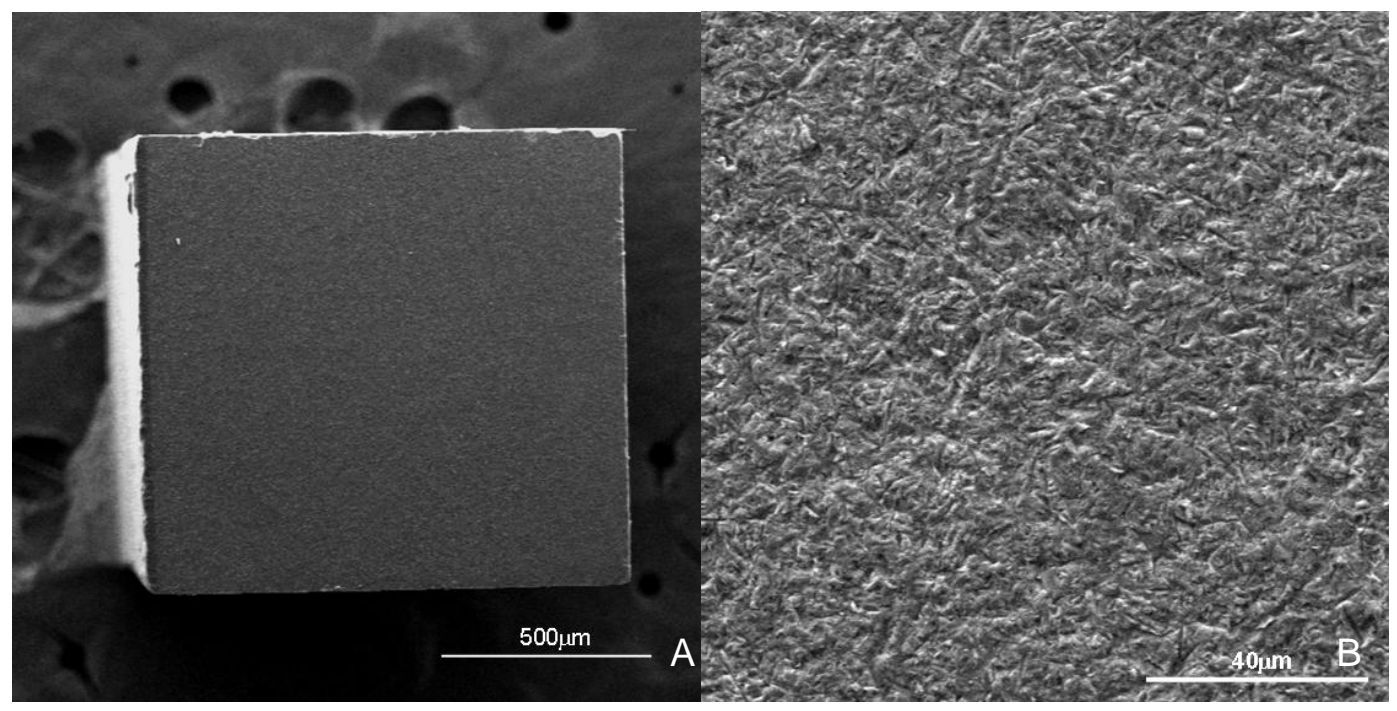

Figura 13 - Falha ADES-cc: falha adesiva na interface cimento-cerâmica. A: dentina (magnificação: 75x). B: cerâmica (magnificação: 1000x), a fotomicrografia ampliada revela a zircônia jateada, sem cimento resinoso residual. Corpo de prova fraturado proveniente do grupo RelyX ARC + Jateamento + Termociclagem. 


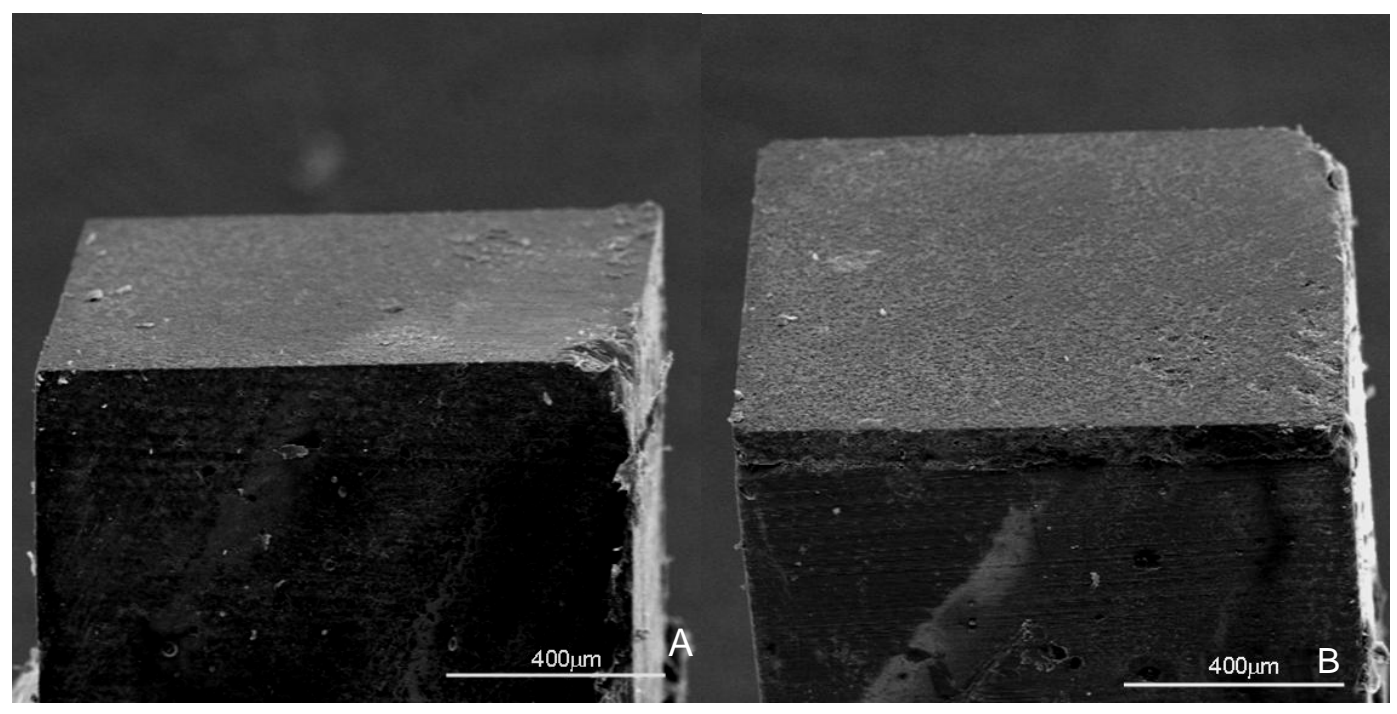

Figura 14 - Falha ADES-cd: falha adesiva na interface cimento-dentina. A: dentina. B: cerâmica. Magnificação: 75x. Corpo de prova fraturado proveniente do grupo Panavia F + Silicatização + Termociclagem.

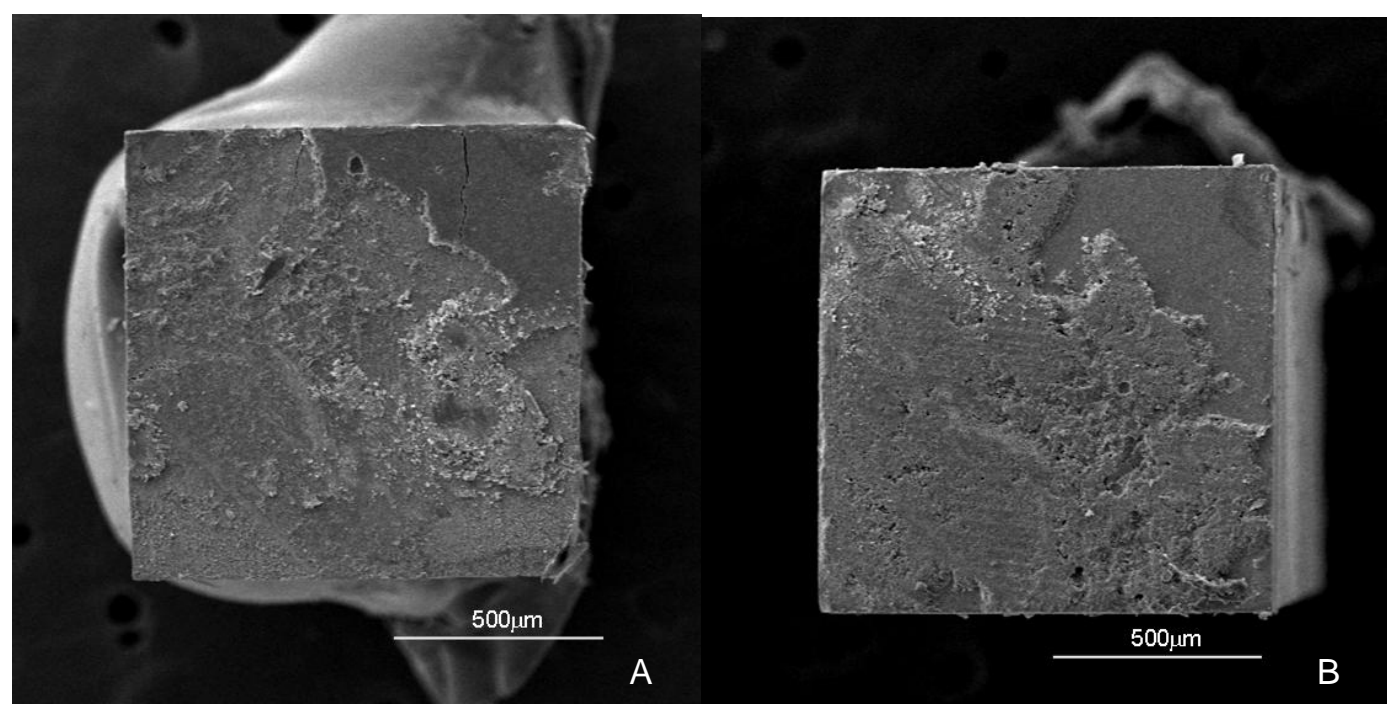

Figura 15 - Falha COES-cim: falha coesiva do cimento resinoso. A: dentina. B: zircônia. Magnificação: 75x. É evidente a camada de cimento resinoso sobre as superfícies de fratura (dentina e cerâmica). Corpo de prova fraturado proveniente do grupo Panavia F + Silicatização + Imediato (24h).

Não ocorreram falhas coesivas na cerâmica (COES-cer). As falhas coesivas na dentina não foram analisadas em MEV por serem de fácil análise em microscópio ótico e até mesmo macroscopicamente. 


\section{DISCUSSÃO}

O contínuo aprimoramento dos materiais restauradores e das técnicas empregadas é o reflexo da busca à estética e à durabilidade. Neste sentido, a utilização de próteses livres de metal e de sistemas de cimentação adesiva é crescente e com indicações cada vez mais abrangentes.

As cerâmicas odontológicas precisam cumprir com os requisitos necessários para suportar as cargas e tensões geradas em função. Porém, grande parte das cerâmicas dentais é friável e o estresse de tração resultante de uma carga externa pode levar a propagação catastrófica de trincas (falhas, defeitos) pré-existentes (Seghi et al., 1995). Sendo assim, cerâmicas com altos valores de dureza e módulo de elasticidade, como as cerâmicas de Y-TZP, foram desenvolvidas na tentativa de melhorar as propriedades mecânicas (Kosmac et al., 1999; Lawn et al., 2002; Guazzato et al., 2004; Zhang et al., 2004; Sundh et al., 2005; Deville et al., 2006; Studart et al., 2007).

O polimento das cerâmicas a base de Y-TZP pode afetar negativamente as características físicas do material. Alguns autores relatam que após o polimento há uma diminuição dos valores de resistência à flexão biaxial e na confiabilidade (módulo de Weibull) (Kosmac et al., 1999), na resistência à flexão por três pontos (Guazzato et al., 2005), bem como o seu desempenho quando submetida à testes de fadiga cíclica e dinâmica, sendo que nesse caso, apresentaram, predominantemente, desenvolvimento subcrítico de trincas (Zhang et al., 2004). Esses relatos justificam o polimento prévio à sinterização.

Cerâmicas ácido-resistentes precisam de um tratamento de superfície diferenciado para otimizar a adesão a resinas (Della Bona, 
2009). Os métodos mais divulgados são o jateamento e a silicatização da superfície cerâmica, aliados à diferentes combinações de cimentos resinosos e primers. Della Bona et al. (2007), comprovaram que o condicionamento com ácido hidrofluorídrico não promove uma união adequada entre resina e cerâmica infiltrada por vidro reforçada por zircônia. Contudo, tratamentos da superfície cerâmica utilizando jateamento com partículas de alumina e o sistema Cojet (silicatização) melhoram os valores de resistência de união.

Estudos mostram que a resistência à flexão biaxial e a confiabilidade (módulo de Weibull) são melhorados após o jateamento (Kosmac et al., 1999; Curtis et al., 2006a; Papanagiotou et al., 2006; Souza, 2009), bem como a resistência à flexão por três pontos (desde que não sejam seguidas de tratamento térmico) (Guazzato et al., 2005). Zhang et al. (2004), relataram que o jateamento diminui os valores de resistência quando a cerâmica (Y-TZP) é submetida à testes de fadiga cíclica e dinâmica, devido aos defeitos causados pelo jateamento. Porém, os resultados ainda são os mais altos em comparação às outras cerâmicas de infra-estrutura, sugerindo um desempenho superior mesmo após esse tratamento de superfície. Além do que, a cerâmica sofre as conseqüências do desenvolvimento subcrítico de trincas quando exposta à umidade mas, tecnicamente, quando da cimentação resinosa, a superfície cerâmica não entra em contato direto com a umidade, negligenciando os efeitos causados pelo jateamento e suportando o uso desse tipo de tratamento de superfície da cerâmica (Della Bona, 2009).

Atsu et al. (2008), encontraram os maiores valores de resistência ao cisalhamento quando foi utilizada a silicatização aliada à um primer composto por MDP e agente silano misturados (Clearfil Liner Bond $2 \mathrm{~V}+$ Porcelain Bond Activator) e um cimento com monômero fosfatado (Panavia F). Porém, Ozcan et al. (2008b), obtiveram valores baixos de resistência ao cisalhamento quando os protocolos de cimentação resinosa indicados pelos fabricantes foram seguidos. Além 
disso, houve falha adesiva em todos os corpos de prova após a termociclagem $\left(6.000\right.$ ciclos, $\left.5^{\circ} \mathrm{C}-55^{\circ} \mathrm{C}\right)$, mesmo quando utilizado cimentos e primers com monômero MDP, contra-indicando o uso de zircônia para próteses fixas quando a retenção adesiva for necessária.

O teste de cisalhamento não é muito indicado para testar a durabilidade de união entre diferentes substratos, visto que para este teste pequenas variações na geometria da amostra, no ponto e no tipo de carregamento, podem produzir valores diferentes de resistência de união, fato este atribuído a não uniformidade dos esforços induzidos na interface durante o carregamento. O teste de tração teria um arranjo menos complexo e mais apropriado para se avaliar a resistência de união da interface adesiva, sendo o mais indicado para este tipo de estudo (Della Bona e Van Noort, 1995).

A maioria dos estudos utilizam o teste de cisalhamento para examinar o desempenho da zircônia unida a agentes cimentantes resinosos. Fato este atribuído pela dificuldade de corte deste material após a sinterização. Neste trabalho, os cortes realizados após a sinterização foram críticos e demorados, sendo que foi necessário fazer um piloto para descobrir qual a melhor velocidade e pressão de corte, além das modificações na técnica tradicional de fabricação (corte) para obter os corpos de prova (descrita no capítulo Materiais e Método).

Os primeiros estudos de durabilidade da união entre uma cerâmica a base de Y-TZP e um cimento resinoso utilizando testes de resistência à tração surgiram em 2009 (Oyagüe et al., 2009a; Oyagüe et al., 2009b; Kern et al., 2009; Yang et al., 2010; Kitayama et al., 2010). Sendo que não há relatos na literatura testando as interfaces cerâmica YTZP-cimento resinoso e cimento resinoso-dentina, concomitantemente, ou seja, a cimentação de Y-TZP à dentina. Isso provavelmente se deve ao fato da dificuldade da metodologia e da baixa resistência de união.

Acreditava-se que os maiores valores de resistência das cerâmicas Y-TZP jateadas, quando comparadas às silicatizadas, eram 
devido à diferença na rugosidade deixada pelos diferentes materiais de jateamento. Estudos recentes apresentaram diferenças estatísticas na rugosidade superficial quando utilizado partículas de óxido de alumínio e partículas de óxido de alumínio modificadas por sílica de tamanhos diferentes (Oyagüe et al., 2009). Quando foram utilizadas partículas de mesmo tamanho $(30 \mu \mathrm{m})$ e mesmas condições de jateamento não houve diferença estatística na rugosidade superficial (Tanaka et al., 2008).

Assim, no presente estudo, o tamanho das partículas utilizadas no tratamento de superfície da cerâmica Y-TZP foi semelhante (30 $\mu \mathrm{m}$ e $45 \mu \mathrm{m}$ ) justamente para que essa possível diferença na rugosidade não interferisse nos resultados.

Os cimentos resinosos RelyX ARC + silicatização e Panavia $\mathrm{F}+$ jateamento produziram os maiores valores médios de $\sigma$ no período de 24 horas, discordando dos resultados encontrados por Oyagüe et al. (2009a).

Durante a termociclagem pode ocorrer hidrólise (acelerada pela água quente) dos componentes da interface e subseqüente absorção de água e remoção dos produtos da degradação ou oligômeros mal polimerizados e/ou devido a um coeficiente de expansão térmico linear mais alto do material restaurador em relação aos tecidos dentais. Assim, os efeitos da termociclagem são muito dependentes do tamanho da interface adesiva, sendo que para corpos de prova de microtração a termociclagem diminuiu significantemente a resistência adesiva, suportanto a hipótese de que a termociclagem acelera a degradação química da interface (De Munck et al., 2005). O que justifica a termociclagem dos corpos de prova e não dos blocos inteiros do conjunto cerâmica-cimento-dentina.

Para este tipo de envelhecimento, a freqüência dos ciclos in vivo permanece indeterminada até o momento e exige maiores investigações. Porém Gale e Darvell (1999) sugeriram, após uma 
detalhada revisão de literatura, que 10.000 termociclos é um número aceitável e compatível a um ano de uso clínico.

Tanaka et al. (2008) concluiu que somente a silicatização da cerâmica Y-TZP não é suficiente para uma adesão adequada a resina, devido a alta tenacidade dessa cerâmica. Valores de adesão mais altos foram encontrados com a interação da silicatização com um adesivo contendo monômero MDP associado a um agente silano. Essas conclusões vão parcialmente contra os resultados do presente estudo, visto que o cimento resinoso Panavia $F$ aliado a um primer com monômero MDP e um agente silano não mostrou o valor de adesão mais alto. Porém, foi o grupo mais estável nas três condições de envelhecimento (24 horas: 9,72 MPa; 60 dias: 10,15 MPa; termociclagem: 9,19 MPa), comprovando que existe uma adesão estável com esse protocolo de cimentação.

A termociclagem diminuiu significativamente a resistência adesiva do cimento resinoso RelyX ARC quando a superfície cerâmica foi jateada $(p<0,05)$. As falhas foram adesivas na interface cimento-cerâmica, apresentando falhas espontâneas durante a termociclagem. O que não aconteceu quando a superfície cerâmica foi silicatizada. O cimento Panavia $F$ promoveu uma adesão estatisticamente melhor $(p<0,05)$ quando a superfície cerâmica foi jateada, muito provavelmente pela ação dos agentes MDP da sua fórmula em contato mais direto com a zircônia. O cimento RelyX U100 comportou-se de maneira semelhante para os dois tipos de tratamento de superfície.

A água foi utilizada como meio de solução na termociclagem, pois soluções de saliva artificial apresentaram-se semelhantes após o armazenamento (De Munck et al., 2005). A maioria dos processos de degradação são dependentes da taxa de difusão, conseqüentemente, a área da interface adesiva é tão dependente quanto o próprio tempo de difusão. Ou seja, se a área adesiva for maior será necessário mais tempo para aparecerem os efeitos do envelhecimento, 
pois é necessário mais tempo para a água se difundir na interface. Uma forma de acelerar os efeitos da difusão é armazenar micro-espécimes, para que torne o caminho da difusão o mais curto possível (De Munck et al., 2005). Assim, justifica-se o método de estocagem na forma de corpos de prova (área adesiva $=1 \mathrm{~mm}^{2}$ ) e não o bloco dente-cimento-cerâmica, no intuito de acelerar o processo de envelhecimento.

No presente trabalho, a armazenagem por 60 dias em água destilada à $37^{\circ} \mathrm{C}$ reduziu significantemente $(p<0,05)$ os valores de adesão para o cimento RelyX ARC quando as amostras foram jateadas (5,83 MPa). Quando a superfície foi silicatizada (Cojet) os valores de adesão foram maiores (10,33 MPa).

O cimento autocondicionante RelyX U100 apresentou resultados melhores, após 60 dias de armazenagem, quando a cerâmica foi silicatizada,,divergindo dos resultados encontrados por Oyagüe et al. (2009b). Esses autores, testaram um cimento com características muito semelhantes (RelyX Unicem) em 24 horas e após armazenagem em água (6 meses), e encontraram valores mais altos de $\sigma$ quando a cerâmica foi jateada. Porém, no estudo de Oyagüe et al. (2009b) o tamanho das partículas para o tratamento da superfície cerâmica eram maiores $(110 \mu \mathrm{m})$.

Todos os cimentos resinosos demonstraram valores de resistência adesiva superiores, após 60 dias, quando a superfície cerâmica foi silicatizada.

Esses resultados sugerem que a união química entre a sílica, depositada na superfície cerâmica, o agente silano e o cimento resinoso, colaboram para a durabilidade da união. O que está parcialmente de acordo com os resultados de Oyagüe et al. (2009b), onde os valores médios de $\sigma$ para o grupo silicatizado e unido com cimento contendo MDP foram maiores do que quando foi realizado jateamento, concordando com o presente estudo. Porém, concluíram que a longevidade da adesão cimento-cerâmica depende mais da seleção do 
cimento do que do pré-tratamento da superfície cerâmica Y-TZP, o que diverge dos protocolos e cimentos utilizados no presente estudo.

$\mathrm{Na}$ análise das falhas, o cimento RelyX ARC foi o cimento que apresentou o maior percentual de falhas adesivas na interface cimento-cerâmica. Quando a superfície cerâmica foi jateada, esse tipo de falha ocorreu em 48\%, 64\% e 100\% dos corpos de prova envelhecidos por 24 h, 60 dias e termociclagem, respectivamente. Esse fato pode ser explicado pela composição química do cimento, onde não existe união química com a cerâmica. Quando a superfície cerâmica foi silicatizada esse tipo de falha ocorreu em 29\%, 0\% e 16\%, respectivamente.

Analisando as superfícies de fratura do cimento RelyX U100, observa-se poucas falhas adesivas entre cimento-cerâmica, tanto na superfície cerâmica que foi jateada quanto na silicatizada. Esse fato pode ser explicado pela composição química do cimento, onde sua matriz resinosa consiste de um ácido metacrilato multifuncional que reage com o substrato e contribui para o mecanismo de adesão (De Munck et al., 2004). A maior parte das falhas ocorreu na interface adesiva cimentodentina, sugerindo que a união entre esses dois substratos é a interface menos resistente e que precisa ser melhorada.

Não foram evidenciadas falhas entre o cimento Panavia F e a superfície da zircônia, independentemente do tratamento cerâmico (jateamento ou silicatização) e do envelhecimento. A maioria das falhas ocorreu no próprio cimento, deixando resíduo de cimento tanto na dentina como na zircônia. Entretanto, a camada residual mais espessa é claramente visualizada na superfície da zircônia.

Novos métodos de tratamento da superfície cerâmico foram propostos para promover uma melhor resistência de união, como por exemplo, o jateamento seguido da aplicação de uma camada de vidro na superfície cerâmica e após o uso do protocolo para cerâmicas ácido sensíveis. O uso dessa técnica com um agente cimentante contendo monômero MDP produziu uma adesão forte e duradoura (Aboushelib et 
al., 2007). Porém este método ainda precisa ser aperfeiçoado, pois a deposição deste vidro é crítica, visto que tem interferência direta com a adaptação interna da restauração protética.

Cimentos resinosos e primers estão em constante desenvolvimento, buscando otimizar os valores de $\sigma$ para cerâmicas $Y$ TZP (Kitayama et al., 2010). Vale lembrar, que a interface entre cimento resinoso e os tecidos dentários (dentina e esmalte) não pode ser esquecida, pois, geralmente, a maior área de cimentação está no substrato dentário.

A busca por adesivos dentinários e cimentos resinosos ideais para cimentação de qualquer tipo de restauração indireta é uma atividade de investigação constante. A durabilidade da união entre os cimentos resinosos e a cerâmica a base de Y-TZP avaliada neste estudo deve ser acompanhada a longo prazo com o objetivo de verificar se a diminuição dos valores de resistência, que ocorreu após 60 dias de armazenagem, é um processo contínuo de degradação.

Recomendações clínicas:

Recomenda-se a silicatização como tratamento de superfície para cerâmicas Y-TZP, mesmo quando se utilizar cimentos com propriedades químicas mais compatíveis com estas cerâmicas, visto que à longo prazo se comportaram de maneira mais estável. 


\section{CONCLUSÕES}

Baseado nos resultados obtidos pôde-se concluir que:

a) após 60 dias de armazenagem, para os 3 cimentos resinosos utilizados, a silicatização demonstrou uma tendência de valores de resistência mais elevados comparado ao jateamento;

b) a armazenagem e a ciclagem térmica não reduziram significantemente a resistência adesiva de todos os cimentos resinosos avaliados, confirmando parcialmente a hipótese experimental;

c) o cimento auto-condicionante não apresentou uma resistência de união menor do que os demais cimentos avaliados, rejeitando a hipótese inicial. 


\section{REFERÊNCIAS*}

Abo-Hamar SE, Hiller KA, Jung H, Federlin M, Friedl KH, Schmalz G. Bond strength of a new universal self-adhesive resin luting cement to dentin and enamel. Clin Oral Invest. 2005 Sep;9(3):161-7.

Aboushelib MN, Kleverlaan CJ, Feilzer AJ. Selective infiltration-etching technique for a strong and durable bond of resin cements to zirconiabased materials. J Prosthet Dent. 2007 Nov;98(5):379-88.

Al-Assaf K, Chakmakchi M, Palaghias G, Karanika-Kouma A, Eliades G. Interfacial characteristics of adhesive luting resins and composites with dentine. Dent Mater. 2007 Jul;23(7):829-39.

Amaral R, Ozcan M, Bottino MA, Valandro LF. Microtensile bond strength of a resin cement to glass infiltrated zirconia-reinforced ceramic: the effect of surface conditioning. Dent Mater. 2006;22:283-90.

Amaral R, Valandro LF, Balducci I, Özcan M, Bottino MA. Effect of conditioning methods on the microtensile bond strength of phosphate monomer-based cement on zirconia ceramic in dry and aged conditions. J Biomed Mater Res B Aplied Biomaterials. 2008;85(1):1-9.

Atsu SS, Kilicarslan MA, Kucukesmen HC, Aka PS. Effect of zirconiumoxide ceramic surface treatments on the bond strength to adhesive resin. $\mathrm{J}$ Proshtet Dent 2006;95:430-6.

Behr M, Rosentritt M, Regnet T, Lang R, Handel G. Marginal adaptation in dentin of a self-adhesive universal resin cement compared with well-tried systems. Dent Mater 2004, Feb;20(2):191-7.

\footnotetext{
* Baseado em:

International Committee of Medical Journal Editors Uniform Requirements for Manuscripts Submitted to Biomedical journals: Sample References [homepage na Internet]. Bethesda: US NLM; c2003 [disponibilidade em 2008 ago; citado em 25 ago.] Disponível em: http://www.nlm.nih.gov/bsd/uniform_requirements.html
} 
Blatz MB, Sadan A, Martin J, Lang BR. In vitro evaluation of shear bond strengths of resin to densely-sintered high purity zirconium-oxide ceramic after long-term storage and thermal cycling. J Prosthet Dent. 2004; 91:356-362.

Bottino MA, Valandro LF, Scotti R, Buso L. Effect of surface treatments on the resin bond to zirconium-based ceramic. Int J Prosthod. 2005;18:60-5.

Bowen RL. Properties of a silica-reinforced polymer for dental restorations. J Am Dent Assoc. 1963 Jan;66(1):57-64.

Buonocore MG. A simple method of increasing the adhesion of acrylic filling materials to enamel surfaces. J Dent Res. 1955;34(6):849-53.

Burke FJ, Fleming GI, Nathanson D, Marquis PM. Are adhesive technologies needed to support ceramics? An assessment of the current evidence. J Aesthet Dent. 2002;4:7-22.

Chevalier J, Calès B, Drouin JM. Low-temperature aging of Y-TZP ceramics. J Am Ceram Soc. 1999;82:2150-4.

Curtis AR, Wright AJ, Fleming GJ. The influence of surface modification techniques on the performance of a Y-TZP dental ceramic. J Dent. 2006a; Mar;34(3):195-206.

Curtis AR, Wright AJ, Fleming GJ. The influence of simulated masticatory loading regimes on the bi-axial flexure strength and reliability of a Y-TZP dental ceramic. J Dent. 2006b; May;34(5):317-25.

De Munck J, Van Landuyt K, Peumans M, Poitevin A, Lambrechts P, Braem $M$, et al. A critical review of the durability of adhesion to tooth tissue: methods and results. J Dent Res. 2005;84(2):118-32.

De Munck J, Vargas M, Van Landuyt K, Hikitaa K, Lambrechts P, Van Meerbeek B. Bonding of an auto-adhesive luting materials to enamel and dentin. Dent Mater. 2004;20:963-71. 
Della Bona A. Bonding to ceramics: scientific evidences for clinical dentistry. São Paulo: Artes Médicas; 2009.

Della Bona A, Anusavice KJ, Mecholsky Jr JJ. Failure analysis of resin composite bonded to ceramic. Dent Mater. 2003;19:693-9.

Della Bona A, Anusavice KJ, Shen C. Microtensile strength of composite bonded to hot-pressed ceramics. J Adhesive Dent. 2000;2(4): 305-13.

Della Bona A, Borba M, Benetti $P$, Cecchetti D. Effect of surface treatments on the bond strength of a zirconia-reinforced ceramic to composite resin. Braz Oral Res. 2007 Jan-Mar;21(1):10-5.

Della Bona A, van Noort R. Shear vs. tensile bond strength of resin composite bonded to ceramic. J Dent Res. 1995;74(9):1591-6.

Denry I, Kelly JR. State of the art of zirconia for dental applications. Dent Mater. 2008;24(3):299-307.

Derand T, Molin M, Kvam K. Bond strength of composite luting cement to zirconia ceramic surfaces. Dent Mater. 2005;21(12):1158-62.

Deville S, Chevalier J, Gremillard L. Influence of surface finish and residual stresses on the ageing sensitivity of biomedical grade zirconia. Biomaterials. 2006; 27(10):2186-92.

Ernst CP, Cohnen U, Stender E, Willershausen B. In vitro retentive strength of zirconium oxide ceramic crowns using different luting agents. J Prosthet Dent. 2005;93(6):551-8.

Fusayama T, Nakamura M, Kurosaki N, Iwaku M. Non-pressure adhesion of a new adhesive restorative resin. J Dent Res. 1979;58(4):1364-70.

Gale MS, Darvell BW. Thermal cycling procedures for laboratory testing of dental restorations. J Dent. 1999;27(2): 89-99. 
Garvie RC, Hannink RG, Pascoe RT. Ceramic steel? Nature. 1975; 258(25):703-4.

Garvie RC, Nicholson PS. Phase analysis in zirconia systems. J Am Ceram Soc. 1972;55(3):303-5.

Goff JP, Hayes W, Hull S, Hutchings MT, Clausen K. Defect structure of yttria-stabilized zirconia and its influence on the ionic conductivity at elevated temperatures. In: Kelly JR, Denry I. Stabilized zirconia as a structural ceramic: an overview. Dent Mater. 2008 Mar;24(3):289-98.

Guazzato M, Albakry M, Ringer SP, Swain MV. Strength, fracture toughness and microstructure of a selection of all-ceramic materials. Part II. Zirconia-based dental ceramics. Dent Mater. 2004;20(5):449-56.

Guazzato M, Quach L, Albakry M, Swain MV. Influence of surface and heat treatments on the flexural strength of Y-TZP dental ceramic. J Dent. 2005 Jan;33(1):9-18.

Guo $X$. On the degradation of zirconia ceramics during low-temperature annealing in water vapor. J Phys Chem Solids 1999;60:539-46.

Heuer AH, Lange FF, Swain MV, Evans AG. Transformation toughening: an overview. J Am Ceram Soc. 1986;69(3):1-4.

Holderegger C, Sailer I, Schuhmacher C, Schläpfer R, Hämmerle C, Fischer J. Shear bond strength of resin cements to human dentin. J Dent Mater. 2008 Jul;24(7):944-50.

Jung YG, Peterson IM, Kim DK, Lawn BR. Lifetime limiting strength degradation from contact fatigue in dental ceramics. $\mathrm{J}$ Dent Res. 2000;79(2):722-31.

Kelly JR, Denry I. Stabilized zirconia as a structural ceramic: an overview. Dent Mater. 2008 Mar;24(3):289-98. 
Kern M, Barloi A, Yang B. Surface conditioning influences zirconia ceramic bonding. J Dent Res. 2009;Sep;88(9):817-22.

Kim BK, Bae HE, Shim JS, Lee KW. The influence of ceramic surface treatments on the tensile bond strength of composite resin to all-ceramic coping materials. J Prosthet Dent. 2005;94(4):357-62.

Kitayama S, Nikaido T, Takahashi R, Zhu L, Ikeda M, Foxton RM, et al. Effect of primer treatment on bonding of resin cements to zirconia ceramic. Dent Mater. 2010 May;26(5):426-32. Epub 2010 Jan 25.

Koibuchi H, Yasuda N, Nakabayashi N. Bonding to dentin with a selfetching primer: the effect of smear layers. Dent Mater. 2001 Mar;17(2):122-6.

Kosmac T, Oblak C, Jevnikar P, Funduk N, Marion L. The effect of surface grinding and sandblasting on flexural strength and reliability of Y-TZP zirconia ceramic. Dent Mater. 1999;15(6):426-33.

Kramer N, Frankenberger R, Pelka M, Petschelt A. IPS Empress inlays and onlays after four years-a clinical study. J Dent. 1999;27(5):325-31.

Kumbuloglu O, Lassila LVJ, User A, Vallitu PK. Bonding of resin composite luting cements to zirconium oxide by two air-particle abrasion methods. Oper Dent. 2006;31(2):248-55.

Lawn BR, Deng Y, Lloyd IK, Janal MN. Materials design of ceramic-based layer structures for crowns. J Dent Res. 2002;81(6):433-8.

Lawn BR, Deng Y, Thompson VP. Use of contact testing in the characterization and design of all-ceramic crown-like layer structures: a review. J Prosth Dent. 2001;86:495-510.

Lawn BR. Physics of fracture. J American Ceramic Society. 1983;66:8391. 
Lopes GC, Baratieri LN, de Andrada MA, Vieira LC. Dental adhesion: present state of the art and future perspectives. Quintessence Int. 2002 Mar;33(3):213-24.

Lopes GC, Vieira LC, Monteiro S Jr, Caldeira de Andrada MA, Baratieri CM. Dentin bonding: effect of degree of mineralization and acid etching time. Oper Dent. 2003; Jul-Aug;28(4):429-39.

Nakabayashi N, Kojima K, Masuhara E. The promotion of adhesion by the infiltration of monomers into tooth substrates. J Biomed Mater Res. 1982;16(3):265-73.

Oyagüe RC, Monticelli F, Toledano M, Osorio E, Ferrari M, Osorio R. Influence of surface treatments and resin cement selection on bonding to densely-sintered zirconium-oxide ceramic. Dent Mater. 2009a Feb;25(2):172-9.

Oyagüe RC, Monticelli F, Toledano M, Osorio E, Ferrari M, Osorio R. Effect of water aging on microtensile bond strength of dual-cured resin cements to pre-treated sintered zirconium-oxide ceramics. Dent Mater. 2009b Mar;25(3):392-9.

Özcan M, Nijhuis $\mathrm{H}$, Valandro LF. Effect of various surface conditioning methods on the adhesion of dual-cure resin cement with MDP functional monomer to zirconia after thermal aging. Dent Mater. 2008a Jan;27(1):99104.

Özcan M, Kerkdijk S, Valandro LF. Comparison of resin cement adhesion to Y-TZP ceramic following manufacturers' instructions of the cements only. Clin Oral Investig. 2008b Sep;12(3):279-82.

Özcan M, Vallittu PK. Effect of surface conditioning methods on the bond strength of luting cement to ceramics. Dent Mater. 2003;19:725-31.

Papanagiotou HP, Morgano SM, Giordano RA, Pober R. In vitro evaluation of low-temperature aging effects and finishing procedures on the flexural strength and structural stability of Y-TZP dental ceramics. J Prosthet Dent. 2006 Sep;96(3):154-64. 
Pashley DH, Horner JA, Brewer PD. Interactions of conditioners on the dentin surface. Oper Dent. 1992;Suppl 5:137-50.

Piwowarczyk A, Lauer HC, Sorensen JA. In vitro shear bond strength of cementing agents to fixed prosthodontic restorative materials. J Prosthet Dent. 2004 Sep;92(3):265-73.

Sano H, Shono T, Sonoda H, Takatsu T, Ciucchi B, Carvalho R. Relationship between surface area for adhesion and tensile bond strength-evaluation of a micro-tensile bond test. Dent Mater 1994;10(4):236-40.

Sato T, Ohtaki S, Shimada M. Transformation of yttria partially stabilized zirconia by low-temperature annealing in air. J Mater Sci. 1985;20:146670 .

Scherrer SS, Kelly JR, Quin GD, Xu K. Fracture toughness (KIc) of a dental porcelain determined by fractographic analysis. Dent Mater. 1999;15:342-8.

Schulze KA, Oliveira SA, Wilson RS, Gansky SA, Marshall GW, Marshall SJ. Effect of hydration variability on hybrid layer properties of a selfetching versus an acid-etching system. Biomaterials. 2005 Mar;26(9):1011-8.

Seghi RR, Denry IL, Rosenstiel SF. Relative fracture toughness and hardness of new dental ceramics. J Prosthet Dent. 1995;74:145-50.

Souza ROA. Influência de diferentes protocolos de jateamento na resistência à flexão e na estabilidade estrutural de uma cerâmica policristalina de zircônia tetragonal parcialmente estabilizada com ítria [tese]. São José dos Campos:Faculdade de Odontologia de São José dos Campos, UNESP-Univ Estadual Paulista, 2009.

Studart AR, Filser F, Kocher P, Gauckler LJ. In vitro lifetime of dental ceramics under cyclic loading in water. Biomaterials. 2007 Jun;28(17):2695-705. 
Subbarao EC. Zirconia-an overview. In: Heur AH, Hobbs LW, editors. Science and technology of zirconia. Columbus, $\mathrm{OH}$ : The American Ceramic Society, 1981; 1-24.

Sundh A, Molin M, Sjögren G. Fracture resistance of yttrium oxide partially-stabilized zirconia all-ceramic bridges after veneering and mechanical fatigue testing. Dent Mater 2005;21:476-82.

Tanaka R, Fujishima A, Shibata Y, Manabe A, Miyazaki T. Cooperation of phosphate monomer and silica modification on zirconia. J Dent Res. 2008 Jul;87(7):666-70.

Tinschert J, Zwez D, Marx R, Anusavice KJ. Structural reliability of alumina-, feldspar-, leucite-, mica- and zirconia-based ceramics. J Dent. 2000 Sep;28(7):529-35.

Valandro LF, Ozcan M, Amaral R, Leite FP, Bottino MA. Microtensile bond strength of a resin cement to silica-coated and silanized In-Ceram Zirconia before and after aging. Int J Prosthod. 2007;20:70-2.

Valandro LF, Özcan M, Bottino MC, Bottino MA, Scotti R, Della Bona A. Bond strength of a resin cement to high-alumina and zirconia-reinforced ceramics: the effect of surface conditioning. J Adhes Dent. 2006;8:175-81.

Van Meerbeek B, Perdigão J, Lambrechts P, Vanherle G. The clinical performance of adhesives. J Dent. 1998 Jan;26(1):1-20.

Van Meerbeek B, Peumans $M$, Verschueren $M$, Gladis S, Braem $M$, Lambrechts $P$, et al. Clinical status of ten dentin adhesive systems. J Dent Res. 1994 Nov;73(11):1690-702.

Van Meerbeek B, Van Landuyt K, De Munck J, Hashimoto M, Peumans M, Lambrechts $P$, et al. Technique-sensivity of contemporary adhesives. Dent Mater J. 2005 Mar;24(1):1-13. 
Watanabe I, Nakabayashi N. Bonding durability of photocured Phenyl-P in TEGDMA to smear layer-retained bovine dentin. Quintessence Int. 1993 May;24(5):335-42.

Watanabe I, Nakabayashi N. Measurement methods for adhesion to dentine: the current status in Japan. J Dent. 1994 Apr;22(2):67-72.

Wolfart M, Lehmann F, Wolfart S, Kern M. Durability of the resin bond strength to zirconia ceramic after using different surface conditioning methods. Dent Mater 2007;23:45-50.

Yang B, Barloi A, Kern M. Influence of air-abrasion on zirconia ceramic bonding using an adhesive composite resin. Dent Mater. 2010 Jan;26(1):44-50. Epub .

Zhang Y, Lawn BR, Rekow ED, Thompson VP. Effect of sandblasting on the long-term performance of dental ceramics. J Biomed Mater Res B Appl Biomater. 2004 Nov 15;71(2):381-6.

Zhang Y, Pajares A, Lawn BR. Fatigue and damage tolerance of Y-TZP ceramics in layered biomechanical systems. J Biomed Mater Res B, Appl Biomater. 2004 Oct 15;71(1):166-71. 
ANEXO A - Aprovação do Comitê de Ética em Pesquisa com Seres Humanos

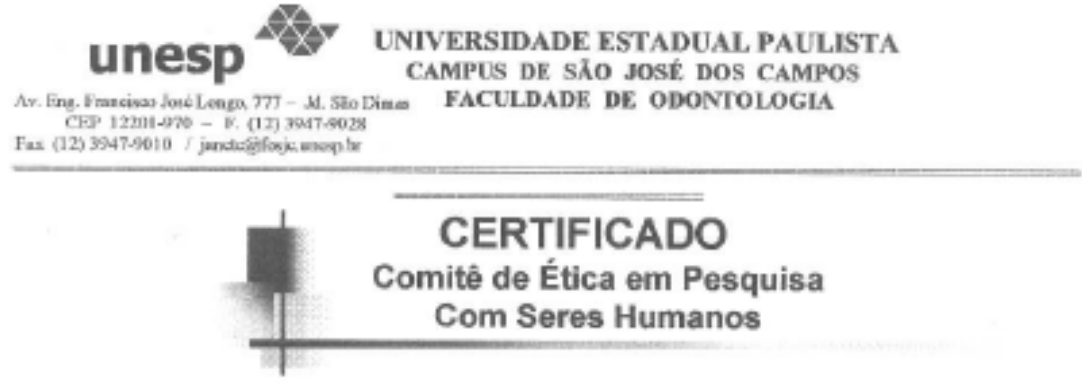

CERTIFICAMOS, que 0 protocolo $n^{\circ}$ 048/2008-PH/CEP, sobre "Avaliaçăo de três cimentos resinosos na resistência de uniăo entre a dentina e uma cerâmica reforçada por zircônia estabilizada por itrio", sob a responsabilidade de HUMBERTO LAGO DE CASTRO, tendo como orientador o Professor Dr. ÁLVARO DELLA BONNA e CoOrientador Prof.Dr. TARCISIO JOSÉ DE ARRUDA PAES JUNIOR, está de acordo com os Principios Éticos, seguindo diretrizes e normas regulamentadoras de pesquisa, com seres humanos, conforme, Resoluçăo $n^{\circ} 196 / 96$ do Conselho Nacional de Saúde e foi aprovado por este Comitê de Ética em Pesquisa.

São José dos Campos, 18 de agosto de 2009.

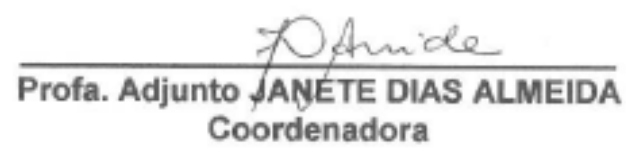


Castro HL. Influence of Y-TZP Ceramic Treatment and Different Resin Cements on Bond Strength to Dentin. [dissertation]. São José dos Campos: School of Dentistry of São José dos Campos, UNESP - Univ. Estadual Paulista; 2010.

\section{ABSTRACT}

The aim of this study was to evaluate the bond strength of three dualcured resin cement systems (RelyX ARC, RelyX U100 and Panavia F) to dentin and to an yttria-stabilized zirconia-based ceramic (In-Ceram $Y Z$, Vita Zanhfabrik) after different surface treatments. The occlusal surface of 54 sound human third molars was exposed and conditioned according to the manufacturers' instructions. Fifty-four ceramic blocks were cut $(6.4 \mathrm{~mm}$ $\times 6.4 \mathrm{~mm} \times 4.8 \mathrm{~mm}$ ), flattened and fired. They were divided into two groups according to the type of surface treatment: air-abrasion with $\leq 50 \mu \mathrm{m}$ alumina particles or CoJet system (3M ESPE) (14-28 psi). The cementation procedure followed the instructions of each manufacturer. Thus, there were 6 groups. All teeth-cement-ceramic blocks were stored in $37^{\circ} \mathrm{C}$ distilled water for 24 hours before cutting into non-trimming specimens (adhesive area= $1 \mathrm{~mm}^{2}$ ). About nine specimens $(\mathrm{sp}$ ) were obtained per block $(n=27)$. The specimens of each block were randomly assigned to one of the three storage conditions: dry- immediate test, W6060 days of storage $\left(37^{\circ} \mathrm{C}\right.$ water) and TC- thermocycling $(10,000 \mathrm{x})(n \geq 12)$. The microtensile bond strength test was performed using an universal testing machine (crosshead speed: $1 \mathrm{~mm} / \mathrm{min}$ ). Immediate groups of RelyX ARC-Cojet and Panavia F-air-abrasion presented the highest $\sigma$ average (13.9 and 13.0 MPa, respectively), followed by RelyX U100-airabrasion (10,2 MPa). After TC, Panavia F-air-abrasion was the best (14.8 MPa) followed by RelyX ARC-Cojet and RelyX U100-air-abrasion (12.9 and 9.9 MPa, repectively). After W60, all the cements behaved similarly, when the groups were treated with Cojet system, tended to higher values of $\sigma(\mathrm{MPa})$.

Keywords: Ceramic; Dental cements; Tensile bond strength test. 